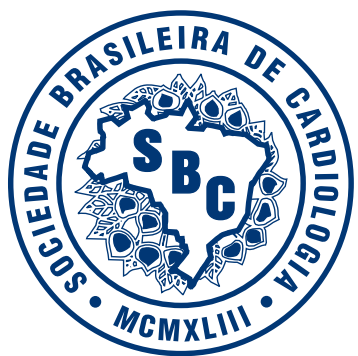

\title{
V Diretrizes Brasileiras de Hipertensão Arterial
}

ReALizaÇão

Sociedade Brasileira de Cardiologia - SBC

Presidente: José Péricles Esteves

Sociedade Brasileira de Hipertensão - SBH

Presidente: Robson Augusto S. dos Santos

Sociedade Brasileira de Nefrologia - SBN

Presidente: Pedro Gordan

\section{Sociedades Patrocinadoras}

Sociedades Patrocinadoras

Associação Brasileira para o Estudo da Obesidade - ABESO

Presidente: Henrique Suplicy

Representante: Marcio Mancini

Academia Brasileira de Neurologia - ABN

Presidente: Sérgio Roberto Haussen

Representante: Ayrton Massaro

Federação Brasileira das Sociedades de Ginecologia e Obstetrícia - FEBRASGO

Presidente: Nilson Roberto Melo

Representante: Lucia Helena de Azevedo

Sociedade Brasileira Clinica Médica - SBCM

Presidente: Antonio Carlos Lopes

Representante: Renato Delascio Lopes

Sociedade Brasileira de Geriatria e Gerontologia - SBGG

Presidente: Elisa Franco de Assis Costa

Representante: Elizabete Viana de Freitas

Sociedade Brasileira de Pediatria - SBP

Presidente: Dioclécio Campos Junior

Representante: Olberes V. B. de Andrade 
Sociedade Brasileira de Diabetes - SBD

Presidente: Marcos Tambascia

Representante: Adriana Forti

Sociedade Brasileira de Endocrinologia e Metabologia - SBEM

Presidente: Marisa Helena César Coral

Sociedade Brasileira de Medicina de Família - SOBRAMFA

Presidente: Sarkis Jound Bayed

Representante: Marcelo Levites

Comissão Organizadora

Décio Mion Jr. (Coordenador)

Osvaldo Kohlmann Jr. (SBH)

Carlos Alberto Machado (SBC)

Celso Amodeo (SBN)

Marco Antônio Mota Gomes (SBC)

José Nery Praxedes (SBN)

Fernando Nobre (SBH)

Andréa Brandão (SBC)

\section{Comissão de Redação}

Décio Mion Jr., Osvaldo Kohlmann Jr., Carlos Alberto Machado, Celso Amodeo, Marco Antônio Mota Gomes, José Nery Praxedes, Fernando Nobre, Andréa Brandão, Maria Tereza Zanella e Josiane Lima Gusmão

Apolo

Bayer HealthCare

Biosintética Farmacêutica Ltda.

Boehringer Ingelheim do Brasil Química e Farmacêutica Ltda.

Farmalab Indústrias Químicas e Farmacêuticas Ltda.

Laboratórios Pfizer Ltda.

Medley S/A Indústria Farmacêutica.

Merck Sharp \& Dohme Farmacêutica Ltda.

Novartis Biociências S.A.

Omron

Sankyo Pharma Brasil Ltda.

Torrent do Brasil Ltda. 


\section{Diretrizes Brasileiras de Hipertensão Arterial}

\section{Apresentação}

Passados quatro anos, foi necessário rever as condutas diagnósticas e terapêuticas em hipertensão arterial para publicar as V Diretrizes Brasileiras de Hipertensão Arterial e oferecer ao médico brasileiro o conhecimento das mudanças mais importantes na prevenção, no diagnóstico, no tratamento e no controle da hipertensão arterial, orientado pelo trabalho árduo e voluntário de 118 especialistas das várias regiões do País sob o patrocínio da Sociedade Brasileira de Cardiologia, da Sociedade Brasileira de Hipertensão e da Sociedade Brasileira de Nefrologia e o apoio e a contribuição de nove Sociedades Médicas.

Mudanças importantes na conduta diagnóstica e terapêutica foram exaustivamente discutidas. No diagnóstico, considerando o progresso verificado nas medidas de pressão arterial fora do consultório médico, a monitorização ambulatorial da pressão arterial (MAPA) e a monitorização residencial da pressão arterial (MRPA) foram incluídas como opções no fluxograma diagnóstico. Com relação à terapêutica, a inclusão da conduta baseada no risco cardiovascular adicional de acordo com os níveis da pressão arterial e a presença de fatores de risco, lesões de órgãos-alvo e doença cardiovascular deixam este documento em sintonia com o que há de mais atual na terapêutica cardiovascular.

Temos certeza que este documento, à semelhança dos anteriores ${ }^{1-4}$, oferecerá à comunidade médica brasileira um guia prático, objetivo e adequado à nossa realidade, para ser utilizado como referência na prática diária.

Agradecemos o empenho de todos os colegas que contribuíram de forma definitiva para o sucesso desta publicação, trabalhando via internet e participando ativamente da reunião plenária no dia 13 de fevereiro de 2006, em São Paulo, SP.

A Comissão Organizadora

\begin{tabular}{|c|c|c|c|c|c|c|c|c|}
\hline \multicolumn{9}{|c|}{$\begin{array}{l}\text { Declaração de conflito de interesses* dos coordenadores dos grupos de trabalho } \\
\text { Se nos últimos } 24 \text { meses um dos Coordenadores das V Diretrizes Brasileiras de Hipertensão Arterial: }\end{array}$} \\
\hline & $\begin{array}{c}\text { Carlos } \\
\text { Alberto } \\
\text { Machado }\end{array}$ & $\begin{array}{c}\text { Marco } \\
\text { Antonio } \\
\text { Mota } \\
\text { Gomes }\end{array}$ & $\begin{array}{l}\text { Andréa } \\
\text { Brandão }\end{array}$ & $\begin{array}{l}\text { Osvaldo } \\
\text { Kohlmann } \\
\text { Júnior }\end{array}$ & $\begin{array}{l}\text { José Nery } \\
\text { Praxedes }\end{array}$ & $\begin{array}{l}\text { Fernando } \\
\text { Nobre }\end{array}$ & $\begin{array}{c}\text { Celso } \\
\text { Amodeo }\end{array}$ & $\begin{array}{l}\text { Décio } \\
\text { Mion } \\
\text { Júnior }\end{array}$ \\
\hline $\begin{array}{l}\text { 1) Recebeu honorário } \\
\text { de consultoria, } \\
\text { palestras, redação de } \\
\text { textos ou quaisquer } \\
\text { outros tipos de serviços } \\
\text { remunerados prestados } \\
\text { do fabricante do } \\
\text { produto. }\end{array}$ & $\begin{array}{c}\text { Astra } \\
\text { Zeneca } \\
\text { Pfizer } \\
\text { Sankyo }\end{array}$ & $\begin{array}{c}\text { Astra } \\
\text { Zeneca } \\
\text { Novartis } \\
\text { Omron } \\
\text { Pfizer } \\
\text { Sankyo } \\
\text { Torrent }\end{array}$ & $\begin{array}{c}\text { Astra } \\
\text { Zeneca } \\
\text { Novartis } \\
\text { Pfizer } \\
\text { Sankyo } \\
\text { Torrent }\end{array}$ & $\begin{array}{c}\text { Abbott } \\
\text { Aché - } \\
\text { Biosintética } \\
\text { Astra } \\
\text { Zeneca } \\
\text { Biolab } \\
\text { Boehringer- } \\
\text { Ingelheim } \\
\text { Farmalab } \\
\text { Chiesi } \\
\text { Libbs } \\
\text { Pfizer }\end{array}$ & Não & $\begin{array}{l}\text { Bayer } \\
\text { Medley } \\
\text { Novartis } \\
\text { Pfizer } \\
\text { Sankyo } \\
\text { Sanofi- } \\
\text { Aventis }\end{array}$ & $\begin{array}{c}\text { Astra } \\
\text { Zeneca } \\
\text { Novartis } \\
\text { Sankyo }\end{array}$ & $\begin{array}{c}\text { Bayer } \\
\text { Medley } \\
\text { Merck } \\
\text { Sharp \& } \\
\text { Dohme } \\
\text { Novartis }\end{array}$ \\
\hline $\begin{array}{l}\text { 2) Recebeu auxílio } \\
\text { do fabricante do } \\
\text { produto (verbas de } \\
\text { pesquisa, fornecimento } \\
\text { de equipamentos, } \\
\text { drogas, mão-de-obra) } \\
\text { relacionado ao projeto } \\
\text { em análise ou outro } \\
\text { projeto que envolva o } \\
\text { mesmo produto. }\end{array}$ & Sankyo & $\begin{array}{c}\text { Aché - } \\
\text { Biosintética } \\
\text { Astra } \\
\text { Zeneca } \\
\text { Libbs } \\
\text { Novartis } \\
\text { Sankyo } \\
\text { Sanofi- } \\
\text { Aventis } \\
\text { Torrent }\end{array}$ & $\begin{array}{c}\text { Aché - } \\
\text { Biosintética } \\
\text { Astra } \\
\text { Zeneca } \\
\text { Boehringer } \\
\text {-Ingelheim } \\
\text { Novartis } \\
\text { Sankyo } \\
\text { Sanofi- } \\
\text { Aventis } \\
\text { Torrent }\end{array}$ & $\begin{array}{l}\text { Aché - } \\
\text { Biosintética } \\
\text { Astra } \\
\text { Zeneca } \\
\text { Biolab } \\
\text { Boehringer- } \\
\text { Ingelheim } \\
\text { Libbs } \\
\text { Novartis } \\
\text { Pfizer }\end{array}$ & Não & $\begin{array}{c}\text { Aché - } \\
\text { Biosintética } \\
\text { Novartis } \\
\text { Pfizer }\end{array}$ & $\begin{array}{l}\text { Biolab } \\
\text { Omron }\end{array}$ & $\begin{array}{c}\text { Aché - } \\
\text { Biosintética } \\
\text { Boehringer- } \\
\text { Ingelheim } \\
\text { Eurofarma } \\
\text { Libbs } \\
\text { Novartis } \\
\text { Sankyo }\end{array}$ \\
\hline
\end{tabular}

1I Consenso Brasileiro de Hipertensão Arterial. Arq Bras Cardiol 1991; 56 (suppl. A): A1-16.

2 II Consenso Brasileiro de Hipertensão Arterial. Arq Bras Cardiol 1994; 63 (4): 333-347.

3 III Consenso Brasileiro de Hipertensão Arterial. Rev Bras Clin Terap 1998; 24 (6): 231-272.

4 IV Brazilian Guidelines in Arterial Hypertension. Arq Bras Cardiol 2004; 82 (suppl. 4): 7-22. 


\begin{tabular}{|c|c|c|c|c|c|c|c|c|}
\hline \multicolumn{9}{|c|}{ continuação } \\
\hline & $\begin{array}{c}\text { Carlos } \\
\text { Alberto } \\
\text { Machado }\end{array}$ & $\begin{array}{c}\text { Marco } \\
\text { Antonio } \\
\text { Mota } \\
\text { Gomes }\end{array}$ & $\begin{array}{l}\text { Andréa } \\
\text { Brandão }\end{array}$ & $\begin{array}{l}\text { Osvaldo } \\
\text { Kohlmann } \\
\text { Júnior }\end{array}$ & $\begin{array}{r}\text { José Nery } \\
\text { Praxedes }\end{array}$ & $\begin{array}{l}\text { Fernando } \\
\text { Nobre }\end{array}$ & $\begin{array}{c}\text { Celso } \\
\text { Amodeo }\end{array}$ & $\begin{array}{l}\text { Décio } \\
\text { Mion } \\
\text { Júnior }\end{array}$ \\
\hline $\begin{array}{l}\text { 3) Recebeu auxílio do } \\
\text { fabricante do produto } \\
\text { para participação em } \\
\text { congressos. }\end{array}$ & & & $\begin{array}{l}\text { Pfizer } \\
\text { Sankyo }\end{array}$ & $\begin{array}{l}\text { Astra } \\
\text { Zeneca } \\
\text { Boehringer- } \\
\text { Ingelheim } \\
\text { Pfizer }\end{array}$ & Não & $\begin{array}{l}\text { Novartis } \\
\text { Pfizer } \\
\text { Sankyo } \\
\text { Sanofi- } \\
\text { Aventis }\end{array}$ & $\begin{array}{c}\text { Astra } \\
\text { Zeneca }\end{array}$ & $\begin{array}{l}\text { Bayer } \\
\text { Boehringer- } \\
\text { Ingelheim } \\
\text { Dr Reddy's } \\
\text { Novartis }\end{array}$ \\
\hline $\begin{array}{l}\text { 4) Deteve ações do } \\
\text { fabricante do produto. }\end{array}$ & Não & Não & Não & Não & Não & Não & Não & Não \\
\hline $\begin{array}{l}\text { 5) Houve } \\
\text { envolvimento do } \\
\text { fabricante do produto } \\
\text { na coleta, análise, } \\
\text { interpretação ou } \\
\text { redação dos dados. }\end{array}$ & Não & Não & Não & Não & Não & Não & Não & Não \\
\hline $\begin{array}{l}\text { 6) É empregado da } \\
\text { empresa que possa se } \\
\text { beneficiar direta ou } \\
\text { indiretamente com os } \\
\text { resultados do estudo. }\end{array}$ & Não & Não & Não & Não & Não & Não & Não & Não \\
\hline
\end{tabular}

*Definição de conflitos de interesse: São considerados potenciais conflitos de interesse, a relação de um autor, diretamente, ou indiretamente através da instituição promotora da pesquisa, com empresas que eventualmente possam se beneficiar dos resultados do estudo. 


\section{Grupos de Trabalho}

\section{Grupo 1 - Diagnóstico e Classificação}

Coordenador:

Décio Mion Júnior (SP)
Secretários:

Giovânio Vieira da Silva (SP)

Katia Coelho Ortega (SP)
Alexandre Alessi (PR)

Angela Maria Geraldo Pierin (SP)

Audes Magalhães Feitosa (PE) Dante Marcelo Artigas Giorgi (SP)
Hilton Chaves (PE) José Carlos Aidar Ayoub (SP) Josiane Lima Gusmão (SP) Lilian Soares da Costa (RJ) Tufik José Magalhães Geleilete (SP)

Fernando Antonio Almeida (SP)

\section{Grupo 2 - Investigação Clínico-Laboratorial e Decisão Terapêutica}

Coordenador:

Osvaldo Kohlmann Junior (SP)
Secretários:

Fernanda Consolim-Colombo (SP)

Eduardo Cantoni Rosa (SP)
Altamiro Reis da Costa (RS)

Antonio Felipe Sanjuliani (RJ)

Ayrton Pires Brandão (RJ) César Pontes (CE)

Frida Liane Plavnik (SP)
José Marcio Ribeiro (MG) José Péricles Esteves (BA)

Pedro Gordan (PR)

Rafael Leite Luna (R)

Weimar Sebba (GO)

\section{Grupo 3 -Abordagem Multiprofissional}

Coordenador:

Marco Antonio Mota Gomes

(AL)
Secretários:

Paulo Roberto Pereira Toscano (PA)

Paulo Cesar Veiga Jardim (GO)
Clovis Oliveira Andrade (SE) Cristina S Atiê (SP)

Eliuden Galvão De Lima (ES) João Carlos Rocha (SP) José Xavier De Mello Filho (MA)

Maria Cecília G. Marinho Arruda
Maria Fátima de Azevedo (RN) Marilda Lipp (SP)

Nárcia Elisa B. Kohlmann (SP) Neide de Jesus (BA) Neusa Eli Portela (SP) (SP)

Grupo 4 - Tratamento Não-Medicamentoso

Coordenador:

José Nery Praxedes (SP)

\section{Secretários:}

Carlos Eduardo Negrão (SP) Heno Lopes (SP)

\section{Armênio Costa Guimarães (BA) Estelamaris Tronco Monego} (GO)

Marcio Kalil (MG) Natalino Salgado Filho (MA)
Osvaldo Passarelli (SP) Sebastião Ferreira Filho (MG) Sergio Fabiano Vieira Ferreira (MG)

Tales de Carvalho (SC)

\section{Grupo 5 - Tratamento Medicamentoso}

Coordenador:

Fernando Nobre (SP)

\section{Secretários:} Eduardo Barbosa Coelho (SP) Cibele Isaac Saad Rodrigues (SP)
Ayrton Pires Brandão (RJ) Artur Beltrame Ribeiro (SP)

Cibeli Isaac Saad Rodrigues (SP)

Eduardo B. Coelho (SP) Gilson Feitosa (BA)

lorge Pinto Ribeiro (RS) José Fernando Vilela Martins (SP)
Maria Helena Catelli Carvalho (SP)

Michel Batlouni (SP)

Miguel Gus (RS)

Roberto Jorge da Silva Franco (SP)

Robson Augusto $\mathrm{S}$ dos Santos (MG)

Wille Oigman (RJ)

\section{Grupo 6 - Hipertensão Secundária}

Coordenador:

Celso Amodeo (SP)
Secretários:

José Gastão Rocha Carvalho (PR)

Flavio Borelli (SP)
Adelaide A. Pereira (SP)

Antonio Cambara (SP)

Antonio Marmo Lucon (SP) José Luiz Santello (SP)
Luiz Aparecido Bortolloto (SP)

Maria Eliete Pinheiro (AL) Pedro Jabur (SP) Rogério A. Mulinari (PR)

\section{Grupo 7 - Situações Especiais}

Coordenadora:

Maria Tereza Zanella (SP)
Secretários:

Roberto Miranda (SP) Maria Eliane Magalhães (RJ)
Adriana Forti (CE)

Airton Massaro (SP)]

Antônio Alberto Silva Lopes (BA)

Istênio Pascoal (DF)

Ivan Cordovil (RJ)
Marcelo Bertolami (SP)

Marcio Mancini (SP)

Mauricio Wajgarten (SP)

Raul Dias dos Santos (SP) Vera Koch (SP) 


\section{Grupo 8 - Prevenção Primária em Hipertensão}

Coordenador:

Carlos Alberto Machado (SP)

\section{Secretárias:}

Claudia Lucia de Moraes Forjaz (SP)

Adriana Ávila (SP)
Álvaro Avezum (SP)

Eduardo Moacyr Krieger (SP)

Lucélia C. Magalhães (BA)

Marcus V. Bolivar Malachias (MG)

Mario Maranhão (PR)

Otavio Rizzi Coelho (SP)

Grupo 9 - Epidemiologia da Hipertensão

Coordenadora:

Andréa Brandão (RJ)
Secretários:

Sandra Fuchs (RS)

Armando da Rocha Nogueira

(RJ)
Abrão Cury (SP)

Agostinho Tavares (SP)

Antônio Felipe Simão (SC)

Edgar Pessoa de Mello (PE)

Ines Lessa (BA)

José Augusto Barreto Filho (SE)
Raimundo Marques

Nascimento Neto (MG)

Regina Teresa Capelari (SP)

Rui Manuel dos Santos Póvoa (SP)

Victor Matsudo (SP)
Luiz Carlos Bodanese (RS)

Luiz Cesar Scala (MT)

Mario Fritsh Neves (RJ)

Paulo Lotufo (SP)

Romero Bezerra (DF)

\section{Grau de Recomendação}

Grau A - grandes ensaios clínicos aleatorizados e metanálises.

Grau B - estudos clínicos e observacionais bem desenhados.

Grau C - relatos e séries de casos.

Grau D - publicações baseadas em consensos e opiniões de especialistas.

\section{Sumário}

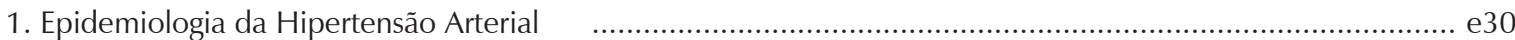

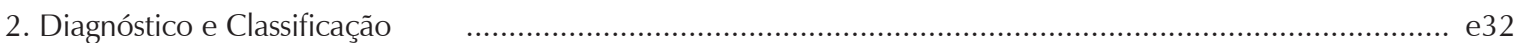

3. Investigação Clínico-Laboratorial e Decisão Terapêutica $\quad$ ….......................................................... e40

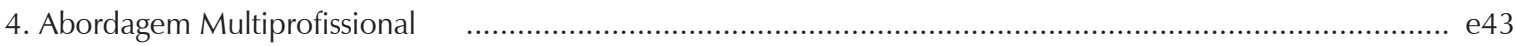

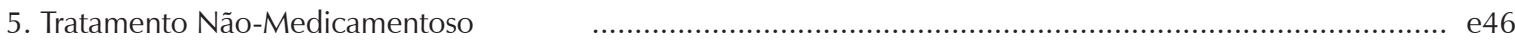

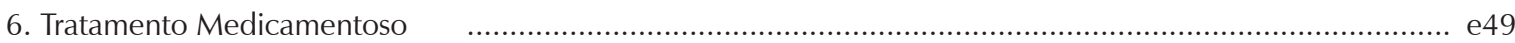

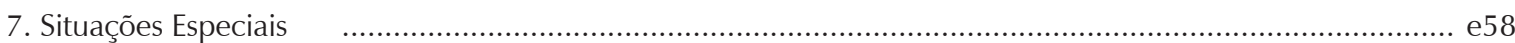

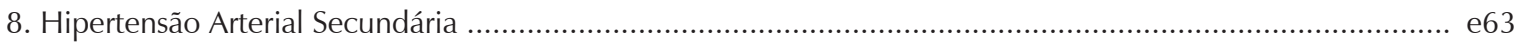

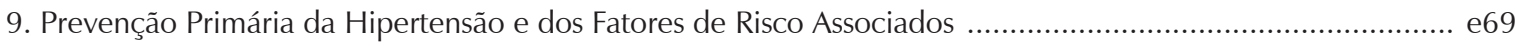

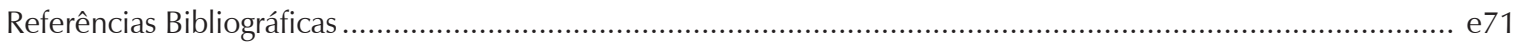




\section{Diretriz}

\section{Epidemiologia da hipertensão arterial}

\subsection{Hipertensão arterial: a importância do problema}

A elevação da pressão arterial representa um fator de risco independente, linear e contínuo para doença cardiovascular ${ }^{1}$. A hipertensão arterial apresenta custos médicos e socioeconômicos elevados, decorrentes principalmente das suas complicações, tais como: doença cerebrovascular, doença arterial coronariana, insuficiência cardíaca, insuficiência renal crônica e doença vascular de extremidades.

\subsection{Mortalidade}

No Brasil, em 2003, 27,4\% dos óbitos foram decorrentes de doenças cardiovasculares, atingindo $37 \%$ quando são excluídos os óbitos por causas mal definidas e a violência. A principal causa de morte em todas as regiões do Brasil é o acidente vascular cerebral, acometendo as mulheres em maior proporção ${ }^{2}$.

Observa-se tendência lenta e constante de redução das taxas de mortalidade cardiovascular. A doença cerebrovascular, cujo fator de risco principal é a hipertensão, teve redução anual das taxas ajustadas por idade de 1,5\% para homens e 1,6\% para mulheres. O conjunto das doenças do coração, hipertensão, doença coronária e insuficiência cardíaca também teve taxas anuais decrescentes de 1,2\% para homens e 1,3\% para mulheres (Figura 1). No entanto, apesar do declínio, a mortalidade no Brasil ainda é elevada em comparação a outros países, tanto para doença cerebrovascular como para doenças do coração ${ }^{3}$.

Entre os fatores de risco para mortalidade, hipertensão arterial explica $40 \%$ das mortes por acidente vascular cerebral e $25 \%$ daquelas por doença coronariana ${ }^{4}$. A mortalidade por doença cardiovascular aumenta progressivamente com a elevação da pressão arterial, a partir de 115/75 mmHg${ }^{1}$.

\subsection{Prevalência}

Inquéritos de base populacional realizados em algumas cidades do Brasil mostram prevalência de hipertensão arterial $(\geq 140 / 90 \mathrm{mmHg} \text { ) de } 22,3 \% \text { a } 43,9 \% \text { (Figura } 2)^{5-7}$.

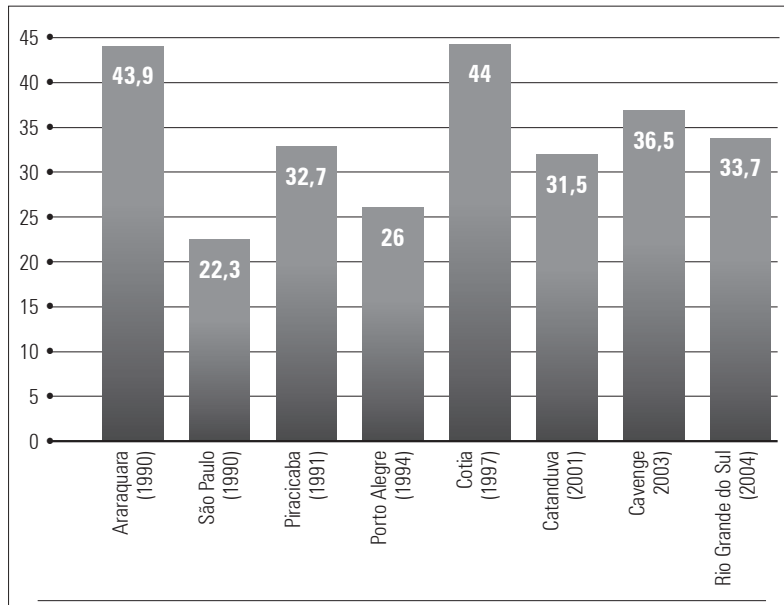

Fig. 2 - Prevalência de hipertensão arterial ( $\geq 140 / 90 \mathrm{mmHg}$ ) em cidades brasileiras.

\subsection{Hospitalizações}

A hipertensão arterial e as doenças relacionadas à pressão arterial são responsáveis por alta freqüência de internações (Figura 3). Insuficiência cardíaca é a principal causa de hospitalização entre as doenças cardiovasculares, sendo duas vezes mais freqüente que as internações por acidente vascular cerebral. Em 2005 ocorreram 1.180.184 internações por doenças cardiovasculares, com custo global de R\$ 1.323.775.008, $28^{3}$.

\subsection{Fatores de risco para hipertensão arterial}

Idade: A pressão arterial aumenta linearmente com a idade $^{8}$. Em indivíduos jovens, a hipertensão decorre mais freqüentemente apenas da elevação na pressão diastólica, enquanto a partir da sexta década o principal componente é a

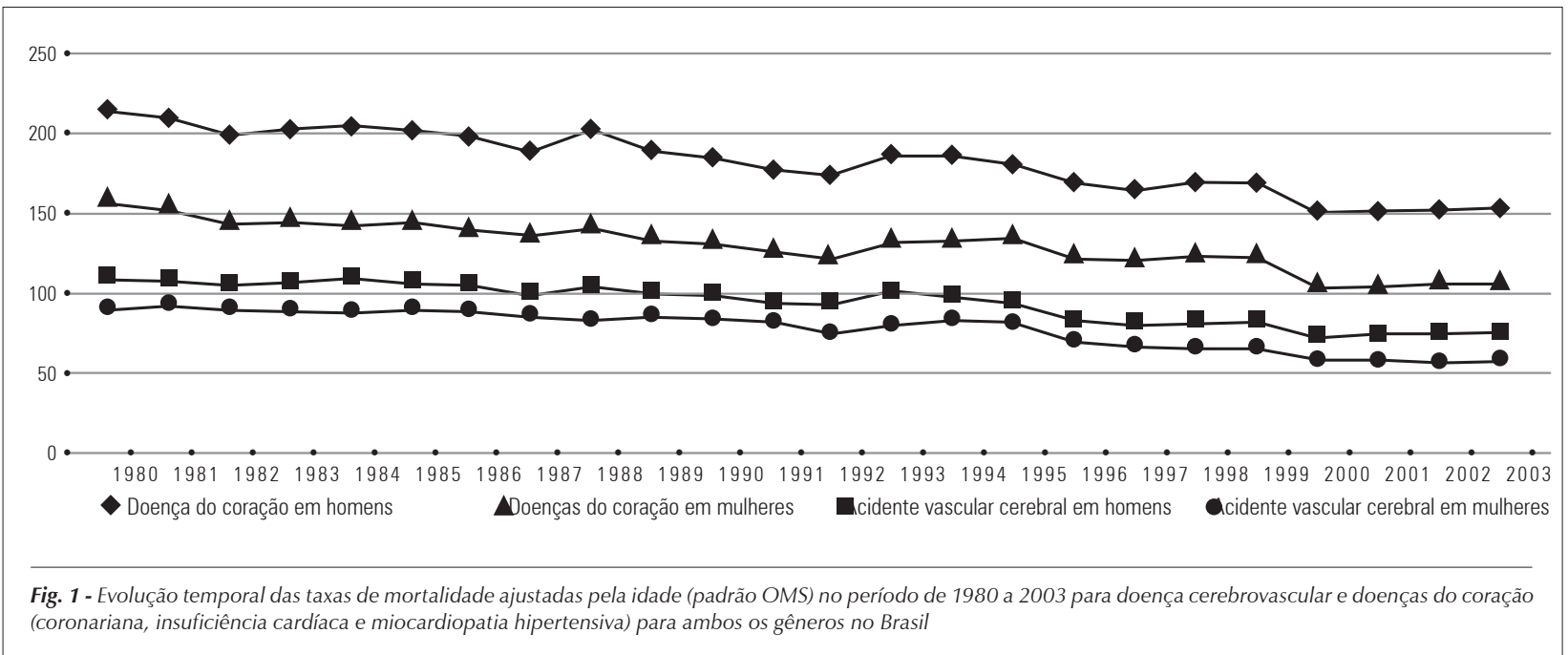




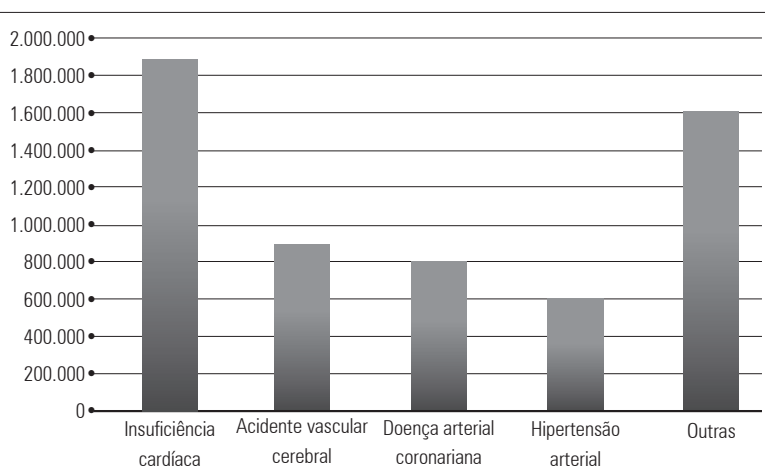

Fig. 3 - Número de hospitalizações por doença cardiovascular no Brasil (2000-2004)

elevação da pressão sistólica ${ }^{9}$. Em indivíduos idosos da cidade de Bambuí, MG, 61,5\% apresentavam hipertensão arterial ${ }^{10}$.

O risco relativo de desenvolver doença cardiovascular associado ao aumento da pressão arterial não diminui com o avanço da idade e o risco absoluto aumenta marcadamente ${ }^{1}$.

Sexo e etnia: A prevalência global de hipertensão entre homens (26,6\%; IC 95\% 26,0-27,2\%) e mulheres $(26,1 \%$; IC $95 \%$ 25,5-26,6\%) insinua que sexo não é um fator de risco para hipertensão. Estimativas globais sugerem taxas de hipertensão mais elevadas para homens até os 50 anos e para mulheres a partir da sexta década ${ }^{11}$. Hipertensão é mais prevalente em mulheres afrodescendentes com excesso de risco de hipertensão de até $130 \%$ em relação às mulheres brancas ${ }^{12}$.

Fatores socioeconômicos: Nível socioeconômico mais baixo está associado a maior prevalência de hipertensão arterial e de fatores de risco para elevação da pressão arterial, além de maior risco de lesão em órgãos-alvo e eventos cardiovasculares. Hábitos dietéticos, incluindo consumo de sal e ingestão de álcool, índice de massa corpórea aumentado, estresse psicossocial, menor acesso aos cuidados de saúde e nível educacional são possíveis fatores associados ${ }^{13}$.

Sal: O excesso de consumo de sódio contribui para a ocorrência de hipertensão arterial $^{14}$. A relação entre aumento da pressão arterial e avanço da idade é maior em populações com alta ingestão de sal. Povos que consomem dieta com reduzido conteúdo deste têm menor prevalência de hipertensão e a pressão arterial não se eleva com a idade. Entre os índios Yanomami, que têm baixa ingestão de sal, não foram observados casos de hipertensão arterial ${ }^{15}$. Em população urbana brasileira, foi identificada maior ingestão de sal nos níveis sócioeconômicos mais baixos (vide capítulo 5, item 5.3; capítulo 9, item 9.1).

Obesidade: O excesso de massa corporal é um fator predisponente para a hipertensão, podendo ser responsável por $20 \%$ a $30 \%$ dos casos de hipertensão arterial ${ }^{16} ; 75 \%$ dos homens e $65 \%$ das mulheres apresentam hipertensão diretamente atribuível a sobrepeso e obesidade. Apesar do ganho de peso estar fortemente associado com o aumento da pressão arterial, nem todos os indivíduos obesos tornamse hipertensos. Estudos observacionais mostraram que ganho de peso e aumento da circunferência da cintura são índices prognósticos importantes de hipertensão arterial, sendo a obesidade central um importante indicador de risco cardiovascular aumentado ${ }^{16-18}$. Estudos sugerem que obesidade central está mais fortemente associada com os níveis de pressão arterial do que a adiposidade total ${ }^{19}$. Indivíduos com nível de pressão arterial ótimo, que ao correr do tempo apresentam obesidade central, têm maior incidência de hipertensão ${ }^{19}$. A perda de peso acarreta redução da pressão arterial ${ }^{20}$.

Álcool: O consumo elevado de bebidas alcoólicas como cerveja, vinho e destilados aumenta a pressão arterial. O efeito varia com o gênero, e a magnitude está associada à quantidade de etanol e à freqüência de ingestão ${ }^{21}$. O efeito do consumo leve a moderado de etanol não está definitivamente estabelecido. Verifica-se redução média de $3,3 \mathrm{mmHg}(2,5$ a 4,1 mmHg) na pressão sistólica e 2,0 mmHg (1,5 a 2,6 mmHg) na pressão diastólica com a redução no consumo de etanol ${ }^{22}$.

Estudo observacional ${ }^{21}$ indica que o consumo de bebida alcoólica fora de refeições aumenta o risco de hipertensão, independentemente da quantidade de álcool ingerida.

Sedentarismo: O sedentarismo aumenta a incidência de hipertensão arterial. Indivíduos sedentários apresentam risco aproximado $30 \%$ maior de desenvolver hipertensão que os ativos $^{23,24}$. O exercício aeróbio apresenta efeito hipotensor maior em indivíduos hipertensos que normotensos ${ }^{25}$. O exercício resistido possui efeito hipotensor semelhante, mas menos consistente $^{26}$ (vide capítulo 5, item 5.5; capítulo 9, item 9.2).

\subsection{Outros fatores de risco cardiovascular}

A presença de fatores de risco cardiovascular ocorre mais comumente na forma combinada ${ }^{27}$. Além da predisposição genética, fatores ambientais podem contribuir para uma agregação de fatores de risco cardiovascular em famílias com estilo de vida pouco saudável ${ }^{28}$. Em amostras da nossa população, a combinação de fatores de risco entre indivíduos hipertensos parece variar com a idade, predominando a inatividade física, o sobrepeso, a hiperglicemia e a dislipidemia ${ }^{5}$. A obesidade aumenta a prevalência da associação de múltiplos fatores de risco $^{29}$.

\subsection{Taxas de conhecimento, controle e tratamento da hipertensão arterial}

Estudo brasileiro revelou que, em indivíduos adultos, $50,8 \%$ sabiam ser hipertensos, 40,5\% estavam em tratamento e apenas $10,4 \%$ tinham pressão arterial controlada $(<140 / 90$ $\mathrm{mmHg})^{6}$. Idade avançada, obesidade e baixo nível educacional mostraram-se associados a menores taxas de controle ${ }^{10}$. 


\section{Diretriz}

\section{Diagnóstico e classificação}

A medida da pressão arterial é o elemento-chave para o estabelecimento do diagnóstico da hipertensão arterial e a avaliação da eficácia do tratamento.

\subsection{Medida da pressão arterial}

A medida da pressão arterial deve ser realizada em toda avaliação de saúde, por médicos das diferentes especialidades e demais profissionais da área de saúde, todos devidamente treinados.

Alguns estudos têm mostrado que, na prática clínica, nem sempre a medida da pressão arterial é realizada de forma adequada. No entanto, os erros podem ser evitados com preparo apropriado do paciente, uso de técnica padronizada de medida da pressão arterial e equipamento calibrado (D) (Tabela 1) ${ }^{30,31}$.

O método mais utilizado para medida da pressão arterial na prática clínica é o indireto, com técnica auscultatória e esfigmomanômetro de coluna de mercúrio ou aneróide, ambos calibrados. Apesar da tendência de substituir os aparelhos de coluna de mercúrio por equipamentos automáticos em razão do risco de toxicidade e contaminação ambiental pelo mercúrio, eles continuam sendo os mais indicados para a medida da pressão arterial porque se descalibram menos freqüentemente do que os aparelhos aneróides ${ }^{32,33}$. Os aparelhos eletrônicos evitam erros relacionados ao observador e podem ser empregados quando validados de acordo com recomendações específicas, inclusive em estudos epidemiológicos (D) ${ }^{34-36}$. Todos os aparelhos devem ser testados e devidamente calibrados a cada seis meses (D).

A medida da pressão arterial na posição sentada deve ser realizada de acordo com os procedimentos descritos na tabela 1 $(D)^{37-39}$, com manguitos de tamanho adequado à circunferência do braço, respeitando a proporção largura/comprimento de 1:2. Embora a maioria dos fabricantes não siga essas orientações, a largura da bolsa de borracha do manguito deve corresponder a 40\% da circunferência do braço, e seu comprimento, a pelo menos $80 \%$ (B) (Tabela 2).

\subsection{Rotina de diagnóstico e seguimento}

Na primeira avaliação, as medidas devem ser obtidas em ambos os membros superiores e, em caso de diferença, utiliza-se sempre o braço com o maior valor de pressão para as medidas subseqüentes (D). O indivíduo deverá ser investigado para doenças arteriais se apresentar diferenças de pressão entre os membros superiores maiores de 20/10 mmHg para a pressão sistólica/diastólica ${ }^{40}(\mathrm{D})$.

Em cada consulta, deverão ser realizadas pelo menos três medidas, com intervalo de um minuto entre elas, sendo a média das duas últimas considerada a pressão arterial do indivíduo (D). Caso as pressões sistólicas e/ou diastólicas obtidas apresentem diferença maior que $4 \mathrm{mmHg}$ entre elas, deverão ser realizadas novas medidas até que se obtenham medidas com diferença inferior ou igual a $4 \mathrm{mmHg}$, utilizando-se a média das duas últimas medidas como a pressão arterial do indivíduo ${ }^{37}$ (D).

A posição recomendada para a medida da pressão arterial é a sentada (D). A medida nas posições ortostática e supina deve ser feita pelo menos na primeira avaliação em todos os
Tabela 1 - Procedimento de medida da pressão arterial (D)

Preparo do paciente para a medida da pressão arterial

1. Explicar o procedimento ao paciente

2. Repouso de pelo menos 5 minutos em ambiente calmo

3. Evitar bexiga cheia

4. Não praticar exercícios físicos 60 a 90 minutos antes

5. Não ingerir bebidas alcoólicas, café ou alimentos e não fumar 30 minutos antes

6. Manter pernas descruzadas, pés apoiados no chão, dorso recostado na cadeira e relaxado

7. Remover roupas do braço no qual será colocado o manguito

8. Posicionar o braço na altura do coração (nível do ponto médio do esterno ou $4^{\circ}$ espaço intercostal), apoiado, com a palma da mão voltada para cima e o cotovelo ligeiramente fletido

9. Solicitar para que não fale durante a medida

Procedimento de medida da pressão arterial

1. Medir a circunferência do braço do paciente

2. Selecionar o manguito de tamanho adequado ao braço

3. Colocar o manguito sem deixar folgas acima da fossa cubital, cerca de 2 a $3 \mathrm{~cm}$

4. Centralizar o meio da parte compressiva do manguito sobre a artéria braquial

5. Estimar o nível da pressão sistólica (palpar o pulso radial e inflar o manguito até seu desaparecimento, desinflar rapidamente e aguardar 1 minuto antes da medida)

6. Palpar a artéria braquial na fossa cubital e colocar a campânula do estetoscópio sem compressão excessiva

7. Inflar rapidamente até ultrapassar 20 a 30 mmHg o nível estimado da pressão sistólica

8. Proceder à deflação lentamente (velocidade de 2 a 4 $\mathrm{mmHg}$ por segundo)

9. Determinar a pressão sistólica na ausculta do primeiro som (fase I de Korotkoff), que é um som fraco seguido de batidas regulares, e, após, aumentar ligeiramente a velocidade de deflação

10. Determinar a pressão diastólica no desaparecimento do som (fase $\mathrm{V}$ de Korotkoff)

11. Auscultar cerca de 20 a $30 \mathrm{mmHg}$ abaixo do último som para confirmar seu desaparecimento e depois proceder à deflação rápida e completa

12. Se os batimentos persistirem até o nível zero, determinar a pressão diastólica no abafamento dos sons (fase IV de Korotkoff) e anotar valores da sistólica/diastólica/zero

13. Esperar 1 a 2 minutos antes de novas medidas

14. Informar os valores de pressão arterial obtidos para o paciente

15. Anotar os valores e o membro

indivíduos e em todas as avaliações em idosos, diabéticos, portadores de disautonomias, alcoolistas e/ou em uso de medicação anti-hipertensiva (D). 
Tabela 2 - Dimensões da bolsa de borracha para diferentes circunferências de braço em crianças e adultos (D)

\section{Denominação do manguito}

Recém-nascido

Criança

Infantil

Adulto pequeno

Adulto

Adulto grande

\section{Circunferência do braço $(\mathrm{cm})$}

$\begin{array}{cc}\leq 10 & 4 \\ 11-15 & 6 \\ 16-22 & 9 \\ 20-26 & 10 \\ 27-34 & 12 \\ 35-45 & 16\end{array}$

Bolsa de borracha $(\mathrm{cm})$

\begin{tabular}{cc}
\hline 4 & Comprimento \\
\hline 6 & 8 \\
9 & 12 \\
10 & 18 \\
12 & 17 \\
16 & 23 \\
\hline
\end{tabular}

A MRPA permite a obtenção de grande número de

Novos algoritmos consideram a utilização da MAPA e da MRPA como ferramentas importantes na investigação de pacientes com suspeita de hipertensão. Recomenda-se, sempre que possível, a medida da pressão arterial fora do consultório para esclarecimento diagnóstico, identificação da hipertensão do avental branco e hipertensão mascarada (D) (Figura 1, Tabela 3$)^{41}$. A hipertensão do avental branco determina risco cardiovascular intermediário entre normotensão e hipertensão, porém mais próximo ao risco dos normotensos ${ }^{42-44}$ (B). No entanto, apesar de não existirem evidências de benefícios de intervenções nesse grupo de pacientes, eles devem ser considerados no contexto do risco cardiovascular global, devendo permanecer em seguimento clínico. Alguns estudos mostram que a hipertensão mascarada determina maior prevalência de lesões de órgãos-alvo do que indivíduos normotensos ${ }^{39}$, mas outros, não (Tabela 4) ${ }^{45}$.

$\mathrm{Na}$ dependência dos valores da pressão arterial de consultório e do risco cardiovascular do indivíduo, define-se o intervalo entre as visitas para seguimento (D) (Tabela 3).

\subsection{Medida residencial da pressão arterial}

A MRPA é o registro da pressão arterial por método indireto, com três medidas pela manhã e três à noite, durante cinco dias, realizado pelo paciente ou outra pessoa treinada, durante a vigília, no domicílio ou no trabalho, com aparelhos validados $^{46}$ identificados em:

- http://www.bhsoc.org/blood_pressure_list.htm

- www.dableducational.com/sphygmomanometers/ devices_3_abpm.html medidas de pressão arterial de modo simples, eficaz e pouco dispendioso, contribuindo para o diagnóstico e o seguimento da hipertensão arterial. A MRPA não deve ser confundida com auto-medida da pressão arterial, que é o registro não sistematizado da pressão arterial realizado de acordo com a orientação do médico do paciente (D) (Tabela 5) ${ }^{46}$.

São consideradas anormais na MRPA as médias de pressão arterial acima de 135/85 $\mathrm{mmHg}(\mathrm{B})^{4,47,48}$.

\subsection{Medida ambulatorial da pressão arterial}

A MAPA é o método que permite o registro indireto e intermitente da pressão arterial durante 24 horas, enquanto o paciente realiza suas atividades habituais na vigília e durante o sono (Tabela 6). O nome "Holter" de pressão deve ser evitado.

Evidências obtidas com estudos de desfechos clínicos têm demonstrado que este método é superior à medida casual da pressão arterial em predizer eventos cardiovasculares, tais como infarto do miocárdio e acidente vascular cerebral ${ }^{42,49,50}$ (B).

São consideradas anormais na MAPA as médias de pressão arterial de 24 horas, vigília e sono acima de 130/80, 135/85 e 120/70 $\mathrm{mmHg}$, respectivamente ${ }^{46}$ (B).

\subsection{Situações especiais de medida da pressão arterial}

Crianças: A medida da pressão arterial em crianças é recomendada em toda avaliação clínica após os três anos de

\begin{tabular}{|c|c|c|}
\hline \multicolumn{2}{|c|}{ Pressão arterial inicial $(\mathrm{mmHg})^{* *}$} & \multirow{2}{*}{ Seguimento } \\
\hline Sistólica & Diastólica & \\
\hline$<130$ & $<85$ & Reavaliar em 1 ano. Estimular mudanças no estilo de vida \\
\hline $130-139$ & $85-89$ & Reavaliar em 6 meses***. Insistir em mudanças no estilo de vida \\
\hline $140-159$ & $90-99$ & Confirmar em 2 meses***. Considerar MAPA/MRPA \\
\hline $160-179$ & $100-109$ & Confirmar em 1 mês***. Considerar MAPA/MRPA \\
\hline$\geq 180$ & $\geq 110$ & Intervenção medicamentosa imediata ou reavaliar em 1 semana*** \\
\hline
\end{tabular}




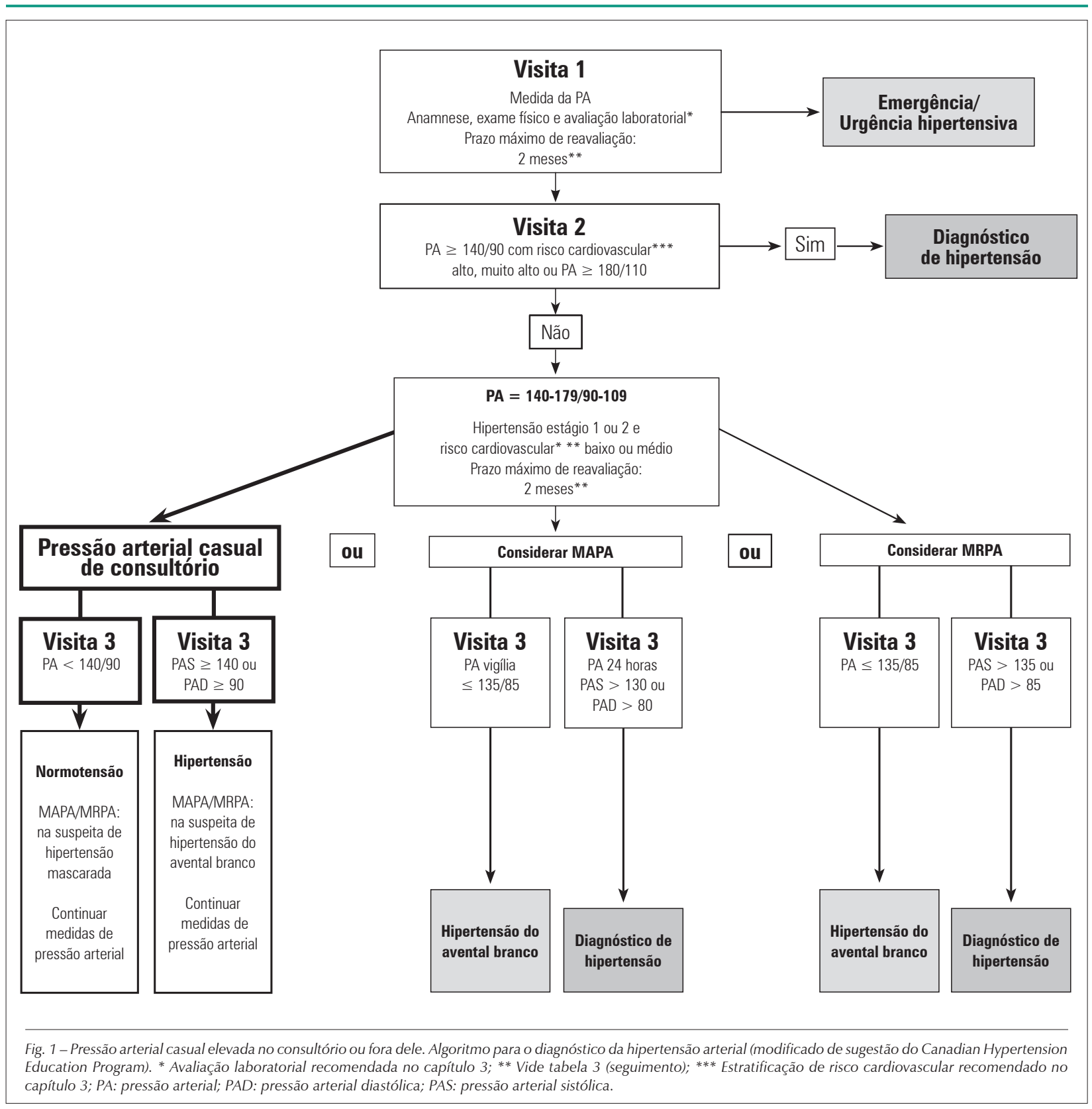

idade ou em circunstâncias especiais de risco antes desta idade, identificando-se a pressão diastólica na fase $\mathrm{V}$ de Korotkoff e empregando-se manguito com bolsa de borracha de tamanho adequado à circunferência do braço (Tabela 2) ${ }^{51}$.

Idosos: Na medida da pressão arterial do idoso, existem três aspectos importantes ${ }^{52}$ : maior freqüência de hiato auscultatório, que consiste no desaparecimento dos sons na ausculta durante a deflação do manguito, geralmente entre o final da fase I e o início da fase II dos sons de Korotkoff. Tal achado pode subestimar a verdadeira pressão sistólica ou superestimar a pressão diastólica; pseudo-hipertensão, caracterizada por nível de pressão arterial superestimado em decorrência do enrijecimento da parede da artéria. Pode ser detectada por meio da manobra de Osler, que consiste na inflação do manguito no braço até o desaparecimento do pulso radial. Se a artéria for palpável após esse procedimento, sugerindo enrijecimento, o paciente é considerado Osler positivo ${ }^{53}$; a hipertensão do avental branco é mais freqüente no idoso.

Gestantes: recomenda-se que a medida da pressão arterial seja feita na posição sentada, identificando-se a pressão diastólica na fase $\mathrm{V}$ de Korotkoff ${ }^{54}$ (D).

\subsection{Critérios diagnósticos e classificação}

Em estudos populacionais, a pressão arterial tem relação direta com o risco de morte e de eventos mórbidos. Os limites de pressão arterial considerados normais são arbitrários e, na avaliação dos pacientes, deve-se considerar também a presença de fatores de risco, lesões de órgãos-alvo e doenças 
Tabela 4 - Valores de pressão arterial no consultório, MAPA e MRPA que caracterizam efeito do avental branco, hipertensão do avental branco e hipertensão mascarada

\begin{tabular}{|c|c|c|c|}
\hline \multicolumn{4}{|c|}{ Pressão Arterial (mmHg) } \\
\hline & Consultório & MAPA & MRPA \\
\hline Normotensão & $<140 / 90$ & s 130/80 Média 24h & $\leq 135 / 85$ \\
\hline Hipertensão & $\geq 140 / 90$ & > 130/80 Média 24h & $>135 / 85$ \\
\hline Hipertensão do avental branco & $\geq 140 / 90$ & $\leq$ 135/85 Média Vigília & $\leq 135 / 85$ \\
\hline Hipertensão mascarada & $<140 / 90$ & > 135/85 Média Vigília & $>135 / 85$ \\
\hline
\end{tabular}

Efeito do avental branco

Diferença entre a medida da pressão arterial no consultório e a da MAPA na vigília ou MRPA, sem haver mudança no diagnóstico de normotensão ou hipertensão

Tabela 5 - Indicações da MRPA segundo a II Diretriz Brasileira
de MRPA

Tabela 6 - Indicações da MAPA segundo a IV Diretriz Brasileira de MAPA

Suspeita de hipertensão do avental branco (B)

\section{Avaliação da eficácia terapêutica anti-hipertensiva (B):}

a) Quando a pressão arterial casual permanecer elevada, apesar da otimização do tratamento anti-hipertensivo para diagnóstico de hipertensão arterial resistente ou efeito do avental branco;

b) Quando a pressão arterial casual estiver controlada e houver indícios da persistência ou da progressão de lesão de órgãos-alvo.

Avaliação de normotensos com lesão de órgãos-alvo (D) Avaliação de sintomas, principalmente hipotensão (D) associadas. A acurácia do diagnóstico de hipertensão arterial depende fundamentalmente dos cuidados dispendidos nas medidas da pressão arterial. Minimizam-se, assim, os riscos de falsos diagnósticos, tanto da hipertensão arterial quanto da normotensão, e suas repercussões na saúde dos indivíduos e no custo social envolvido.

Os valores que permitem classificar os indivíduos adultos acima de 18 anos, de acordo com os níveis de pressão arterial estão na tabela 7 .

As tabelas 9 e 10 apresentam os valores de pressão arterial referentes aos percentis 90, 95 e 99 de pressão arterial para crianças e adolescentes, de acordo com os percentis de estatura para ambos os sexos (Tabela 11). Consideram-se os valores abaixo do percentil 90 como normotensão, desde que inferiores a 120/80 mmHg; entre os percentis 90 e 95, como limítrofe ${ }^{51}$ ("pré-hipertensão", de acordo com o The Fourth Report on the Diagnosis, Evaluation, and Treatment of High Blood Pressure in Children and Adolescents), e igual ou superior ao percentil 95, como hipertensão arterial, salientando-se que qualquer valor igual ou superior a 120/80 mmHg em adolescentes, mesmo que inferior ao percentil 95, deve ser considerado limítrofe (Tabela $8)^{51}$. Por exemplo, um menino com 6 anos de idade, medindo 110 cm (percentil 10) e apresentando pressão arterial de 100/60 $\mathrm{mmHg}$, seria considerado normotenso. Já um menino de mesma idade e altura, mas com pressão arterial de 108/70 mmHg, seria considerado limítrofe. Se esta segunda criança, em vez de 110 cm, tivesse estatura de $119 \mathrm{~cm}$ (percentil 75), a pressão arterial de $115 / 75 \mathrm{mmHg}$ o faria ser considerado hipertenso.

Tabela 7 - Classificação da pressão arterial de acordo com a medida casual no consultório (> 18 anos)

\begin{tabular}{lcc} 
Classificação & Pressão sistólica (mmHg) & Pressão diastólica (mmHg) \\
\hline Ótima & $<120$ & $<80$ \\
\hline Normal & $<130$ & $<5$ \\
\hline Limítrofe & $130-139$ & $85-89$ \\
\hline Hipertensão estágio 1 & $140-159$ & $90-99$ \\
\hline Hipertensão estágio 2 & $160-179$ & $100-109$ \\
\hline Hipertensão estágio 3 & $\geq 180$ & $\geq 110$ \\
\hline Hipertensão sistólica isolada & $\geq 140$ & $<90$ \\
\hline
\end{tabular}

Quando as pressões sistólica e diastólica de um paciente situam-se em categorias diferentes, a maior deve ser utilizada para classificação da pressão arterial. 


\section{Diretriz}

Tabela 8 - Classificação da pressão arterial para crianças e adolescentes (modificado do The Fourth Report on the Diagnosis, Evaluation and Teatment of High Blood Pressure in Children and Adolescents)

\begin{tabular}{lc} 
Classificação & Percentil* para PAS e PAD \\
\hline Normal & PA $<$ percentil 90 \\
& PA entre percentis 90 a 95 ou se PA exceder \\
Limítrofe & $120 / 80$ mm sempre $<$ percentil 90 até $<$ \\
& percentil 95
\end{tabular}

Freqüência de medida da pressão arterial

Reavaliar na próxima consulta médica agendada percentil 95

Paciente assintomático: reavaliar em 1 a 2 semanas; se hipertensão confirmada encaminhar para avaliação diagnóstica

Paciente sintomático: encaminhar para avaliação diagnóstica

Hipertensão estágio 2

PA > percentil 99 mais $5 \mathrm{mmHg}$

Encaminhar para avaliação diagnóstica

PA > percentil 95 em ambulatório ou

Hipertensão do avental branco consultório e PA normal em ambientes não relacionados à prática clínica

* Para idade, sexo e percentil de estatura.

Tabela 9 - Valores de pressão arterial referentes aos percentis 90, 95 e 99 de pressão arterial para meninas de 1 a 17 anos de idade, de acordo com o percentil de estatura

\begin{tabular}{|c|c|c|c|c|c|c|c|c|c|c|c|c|c|c|c|}
\hline \multirow{2}{*}{$\begin{array}{l}\text { Idade } \\
\text { (anos) }\end{array}$} & \multirow[t]{2}{*}{ Percentil } & \multicolumn{7}{|c|}{ PA sistólica ( $\mathrm{mmHg}$ ) por percentil de estatura } & \multicolumn{7}{|c|}{ PA diastólica (mmHg) por percentil de estatura } \\
\hline & & $5 \%$ & $10 \%$ & $25 \%$ & $50 \%$ & $75 \%$ & $90 \%$ & $95 \%$ & $5 \%$ & $10 \%$ & $25 \%$ & $50 \%$ & $75 \%$ & $90 \%$ & $95 \%$ \\
\hline \multirow[t]{3}{*}{1} & 90 & 97 & 97 & 98 & 100 & 101 & 102 & 103 & 52 & 53 & 53 & 54 & 55 & 55 & 56 \\
\hline & 95 & 100 & 101 & 102 & 104 & 105 & 106 & 107 & 56 & 57 & 57 & 58 & 59 & 59 & 60 \\
\hline & 99 & 108 & 108 & 109 & 111 & 112 & 113 & 114 & 64 & 64 & 65 & 65 & 66 & 67 & 67 \\
\hline \multirow[t]{3}{*}{2} & 90 & 98 & 99 & 100 & 101 & 103 & 104 & 105 & 57 & 58 & 58 & 59 & 60 & 61 & 61 \\
\hline & 95 & 102 & 103 & 104 & 105 & 107 & 108 & 109 & 61 & 62 & 62 & 63 & 64 & 65 & 65 \\
\hline & 99 & 109 & 110 & 111 & 112 & 114 & 115 & 116 & 69 & 69 & 70 & 70 & 71 & 72 & 72 \\
\hline \multirow[t]{3}{*}{3} & 90 & 100 & 100 & 102 & 103 & 104 & 106 & 106 & 61 & 62 & 62 & 63 & 64 & 64 & 65 \\
\hline & 95 & 104 & 104 & 105 & 107 & 108 & 109 & 110 & 65 & 66 & 66 & 67 & 68 & 68 & 69 \\
\hline & 99 & 111 & 111 & 113 & 114 & 115 & 116 & 117 & 73 & 73 & 74 & 74 & 75 & 76 & 76 \\
\hline \multirow[t]{3}{*}{4} & 90 & 101 & 102 & 103 & 104 & 106 & 107 & 108 & 64 & 64 & 65 & 66 & 67 & 67 & 68 \\
\hline & 95 & 105 & 106 & 107 & 108 & 110 & 111 & 112 & 68 & 68 & 69 & 70 & 71 & 71 & 72 \\
\hline & 99 & 112 & 113 & 114 & 115 & 117 & 118 & 119 & 76 & 76 & 76 & 77 & 78 & 79 & 79 \\
\hline \multirow[t]{3}{*}{5} & 90 & 103 & 103 & 105 & 106 & 107 & 109 & 109 & 66 & 67 & 67 & 68 & 69 & 69 & 70 \\
\hline & 95 & 107 & 107 & 108 & 110 & 111 & 112 & 113 & 70 & 71 & 71 & 72 & 73 & 73 & 74 \\
\hline & 99 & 114 & 114 & 116 & 117 & 118 & 120 & 120 & 78 & 78 & 79 & 79 & 80 & 81 & 81 \\
\hline \multirow[t]{3}{*}{6} & 90 & 104 & 105 & 106 & 108 & 109 & 110 & 111 & 68 & 68 & 69 & 70 & 70 & 71 & 72 \\
\hline & 95 & 108 & 109 & 110 & 111 & 113 & 114 & 115 & 72 & 72 & 73 & 74 & 74 & 75 & 76 \\
\hline & 99 & 115 & 116 & 117 & 119 & 120 & 121 & 122 & 80 & 80 & 80 & 81 & 82 & 83 & 83 \\
\hline \multirow[t]{3}{*}{7} & 90 & 106 & 107 & 108 & 109 & 111 & 112 & 113 & 69 & 70 & 70 & 71 & 72 & 72 & 73 \\
\hline & 95 & 110 & 111 & 112 & 113 & 115 & 116 & 116 & 73 & 74 & 74 & 75 & 76 & 76 & 77 \\
\hline & 99 & 117 & 118 & 119 & 120 & 122 & 123 & 124 & 81 & 81 & 82 & 82 & 83 & 84 & 84 \\
\hline \multirow[t]{3}{*}{8} & 90 & 108 & 109 & 110 & 111 & 113 & 114 & 114 & 71 & 71 & 71 & 72 & 73 & 74 & 74 \\
\hline & 95 & 112 & 112 & 114 & 115 & 116 & 118 & 118 & 75 & 75 & 75 & 76 & 77 & 78 & 78 \\
\hline & 99 & 119 & 120 & 121 & 122 & 123 & 125 & 125 & 82 & 82 & 83 & 83 & 84 & 85 & 86 \\
\hline
\end{tabular}




\begin{tabular}{|c|c|c|c|c|c|c|c|c|c|c|c|c|c|c|c|}
\hline \multicolumn{16}{|c|}{ continuação Tabela 9} \\
\hline \multirow[t]{3}{*}{9} & 90 & 110 & 110 & 112 & 113 & 114 & 116 & 116 & 72 & 72 & 72 & 73 & 74 & 75 & 75 \\
\hline & 95 & 114 & 114 & 115 & 117 & 118 & 119 & 120 & 76 & 76 & 76 & 77 & 78 & 79 & 79 \\
\hline & 99 & 121 & 121 & 123 & 124 & 125 & 127 & 127 & 83 & 83 & 84 & 84 & 85 & 86 & 87 \\
\hline \multirow[t]{3}{*}{10} & 90 & 112 & 112 & 114 & 115 & 116 & 118 & 118 & 73 & 73 & 73 & 74 & 75 & 76 & 76 \\
\hline & 95 & 116 & 116 & 117 & 119 & 120 & 121 & 122 & 77 & 77 & 77 & 78 & 79 & 80 & 80 \\
\hline & 99 & 123 & 123 & 125 & 126 & 127 & 129 & 129 & 84 & 84 & 85 & 86 & 86 & 87 & 88 \\
\hline \multirow[t]{3}{*}{11} & 90 & 114 & 114 & 116 & 117 & 118 & 119 & 120 & 74 & 74 & 74 & 75 & 76 & 77 & 77 \\
\hline & 95 & 118 & 118 & 119 & 121 & 122 & 123 & 124 & 78 & 78 & 78 & 79 & 80 & 81 & 81 \\
\hline & 99 & 125 & 125 & 126 & 128 & 129 & 130 & 131 & 85 & 85 & 86 & 87 & 87 & 88 & 89 \\
\hline \multirow[t]{3}{*}{12} & 90 & 116 & 116 & 117 & 119 & 120 & 121 & 122 & 75 & 75 & 75 & 76 & 77 & 78 & 78 \\
\hline & 95 & 119 & 120 & 121 & 123 & 124 & 125 & 126 & 79 & 79 & 79 & 80 & 81 & 82 & 82 \\
\hline & 99 & 127 & 127 & 128 & 130 & 131 & 132 & 133 & 86 & 86 & 87 & 88 & 88 & 89 & 90 \\
\hline \multirow[t]{3}{*}{13} & 90 & 117 & 118 & 119 & 121 & 122 & 123 & 124 & 76 & 76 & 76 & 77 & 78 & 79 & 79 \\
\hline & 95 & 121 & 122 & 123 & 124 & 126 & 127 & 128 & 80 & 80 & 80 & 81 & 82 & 83 & 83 \\
\hline & 99 & 128 & 129 & 130 & 132 & 133 & 134 & 135 & 87 & 87 & 88 & 89 & 89 & 90 & 91 \\
\hline \multirow[t]{3}{*}{14} & 90 & 119 & 120 & 121 & 122 & 124 & 125 & 125 & 77 & 77 & 77 & 78 & 79 & 80 & 80 \\
\hline & 95 & 123 & 123 & 125 & 126 & 127 & 129 & 129 & 81 & 81 & 81 & 82 & 83 & 84 & 84 \\
\hline & 99 & 130 & 131 & 132 & 133 & 135 & 136 & 136 & 88 & 88 & 89 & 90 & 90 & 91 & 92 \\
\hline \multirow[t]{3}{*}{15} & 90 & 120 & 121 & 122 & 123 & 125 & 126 & 127 & 78 & 78 & 78 & 79 & 80 & 81 & 81 \\
\hline & 95 & 124 & 125 & 126 & 127 & 129 & 130 & 131 & 82 & 82 & 82 & 83 & 84 & 85 & 85 \\
\hline & 99 & 131 & 132 & 133 & 134 & 136 & 137 & 138 & 89 & 89 & 90 & 91 & 91 & 92 & 93 \\
\hline \multirow[t]{3}{*}{16} & 90 & 121 & 122 & 123 & 124 & 126 & 127 & 128 & 78 & 78 & 79 & 80 & 81 & 81 & 82 \\
\hline & 95 & 125 & 126 & 127 & 128 & 130 & 131 & 132 & 82 & 82 & 83 & 84 & 85 & 85 & 86 \\
\hline & 99 & 132 & 133 & 134 & 135 & 137 & 138 & 139 & 90 & 90 & 90 & 91 & 92 & 93 & 93 \\
\hline \multirow[t]{3}{*}{17} & 90 & 122 & 122 & 123 & 125 & 126 & 127 & 128 & 78 & 79 & 79 & 80 & 81 & 81 & 82 \\
\hline & 95 & 125 & 126 & 127 & 129 & 130 & 131 & 132 & 82 & 83 & 83 & 84 & 85 & 85 & 86 \\
\hline & 99 & 133 & 133 & 134 & 136 & 137 & 138 & 139 & 90 & 90 & 91 & 91 & 92 & 93 & 93 \\
\hline
\end{tabular}

Tabela 10 - Valores de pressão arterial referentes aos percentis 90, 95 e 99 de pressão arterial para meninos de 1 a 17 anos de idade, de acordo com o percentil de estatura

\begin{tabular}{|c|c|c|c|c|c|c|c|c|c|c|c|c|c|c|c|}
\hline \multirow[t]{2}{*}{$\begin{array}{l}\text { Idade } \\
\text { (anos) }\end{array}$} & \multirow[t]{2}{*}{ Percentil } & \multicolumn{7}{|c|}{ PA sistólica $(\mathrm{mmHg})$ por percentil de estatura } & \multicolumn{7}{|c|}{ PA diastólica $(\mathrm{mmHg})$ por percentil de estatura } \\
\hline & & $5 \%$ & $10 \%$ & $25 \%$ & $50 \%$ & $75 \%$ & $90 \%$ & $95 \%$ & $5 \%$ & $10 \%$ & $25 \%$ & $50 \%$ & $75 \%$ & $90 \%$ & $95 \%$ \\
\hline \multirow[t]{3}{*}{1} & 90 & 94 & 95 & 97 & 99 & 100 & 102 & 103 & 49 & 50 & 51 & 52 & 53 & 53 & 54 \\
\hline & 95 & 98 & 99 & 101 & 103 & 104 & 106 & 106 & 54 & 54 & 55 & 56 & 57 & 58 & 58 \\
\hline & 99 & 105 & 106 & 108 & 110 & 112 & 113 & 114 & 61 & 62 & 63 & 64 & 65 & 66 & 66 \\
\hline \multirow[t]{3}{*}{2} & 90 & 97 & 99 & 100 & 102 & 104 & 105 & 106 & 54 & 55 & 56 & 57 & 58 & 58 & 59 \\
\hline & 95 & 101 & 102 & 104 & 106 & 108 & 109 & 110 & 59 & 59 & 60 & 61 & 62 & 63 & 63 \\
\hline & 99 & 109 & 110 & 111 & 113 & 115 & 117 & 117 & 66 & 67 & 68 & 69 & 70 & 71 & 71 \\
\hline \multirow[t]{3}{*}{3} & 90 & 100 & 101 & 103 & 105 & 107 & 108 & 109 & 59 & 59 & 60 & 61 & 62 & 63 & 63 \\
\hline & 95 & 104 & 105 & 107 & 109 & 110 & 112 & 113 & 63 & 63 & 64 & 65 & 66 & 67 & 67 \\
\hline & 99 & 111 & 112 & 114 & 116 & 118 & 119 & 120 & 71 & 71 & 72 & 73 & 74 & 75 & 75 \\
\hline 4 & 90 & 102 & 103 & 105 & 107 & 109 & 110 & 111 & 62 & 63 & 64 & 65 & 66 & 66 & 67 \\
\hline
\end{tabular}




\begin{tabular}{|c|c|c|c|c|c|c|c|c|c|c|c|c|c|c|c|}
\hline \multicolumn{16}{|c|}{ continuação Tabela 10} \\
\hline & 95 & 106 & 107 & 109 & 111 & 112 & 114 & 115 & 66 & 67 & 68 & 69 & 70 & 71 & 71 \\
\hline & 99 & 113 & 114 & 116 & 118 & 120 & 121 & 122 & 74 & 75 & 76 & 77 & 78 & 78 & 79 \\
\hline \multirow[t]{3}{*}{5} & 90 & 104 & 105 & 106 & 108 & 110 & 111 & 112 & 65 & 66 & 67 & 68 & 69 & 69 & 70 \\
\hline & 95 & 108 & 109 & 110 & 112 & 114 & 115 & 116 & 69 & 70 & 71 & 72 & 73 & 74 & 74 \\
\hline & 99 & 115 & 116 & 118 & 120 & 121 & 123 & 123 & 77 & 78 & 79 & 80 & 81 & 81 & 82 \\
\hline \multirow[t]{3}{*}{6} & 90 & 105 & 106 & 108 & 110 & 111 & 113 & 113 & 68 & 68 & 69 & 70 & 71 & 72 & 72 \\
\hline & 95 & 109 & 110 & 112 & 114 & 115 & 117 & 117 & 72 & 72 & 73 & 74 & 75 & 76 & 76 \\
\hline & 99 & 116 & 117 & 119 & 121 & 123 & 124 & 125 & 80 & 80 & 81 & 82 & 83 & 84 & 84 \\
\hline \multirow[t]{3}{*}{7} & 90 & 106 & 107 & 109 & 111 & 113 & 114 & 115 & 70 & 70 & 71 & 72 & 73 & 74 & 74 \\
\hline & 95 & 110 & 111 & 113 & 115 & 117 & 118 & 119 & 74 & 74 & 75 & 76 & 77 & 78 & 78 \\
\hline & 99 & 117 & 118 & 120 & 122 & 124 & 125 & 126 & 82 & 82 & 83 & 84 & 85 & 86 & 86 \\
\hline \multirow[t]{3}{*}{8} & 90 & 107 & 109 & 110 & 112 & 114 & 115 & 116 & 71 & 72 & 72 & 73 & 74 & 75 & 76 \\
\hline & 95 & 111 & 112 & 114 & 116 & 118 & 119 & 120 & 75 & 76 & 77 & 78 & 79 & 79 & 80 \\
\hline & 99 & 119 & 120 & 122 & 123 & 125 & 127 & 127 & 83 & 84 & 85 & 86 & 87 & 87 & 88 \\
\hline \multirow[t]{3}{*}{9} & 90 & 109 & 110 & 112 & 114 & 115 & 117 & 118 & 72 & 73 & 74 & 75 & 76 & 76 & 77 \\
\hline & 95 & 113 & 114 & 116 & 118 & 119 & 121 & 121 & 76 & 77 & 78 & 79 & 80 & 81 & 81 \\
\hline & 99 & 120 & 121 & 123 & 125 & 127 & 128 & 129 & 84 & 85 & 86 & 87 & 88 & 88 & 89 \\
\hline \multirow[t]{3}{*}{10} & 90 & 111 & 112 & 114 & 115 & 117 & 119 & 119 & 73 & 73 & 74 & 75 & 76 & 77 & 78 \\
\hline & 95 & 115 & 116 & 117 & 119 & 121 & 122 & 123 & 77 & 78 & 79 & 80 & 81 & 81 & 82 \\
\hline & 99 & 122 & 123 & 125 & 127 & 128 & 130 & 130 & 85 & 86 & 86 & 88 & 88 & 89 & 90 \\
\hline \multirow[t]{3}{*}{11} & 90 & 113 & 114 & 115 & 117 & 119 & 120 & 121 & 74 & 74 & 75 & 76 & 77 & 78 & 78 \\
\hline & 95 & 117 & 118 & 119 & 121 & 123 & 124 & 125 & 78 & 78 & 79 & 80 & 81 & 82 & 82 \\
\hline & 99 & 124 & 125 & 127 & 129 & 130 & 132 & 132 & 86 & 86 & 87 & 88 & 89 & 90 & 90 \\
\hline \multirow[t]{3}{*}{12} & 90 & 115 & 116 & 118 & 120 & 121 & 123 & 123 & 74 & 75 & 75 & 76 & 77 & 78 & 79 \\
\hline & 95 & 119 & 120 & 122 & 123 & 125 & 127 & 127 & 78 & 79 & 80 & 81 & 82 & 82 & 83 \\
\hline & 99 & 126 & 127 & 129 & 131 & 133 & 134 & 135 & 86 & 87 & 88 & 89 & 90 & 90 & 91 \\
\hline \multirow[t]{3}{*}{13} & 90 & 117 & 118 & 120 & 122 & 124 & 125 & 126 & 75 & 75 & 76 & 77 & 78 & 79 & 79 \\
\hline & 95 & 121 & 122 & 124 & 126 & 128 & 129 & 130 & 79 & 79 & 80 & 81 & 82 & 83 & 83 \\
\hline & 99 & 128 & 130 & 131 & 133 & 135 & 136 & 137 & 87 & 87 & 88 & 89 & 90 & 91 & 91 \\
\hline \multirow[t]{3}{*}{14} & 90 & 120 & 121 & 123 & 125 & 126 & 128 & 128 & 75 & 76 & 77 & 78 & 79 & 79 & 80 \\
\hline & 95 & 124 & 125 & 127 & 128 & 130 & 132 & 132 & 80 & 80 & 81 & 82 & 83 & 84 & 84 \\
\hline & 99 & 131 & 132 & 134 & 136 & 138 & 139 & 140 & 87 & 88 & 89 & 90 & 91 & 92 & 92 \\
\hline \multirow[t]{3}{*}{15} & 90 & 122 & 124 & 125 & 127 & 129 & 130 & 131 & 76 & 77 & 78 & 79 & 80 & 80 & 81 \\
\hline & 95 & 126 & 127 & 129 & 131 & 133 & 134 & 135 & 81 & 81 & 82 & 83 & 84 & 85 & 85 \\
\hline & 99 & 134 & 135 & 136 & 138 & 140 & 142 & 142 & 88 & 89 & 90 & 91 & 92 & 93 & 93 \\
\hline \multirow[t]{3}{*}{16} & 90 & 125 & 126 & 128 & 130 & 131 & 133 & 134 & 78 & 78 & 79 & 80 & 81 & 82 & 82 \\
\hline & 95 & 129 & 130 & 132 & 134 & 135 & 137 & 137 & 82 & 83 & 83 & 84 & 85 & 86 & 87 \\
\hline & 99 & 136 & 137 & 139 & 141 & 143 & 144 & 145 & 90 & 90 & 91 & 92 & 93 & 94 & 94 \\
\hline \multirow[t]{3}{*}{17} & 90 & 127 & 128 & 130 & 132 & 134 & 135 & 136 & 80 & 80 & 81 & 82 & 83 & 84 & 84 \\
\hline & 95 & 131 & 132 & 134 & 136 & 138 & 139 & 140 & 84 & 85 & 86 & 87 & 87 & 88 & 89 \\
\hline & 99 & 139 & 140 & 141 & 143 & 145 & 146 & 147 & 92 & 93 & 93 & 94 & 95 & 96 & 97 \\
\hline
\end{tabular}


Tabela 11 - Gráficos de desenvolvimento para cálculo do percentil de altura
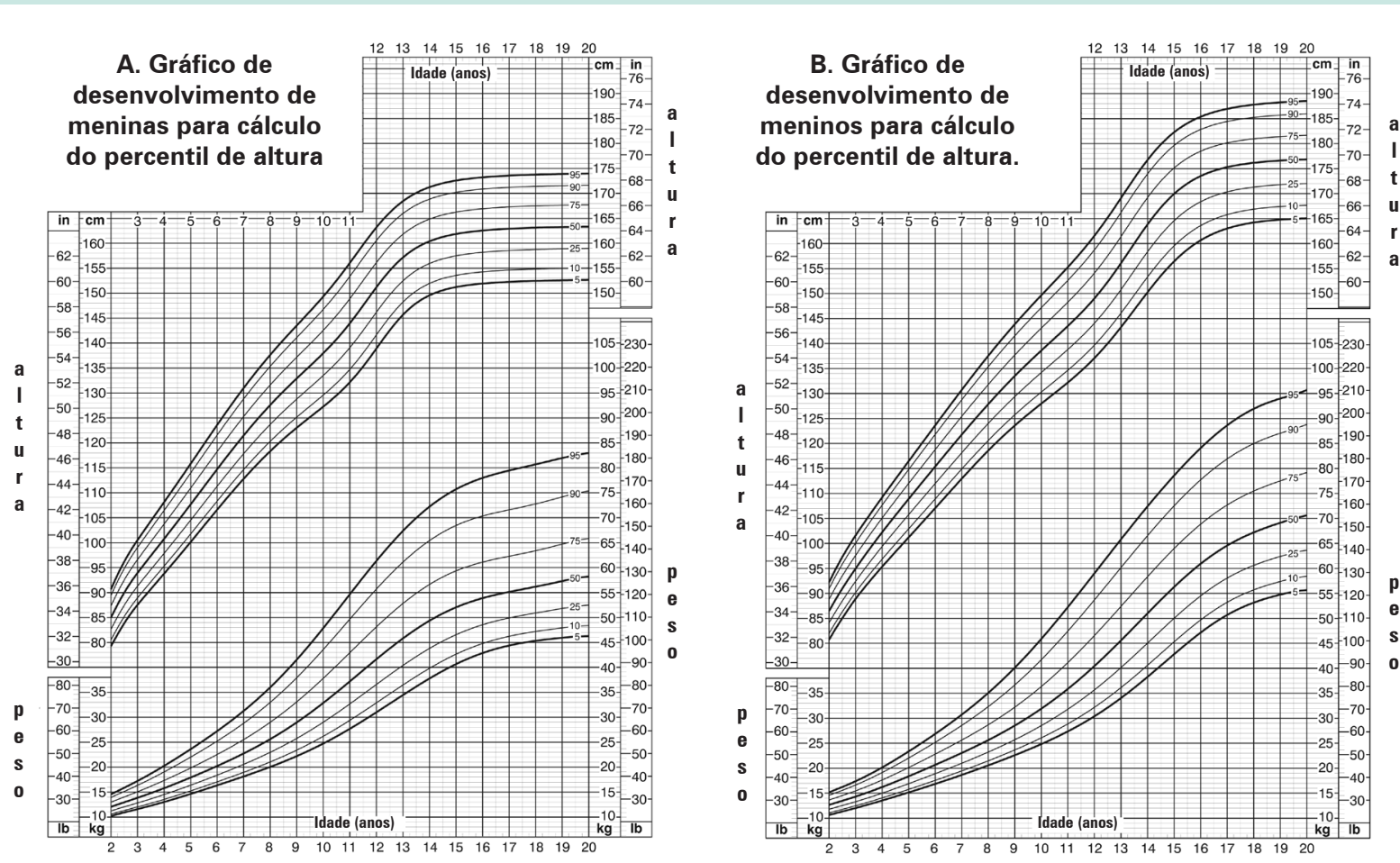

Published May 30, 2000 (modified 11/21/00). SOURCE: Developed by the National Center for Health Statistics in collaboration with the National Center for Chronic Disease Prevention and Health Promotion (2000). http://www.cdc.gov/growthcharts .

Por outro lado, um menino com 14 anos de idade, medindo $158 \mathrm{~cm}$ (percentil 25) e com pressão arterial de 110/70 mmHg, seria considerado normotenso. Já outro menino de mesma idade e mesma altura, mas com pressão arterial de 122/70 mmHg, seria considerado limítrofe. Se esta segunda criança, em vez de $158 \mathrm{~cm}$, tivesse estatura de 170 $\mathrm{cm}$ (percentil 75), a pressão arterial de 130/83 mmHg o faria ser considerado hipertenso. 


\section{Diretriz}

\section{Investigação Clínico-Laboratorial e Decisão Terapêutica}

Os objetivos da investigação clínico-laboratorial estão na tabela 1.

Tabela 1 - Objetivos da investigação clínico-laboratorial

Confirmar a elevação da pressão arterial e firmar o diagnóstico de hipertensão arterial

Identificar fatores de risco para doenças cardiovasculares

Avaliar lesões de órgãos-alvo e presença de doença cardiovascular

Diagnosticar doenças associadas à hipertensão

Estratificar o risco cardiovascular do paciente

Diagnosticar hipertensão arterial secundária

Para atingir tais objetivos, são fundamentais:

- História clínica, considerando, em especial, o que consta da tabela 2

-Exame físico (Tabela 3)

-Avaliação laboratorial inicial do hipertenso (Tabela 4)

Tabela 2 - Dados relevantes da história clínica

Identificação: sexo, idade, cor da pele, profissão e condição socioeconômica

História atual: duração conhecida de hipertensão arterial e níveis de pressão de consultório e domiciliar, adesão e reações adversas aos tratamentos prévios

Sintomas de doença arterial coronária, sinais e sintomas sugestivos de insuficiência cardíaca, doença vascular encefálica, insuficiência vascular de extremidades, doença renal, diabetes melito, indícios de hipertensão secundária (Tabela 6)

Fatores de risco modificáveis: dislipidemia, tabagismo, sobrepeso e obesidade, sedentarismo, etilismo e hábitos alimentares não saudáveis

Avaliação dietética, incluindo consumo de sal, bebidas alcoólicas, gordura saturada, cafeína e ingestão de fibras, frutas e vegetais

Consumo pregresso ou atual de medicamentos ou drogas que podem elevar a pressão arterial ou interferir em seu tratamento

\section{Grau de atividade física}

História atual ou pregressa de gota, doença arterial coronária, insuficiência cardíaca, pré-eclâmpsia/eclâmpsia, doença renal, doença pulmonar obstrutiva crônica, asma, disfunção sexual e apnéia do sono

Perfil psicossocial: fatores ambientais e psicossociais, sintomas de depressão, ansiedade e pânico, situação familiar, condições de trabalho e grau de escolaridade

História familiar de diabetes melito, dislipidemias, doença renal, acidente vascular cerebral, doença arterial coronariana prematura ou morte prematura e súbita de familiares próximos (homens $<55$ anos e mulheres $<65$ anos)

\section{Tabela 3 - Dados relevantes do exame físico}

Sinais vitais: medida da pressão arterial (vide capítulo 2, tabela 1) e freqüência cardíaca

Obtenção das medidas antropométricas: a) circunferências da cintura ( $\mathrm{C}=$ no ponto médio entre a última costela e a crista ilíaca lateral) e do quadril $(\mathrm{Q}=$ ao nível do trocanter maior) e cálculo da relação cintura/quadril $(\mathrm{C} / \mathrm{Q})^{55}$. Limite de normalidade: mulheres: $\mathrm{C}=88 \mathrm{~cm}$ e $\mathrm{C} / \mathrm{Q}=0,85$; homens: $\mathrm{C}=102 \mathrm{~cm}$ e $\mathrm{C} / \mathrm{Q}=0,95$. b) obtenção de peso e altura e cálculo do índice de massa corporal [IMC = peso $(\mathrm{kg}) /$ altura $\left.^{2}(\mathrm{~m})\right]$. Sobrepeso $25 \leq \mathrm{IMC}<30 \mathrm{~kg} / \mathrm{m}^{2} \mathrm{e}$ obesidade IMC $\geq 30 \mathrm{~kg} / \mathrm{m}^{2}$.

Inspeção: fácies e aspectos sugestivos de hipertensão secundária (Tabela 6)

Pescoço: palpação e ausculta das artérias carótidas, verificação da presença de estase venosa e palpação de tireóide

Exame do precórdio: íctus sugestivo de hipertrofia ou dilatação do ventrículo esquerdo; arritmias; $3^{a}$ bulha, que sinaliza disfunção sistólica do ventrículo esquerdo; ou $4^{\text {a }}$ bulha, que sinaliza presença de disfunção diastólica do ventrículo esquerdo, hiperfonese de $2^{a}$ bulha em foco aórtico, além de sopros nos focos mitral e aórtico

Exame do pulmão: ausculta de estertores, roncos e sibilos.

Exame do abdome: massas abdominais indicativas de rins policísticos, hidronefrose, tumores e aneurismas. Identificação de sopros abdominais na aorta e nas artérias renais

Extremidades: palpação de pulsos braquiais, radiais, femorais, tibiais posteriores e pediosos. A diminuição da amplitude ou o retardo do pulso das artérias femorais sugerem doença obstrutiva ou coartação da aorta. Se houver forte suspeita de doença arterial obstrutiva periférica, determinar o Índice Tornozelo-Braquial (ITB) ${ }^{56}$ *. Avaliação de eventual edema.

Exame neurológico sumário.

Exame de fundo do olho: identificar estreitamento arteriolar, cruzamentos arteriovenosos patológicos, hemorragias, exsudatos e papiledema.

* Para o cálculo do ITB, utilizam-se os valores de pressão arterial do braço e tornozelo. ITB direito = pressão tornozelo direito/pressão braço direito. ITB esquerdo = pressão tornozelo esquerdo/pressão braço esquerdo. Interpretação: normal = acima de 0,9; obstrução leve =0,71-0,90; obstrução moderada =0,41-0,70; obstrução grave $=0,00-0,40$.

A avaliação complementar (Tabela 5) está indicada em pacientes que apresentam elementos indicativos de doenças associadas, lesões em órgãos-alvo, doença cardiovascular ou três ou mais fatores de risco. Quando houver indícios de hipertensão secundária (Tabela 6), esta possibilidade deve ser investigada por métodos específicos (vide capítulo 8).

As indicações para exames específicos, como MRPA e MAPA, estão no capítulo 2, tabelas 5 e 6.

\subsection{Estratificação de Risco e Decisão Terapêutica}

Para a tomada da decisão terapêutica é necessária a confirmação diagnóstica, seguindo-se a estratificação de 
Tabela 4 - Avaliação inicial de rotina para o paciente hipertenso

Análise de urina (D)

Potássio plasmático (D)

Creatinina plasmática $(\mathrm{D})^{*}$

Glicemia de jejum (D)

Colesterol total, HDL, triglicérides plasmáticos (D)**

Ácido úrico plasmático (D)

Eletrocardiograma convencional (D)

* Calcular a taxa de filtração glomerular estimada (TFGE) pela fórmula de Cockroft-Gault57:TFGE (ml/min) = [140 - idade] x peso $(\mathrm{kg}) /$ creatinina plasmática $(\mathrm{mg} / \mathrm{dl})$ x 72 para homens; para mulheres, multiplicar o resultado por 0,85. Interpretação: função renal normal: $>90 \mathrm{ml} / \mathrm{min}$; disfuncão renal leve: $60-90 \mathrm{ml} / \mathrm{min}$; disfunção renal moderada: $30-60 \mathrm{ml} / \mathrm{min}$ e disfunção renal grave: $<30 \mathrm{ml} / \mathrm{min}$. **O $L D L-c$ é calculado pela fórmula: $L D L-c=$ colesterol total $-H D L-c$ - triglicérides/5 (quando a dosagem de triglicérides for abaixo de $400 \mathrm{mg} / \mathrm{dl}$ ).
Tabela 5 - Avaliação complementar para o paciente hipertenso

Pacientes hipertensos diabéticos, hipertensos com síndrome metabólica e hipertensos com três ou mais fatores de risco: recomenda-se pesquisa de microalbuminúria - índice albumina/ creatinina em amostra isolada de urina ( $m g$ de albumina/g de creatinina ou $\mathrm{mg}$ de albumina/mmol de creatinina) (B) ${ }^{58-60}$.

- $\quad$ Normal $<30 \mathrm{mg} / \mathrm{g}$ ou $<2,5 \mathrm{mg} / \mathrm{mmol}$;

- Microalbuminúria: 30 a $300 \mathrm{mg} / \mathrm{g}$ ou 2,5 a $25 \mathrm{mg} / \mathrm{mmol}$ ).

Pacientes com glicemia de jejum entre 100 e $125 \mathrm{mg} / \mathrm{dl}$ : recomenda-se determinar a glicemia duas horas após sobrecarga oral de glicose (75 g) (B)

Em hipertensos estágios 1 e 2 sem hipertrofia ventricular esquerda ao ECG, mas com três ou mais fatores de risco, considerar o emprego do ecocardiograma para detecção de hipertrofia ventricular esquerda ${ }^{61}$ (D).

Para hipertensos com suspeita clínica de insuficiência cardíaca considerar a utilização do ecocardiograma para avaliação da função sistólica e diastólica (D) risco (Tabela 7), que levará em conta, além dos valores de pressão arterial $^{64,65}$, a presença de fatores de risco cardiovasculares (Tabela 8), as lesões em órgãos-alvo e as doenças cardiovasculares (Tabela 9) e, finalmente, a meta mínima de valores da pressão arterial, que deverá ser atingida com o tratamento ${ }^{64,65}$ (Tabela 10).

A estratégia terapêutica deverá ser individualizada de acordo com a estratificação de risco e a meta do nível de pressão arterial a ser alcançado (Tabela 10).

Preconizam-se mudanças dos hábitos alimentares e do estilo de vida (tratamento não-medicamentoso) para todos os pacientes, independentemente do risco cardiovascular.

Para emprego isolado do tratamento não-medicamentoso, ou associado ao tratamento medicamentoso como estratégia terapêutica, deve-se considerar a meta da pressão arterial a ser atingida, que em geral é determinada pelo grau de risco cardiovascular.

A tabela 11 aponta a estratégia de tratamento da hipertensão arterial mais provável de acordo com a estratificação do risco cardiovascular.

\section{Tabela 6 - Indícios de hipertensão secundária}

Início da hipertensão antes dos 30 anos ou após os 50 anos de idade

Hipertensão arterial grave (estágio 3) e/ou resistente à terapia

Tríade do feocromocitoma: palpitações, sudorese e cefaléia em crises

Uso de medicamentos e drogasque possam elevar a pressão arterial (vide capítulo 8, Tabela 4)

Fácies ou biotipo de doença que cursa com hipertensão:doença renal, hipertireoidismo, acromegalia, síndrome de Cushing

Presença de massas ou sopros abdominais

Assimetria de pulsos femorais

Aumento da creatinina sérica ou taxa de filtração glomerular estimada diminuída

Hipopotassemia espontânea

Exame de urina anormal (proteinúria ou hematúria)

Sintomas de apnéia durante o sono

Tabela 7 - Estratificação do risco individual do paciente hipertenso: risco cardiovascular adicional de acordo com os níveis da pressão arterial e a presença de fatores de risco, lesões de órgãos-alvo e doença cardiovascular

\section{Fatores de risco}

\section{Pressão arterial}

$\begin{array}{ccc}\text { Hipertensão } & \text { Hipertensão } & \text { Hipertensão } \\ \text { estágio } 1 & \text { estágio } 2 & \text { estágio } 3\end{array}$

Sem fator de risco

1 a 2 fatores de risco Sem risco adicional

Risco baixo

Risco médio

Risco alto

3 ou mais fatores de risco ou lesão de órgãos-alvo ou diabetes melito

Risco baixo Risco baixo

Risco médio

Risco médio

Risco muito alto

Risco médio

Risco alto

Risco alto

Risco alto

Risco muito alto

Doença cardiovascular

Risco alto

Risco muito alto Risco muito alto Risco muito alto

Risco muito alto 


\section{Diretriz}

Tabela 8 - Identificação de fatores do risco cardiovascular

\section{Fatores de risco maiores}

Tabagismo

Dislipidemias

Diabetes melito

Nefropatia

Idade acima de 60 anos

História familiar de doença cardiovascular em:

- Mulheres com menos de 65 anos

- Homens com menos de 55 anos

\section{Outros fatores}

Relação cintura/quadril aumentada

Circunferência da cintura aumentada

Microalbuminúria

Tolerância à glicose diminuída/glicemia de jejum alterada

Hiperuricemia

PCR ultra-sensível aumentada ${ }^{62,63}$

Tabela 9 - Identificação de lesões de órgãos-alvo e doenças cardiovasculares

Hipertrofia do ventrículo esquerdo

Angina do peito ou infarto agudo do miocárdio prévio

Revascularização miocárdica prévia

Insuficiência cardíaca

Acidente vascular cerebral

Isquemia cerebral transitória

Alterações cognitivas ou demência vascular

Nefropatia

Doença vascular arterial de extremidades

Retinopatia hipertensiva

Para pacientes com três ou mais fatores de risco cardiovascular considerar marca dores mais precoces da lesão de órgãosalvo, como:

Microalbuminúria (índice albumina/creatinina em amostra isolada de urina)

Parâmetros ecocardiográficos:remodelação ventricular, função sistólica e diastólica

Espessura do complexo íntima-média da carótida (ultrasom vascular)

Rigidez arterial

Função endotelial
Tabela 10 - Metas de valores da pressão arterial a serem obtidas com o tratamento

\section{Categorias}

Meta (no mínimo)*

Hipertensos estágio 1 e 2 com risco cardiovascular baixo e médio

$$
<140 / 90 \mathrm{mmHg}
$$

Hipertensos e limítrofes com risco cardiovascular alto

$<130 / 85 \mathrm{mmHg}$

Hipertensos e limítrofes com risco cardiovascular muito alto

Hipertensos nefropatas com proteinúria $>1,0 \mathrm{~g} / \mathrm{l}$

* Se o paciente tolerar, recomenda-se atingir com o tratamento valores de pressão arterial menores que os indicados como metas mínimas, alcançando, se possível, os níveis da pressão arterial considerada ótima ( $\leq 120 / 80 \mathrm{mmHg}$ ).

\section{Tabela 11 - Decisão terapêutica da hipertensão arterial segundo o risco cardiovascular \\ Categoria de risco \\ Estratégia \\ Sem risco adicional \\ Tratamento não-medicamentoso isolado \\ Tratamento não-medicamentoso \\ Risco adicional baixo isolado por até 6 meses. Se não atingir a meta, associar tratamento medicamentoso

$\begin{array}{cc}\text { Risco adicional médio } & \text { Tratamento não-medicamentoso } \\ + \text { medicamentoso }\end{array}$ \\ Risco adicional alto \\ Tratamento não-medicamentoso + medicamentoso}

Risco adicional muito alto

Tratamento não-medicamentoso + medicamentoso 


\section{Abordagem Multiprofissional}

A necessidade de trabalho multiprofissional nos cuidados com a saúde é reconhecida por todos e vem sendo incorporada de forma progressiva na prática diária. Treinados durante a formação para atuar individualmente, os profissionais de saúde vivem uma fase contraditória na qual, mesmo sabendo o que é melhor, se vêem com dificuldades e pudores para definir limites, intersecções e interfaces. Este é um trabalho necessário, que exige coragem, determinação e contínua autocrítica para que os objetivos sejam atingidos ${ }^{66-71}$.

A hipertensão arterial é um excelente modelo para o trabalho de uma equipe multiprofissional. Por ser uma doença multifatorial, que envolve orientações voltadas para vários objetivos, terá seu tratamento mais efetivo com o apoio de vários profissionais de saúde ${ }^{72}$. Objetivos múltiplos exigem diferentes abordagens, e a formação de uma equipe multiprofissional proporcionará essa ação diferenciada ${ }^{71-78}$, ampliando o sucesso do controle da hipertensão e dos demais fatores de risco cardiovascular.

Prevenir e tratar a hipertensão arterial envolve ensinamentos para o conhecimento da doença, de suas inter-relações, de suas complicações e implica, na maioria das vezes, a necessidade da introdução de mudanças de hábitos de vida.

A aquisição do conhecimento é fundamental, mas é apenas o primeiro passo. A implementação efetiva das mudanças é lenta e, por dependerem de medidas educativas, necessitam de continuidade ${ }^{73-75}$. Devem ser promovidas por meio de ações individualizadas, elaboradas para atender às necessidades específicas de cada paciente, e de ações coletivas de modo a ampliar o campo de ação e apresentar a melhor relação custo-benefício, podendo, assim, ser mantidas a longo prazo $^{76,77}$.

O trabalho da equipe multiprofissional contribuirá para oferecer ao paciente e à comunidade uma visão mais ampla do problema, dando-Ihes conhecimento e motivação para vencer o desafio e adotar atitudes de mudanças de hábitos de vida e adesão real ao tratamento proposto com base no risco cardiovascular global ${ }^{71-79,80}(\mathrm{~B})$.

\subsection{Equipe Multiprofissional}

A equipe multiprofissional pode ser constituída por todos os profissionais que lidem com pacientes hipertensos: médicos, enfermeiros, técnicos e auxiliares de enfermagem, nutricionistas, psicólogos, assistentes sociais, professores de educação física, fisioterapeutas, musicoterapeutas, farmacêuticos, funcionários administrativos e agentes comunitários de saúde.

Os membros de um grupo multiprofissional devem trabalhar de acordo com os limites e especificidades de sua formação, e respeitada esta especificidade, necessitam conhecer a ação individual de cada um dos outros membros ${ }^{66,68,69,71,73,74,80,81}$. Além disso, cada local de trabalho deve adequar-se à sua realidade.

Deve ficar claro que não há necessidade de todo esse grupo para a formação da equipe.

\section{Principais vantagens desse tipo de atuação}

- O número de indivíduos atendidos será maior; a adesão ao tratamento será superior; cada paciente poderá ser um replicador de conhecimentos e atitudes.

- Haverá favorecimento de ações de pesquisa em serviço.

- Como vantagem adicional, teremos o crescimento profissional no serviço como um todo (C).

\section{Ações comuns à equipe multiprofissional}

- Promoção à saúde (ações educativas com ênfase em mudanças do estilo de vida, correção dos fatores de risco e produção de material educativo).

- Treinamento de profissionais.

- Ações assistenciais individuais e em grupo de acordo com as especificidades; participação em projetos de pesquisa ${ }^{81}$.

\section{Ações específicas individuais}

As ações específicas definidas pelas diretrizes de cada profissão devem obviamente ser respeitadas. Nas situações e circunstâncias em que houver superposições de funções, isso deve acontecer de maneira natural e só será possível se houver harmonia entre o grupo, estabelecimento de regras claras e perfeita uniformidade de linguagem. O processo educativo é lento, as mudanças de atitudes são demoradas, e a comunicação clara, objetiva e equilibrada é crucial para o alcance das metas ${ }^{75,81}$.

Participação do médico

- Consulta médica (ver avaliação clínico-laboratorial).

- Responsabilidade pelo diagnóstico e pelas condutas terapêuticas.

- Avaliação clínica dos pacientes pelo menos duas vezes por ano.

- Apoio aos demais membros, quando necessário ${ }^{72,73}$ (B).

- Administração do serviço.

- Encaminhamento de pacientes e delegação de atividades a outros profissionais quando necessário (B).

\section{Participação do enfermeiro}

- Consulta de enfermagem ${ }^{72,82,83}$ :

$\sqrt{ }$ Medida da pressão arterial com manguito adequado à circunferência do braço; medida de altura e peso com roupas leves e sem sapatos, medida da circunferência da cintura e quadril e cálculo do índice de massa corporal;

$\sqrt{ }$ Investigação sobre fatores de risco e hábitos de vida;

$\checkmark$ Orientação sobre a doença e o uso regular de medicamentos prescritos pelo médico;

$\checkmark$ Orientações sobre hábitos de vida pessoais e familiares

- Acompanhamento do tratamento dos pacientes hipertensos;

- Encaminhamento ao médico pelo menos duas vezes ao ano e com maior freqüência nos casos em que a pressão não estiver devidamente controlada ou na presença de outras intercorrências. 


\section{Diretriz}

- Administração do serviço.

- Delegação e supervisão das atividades do técnico/ auxiliar de enfermagem ${ }^{73,84-87}(\mathrm{~B})$.

\section{Participação da nutricionista}

- Consulta de nutrição:

$\checkmark$ Medida da pressão arterial com manguito adequado à circunferência do braço; medida de altura e peso com roupas leves e sem sapatos, medida da circunferência da cintura e quadril e cálculo do índice de massa corporal;

$\checkmark$ Anamnese alimentar, avaliando freqüência, quantidade e qualidade de alimentos, intolerâncias e alergias alimentares ${ }^{88}$;

$\sqrt{ }$ Diagnóstico nutricional;

$\sqrt{ }$ Prescrição e orientação específica da dieta, considerando aspectos socioeconômicos, culturais e ambientais, com ensinamentos que possibilitem preparações alimentares saborosas, práticas e saudáveis; identificação dos alimentos diet e/ou light e do teor de sódio existente nos alimentos processados ${ }^{87,89,90 ;}$

$\sqrt{ }$ Avaliação da interação de alimentos e/ou nutrientes com medicamentos ${ }^{89}$.

- Seguimento da evolução nutricional.

- Educação nutricional ${ }^{87-90}$ (B).

\section{Participação do psicólogo $73,75,76,91-93$}

- Consulta de psicologia:

$\sqrt{ }$ Avaliação e tratamento de aspectos emocionais que interfiram na qualidade de vida do paciente, seu nível de estresse e adesão ao tratamento global da hipertensão arterial ${ }^{73,75,76,91-93}$;

$\sqrt{ }$ Avaliação de como o paciente processa a informação quanto à saúde, para que o método de comunicação com ele seja devidamente individualizado e o plano de mudanças de hábitos de vida, mantido ${ }^{73}$.

- Atendimento a familiares, para facilitar as mudanças de hábitos de vida do grupo familiar e a adesão ao tratamento.

- Treinamento de controle de estresse.

- Trabalho sistemático junto à equipe com o objetivo de promover o entrosamento e a harmonia entre todos, com o objetivo de que o grupo, de fato, constitua-se em uma equipe multiprofissional $67,76,93$.

\section{Participação da assistente social}

- Entrevista social para identificação socioeconômica e familiar (visando a uma atuação preventiva), caracterização da situação de trabalho e previdência, e levantamento de expectativas sobre a doença e o seu tratamento ${ }^{72}$.

- Atualização do cadastro de recursos sociais (para encaminhamento do atendimento das dificuldades dos pacientes e familiares que possam interferir na terapêutica $)^{71}$.

- Desenvolvimento de atividades visando à organização dos pacientes em associações de portadores de hipertensão arterial.

- Busca ativa de faltosos (B).

Participação do professor de educação física

- Programação e supervisão das atividades físicas, presencial ou a distância (individuais e em grupo) dos pacientes, após consulta médica, adequando-as às realidades locais e às características específicas de cada $u^{94,95}(\mathrm{~B})$.

- Programação e execução de projetos de atividade física para prevenção da hipertensão arterial na comunidade.

Participação do farmacêutico

- Participação em comitês para a seleção de medicamentos.

- Gerenciamento de estoque, armazenamento correto e dispensação de medicamentos.

- Promoção da atenção farmacêutica ao paciente (orientação individual ou em grupo e acompanhamento do uso de medicamentos) ${ }^{72,96}$.

- Orientação quanto ao uso racional de medicamentos à população ${ }^{72,96}$.

Participação do fisioterapeuta $66,68,69,71,74$

- Atendimento individual e em grupo aos pacientes encaminhados.

- Identificação e atuação fisioterapêutica sobre problemas que causem limitação às mudanças de hábitos de vida (dores limitantes, posturas etc).

\section{Participação do musicoterapeuta ${ }^{66,68,69,71,74,91}$}

- Atividades em grupo para trabalho musicoterapêutico visando à adoção de hábitos saudáveis e à diminuição do estresse.

Participação de funcionários administrativos

- Recepção dos pacientes ${ }^{71,73,74}$.

- Controle e agendamento de consultas e reuniões ${ }^{73,74}(\mathrm{C})$.

Participação de agentes comunitários de saúde ${ }^{67,69}$

- Ações educativas primárias, visando à promoção de saúde.

- Busca ativa de faltosos.

- Sugestão de encaminhamento para unidades de básicas de saúde.

- Coleta de dados referentes à hipertensão arterial, conforme impresso padronizado.

\subsection{Ações em Grupo}

Reuniões com pacientes

As ações educativas e terapêuticas em saúde devem ser 
desenvolvidas com grupos de pacientes, seus familiares e a comunidade, sendo adicionais às atividades individuais.

A equipe deve usar todos os recursos disponíveis para orientação, educação e motivação a fim de, modificando hábitos de vida, diminuir os fatores de risco cardiovasculares e incentivar o uso ininterrupto dos medicamentos, quando necessários.

Os recursos disponíveis vão desde o contato individual até a utilização de fontes de informações coletivas, como reuniões, palestras, simpósios, peças teatrais, folhetos, vídeos e músicas educativas. Devem ser sempre consideradas as particularidades regionais para a aplicação de qualquer um dos métodos educativos. Nesse tipo de atividade, o paciente se identifica com outros indivíduos com problemas semelhantes, aprendendo a expressar seus medos e expectativas. Com isso, passa a compartilhar das experiências de todos, buscando soluções reais para problemas de saúde semelhantes aos seus $s^{72,76-78,97}$ (B).

\section{Reuniões da equipe}

Atividades periódicas com a participação de todo o grupo para análise crítica das ações desenvolvidas, acerto de arestas e novas orientações, caso necessárias ${ }^{74}(\mathrm{C})$. Ter em mente que: trabalhar em equipe é mais do que agregar profissionais de diferentes áreas; só existe equipe quando todos conhecem os objetivos, estão cientes da necessidade de alcançá-los e desenvolvem uma visão crítica a respeito do desempenho de cada um e do grupo.

\subsection{Atividades que Devem Contar com a Participação da Equipe Multiprofissional}

\section{Programas comunitários}

A equipe multiprofissional deve procurar estimular, por meio dos pacientes, dos representantes da comunidade, de profissionais da área de comunicação e da sociedade civil, o desenvolvimento de atividades comunitárias ${ }^{4}$.

A criação de Ligas e Associações de Portadores de Hipertensão Arterial é uma estratégia que também pode aumentar a adesão do paciente ao tratamento instituído (B).

\section{Atividades conjuntas (equipes/pacientes)}

Devem ocorrer concomitantemente, reunindo diversas equipes multiprofissionais e grupos de pacientes.

\section{Sugestões para implantação do serviço}

Identificação da equipe multiprofissional mínima possível, de acordo com a realidade existente, e definição das tarefas de cada um.

Fluxograma de atendimento: cada serviço, de acordo com sua equipe, estabelecerá uma estratégia, devendo estar aí incluídas atividades individuais e/ou de grupo. Informação ao paciente sobre a rotina de atendimento, para que tenha maior compreensão e, conseqüentemente, maior adesão ao tratamento.

Ações administrativas

- Cartão do paciente.

- Obrigatoriedade do registro de todos os dados do paciente em prontuário.

- Reuniões periódicas da equipe buscando uniformização de procedimentos e linguagem.

O que determina o bom funcionamento do grupo é sua filosofia de trabalho: caminhar unidos na mesma direção. 


\section{Diretriz}

\section{Tratamento não-medicamentoso}

A adoção de um estilo saudável de vida é fundamental no tratamento de hipertensos ${ }^{4}$, particularmente quando há síndrome metabólica ${ }^{98-100}$.

Os principais fatores ambientais modificáveis da hipertensão arterial são os hábitos alimentares inadequados, principalmente ingestão excessiva de sal e baixo consumo de vegetais, sedentarismo, obesidade e consumo exagerado de álcool, podendo-se obter redução da pressão arterial e diminuição do risco cardiovascular controlando esses fatores 98,101 (Tabela 1).

\subsection{Controle de peso}

Hipertensos com excesso de peso devem ser incluídos em programas de emagrecimento com restrição de ingestão calórica e aumento de atividade física. A meta é alcançar índice de massa corporal inferior a $25 \mathrm{~kg} / \mathrm{m}^{2}{ }^{(102)}$ e circunferência da cintura inferior a $102 \mathrm{~cm}$ para homens e $88 \mathrm{~cm}$ para mulheres, embora a diminuição de $5 \%$ a $10 \%$ do peso corporal inicial já seja suficiente para reduzir a pressão arterial (B).

A redução do peso está relacionada à queda da insulinemia, à redução da sensibilidade ao sódio e à diminuição da atividade do sistema nervoso simpático ${ }^{99}$.

\subsection{Padrão alimentar}

O consumo dos alimentos pode levar à ingestão de certos nutrientes que induzem respostas às vezes indesejáveis na pressão arterial e no sistema cardiovascular. Os alimentos "de risco", ricos em sódio e gorduras saturadas, por exemplo, devem ser evitados, ao passo que os "de proteção", ricos em fibras e potássio, são permitidos ${ }^{103}(\mathrm{~B})$.

Padrão alimentar é definido como o perfil do consumo de alimentos pelo indivíduo ao longo de um determinado período de tempo. É utilizado no estudo da relação entre a ingestão de certos nutrientes e o risco de doenças, pois permite uma compreensão mais clara sobre a alimentação como um todo, em lugar de se considerarem os nutrientes individualmente ${ }^{101,103-106}(\mathrm{~B})$.
A dieta preconizada pelo estudo DASH (Dietary Approachs to Stop Hypertension) mostrou benefícios no controle da pressão arterial, inclusive em pacientes fazendo uso de antihipertensivos. Enfatiza o consumo de frutas, verduras, alimentos integrais, leite desnatado e derivados, quantidade reduzida de gorduras saturadas e colesterol, maior quantidade de fibras, potássio, cálcio e magnésio ${ }^{107}$. Associada à redução no consumo de sal, mostra benefícios ainda mais evidentes, sendo, portanto, fortemente recomendada para hipertensos ${ }^{108}$. Compõe-se de quatro a cinco porções de frutas, quatro a cinco porções de vegetais e duas a três porções de laticínios desnatados por dia, com menos de $25 \%$ de gordura ${ }^{107}$.

Dietas vegetarianas podem ocasionar discreta redução na pressão arterial sistólica em hipertensos leves ${ }^{109}$. O estilo de vida vegetariano com atividade física regular, controle de peso, aumento do consumo de potássio e baixa ingestão de álcool e a dieta em si, rica em fibras, pode ser favorável na redução do risco cardiovascular ${ }^{102,109,110}$.

O hábito alimentar dos hipertensos deve incluir ${ }^{101,102,110}$ : redução da quantidade de sal na elaboração de alimentos (A); retirada do saleiro da mesa $(\mathrm{A})$; restrição das fontes industrializadas de sal: molhos prontos, sopas em pó, embutidos, conservas, enlatados, congelados, defumados e salgados de pacote tipo snacks (B); uso restrito ou abolição de bebidas alcoólicas (B); preferência por temperos naturais como limão, ervas, alho, cebola, salsa e cebolinha, em substituição aos similares industrializados (D); redução de alimentos de alta densidade calórica, substituindo doces e derivados do açúcar por carboidratos complexos e frutas (A), diminuindo o consumo de bebidas açucaradas e dando preferência a adoçantes não calóricos (C); inclusão de, pelo menos, cinco porções de frutas/verduras no plano alimentar diário, com ênfase em vegetais ou frutas cítricas e cereais integrais (A); opção por alimentos com reduzido teor de gordura, eliminando as gorduras hidrogenadas ("trans") e preferindo as do tipo mono ou poliinsaturadas, presentes nas fontes de origem vegetal, exceto dendê e coco (A); ingestão adequada de cálcio pelo uso de produtos lácteos, de preferência,

\begin{tabular}{|c|c|c|}
\hline Modificação & Recomendação & Redução aproximada na PAS** \\
\hline Controle de peso & $\begin{array}{l}\text { Manter o peso corporal na faixa normal } \\
\text { (índice de massa corporal entre } 18,5 \text { a } 24,9 \mathrm{~kg} / \mathrm{m}^{2} \text { ) }\end{array}$ & $\begin{array}{l}5 \text { a } 20 \mathrm{mmHg} \text { para cada } \\
10 \mathrm{~kg} \text { de peso reduzido }\end{array}$ \\
\hline Padrão alimentar & $\begin{array}{l}\text { Consumir dieta rica em frutas e vegetais e alimentos } \\
\text { com baixa densidade calórica e baixo teor de } \\
\text { gorduras saturadas e totais. Adotar dieta DASH }\end{array}$ & 8 a 14 mmHg \\
\hline Redução do consumo de sal & $\begin{array}{c}\text { Reduzir a ingestão de sódio para não mais de } 100 \\
\mathrm{mmol} / \mathrm{dia}=2,4 \mathrm{~g} \text { de sódio }(6 \mathrm{~g} \text { de sal/dia }=4 \\
\text { colheres de café rasas de sal }=4 \mathrm{~g}+2 \mathrm{~g} \text { de sal } \\
\text { próprio dos alimentos) }\end{array}$ & 2 a $8 \mathrm{mmHg}$ \\
\hline $\begin{array}{l}\text { Moderação no consumo de } \\
\text { álcool }\end{array}$ & $\begin{array}{l}\text { Limitar o consumo a } 30 \mathrm{~g} / \text { dia de etanol para os } \\
\text { homens e } 15 \mathrm{~g} / \text { dia para mulheres }\end{array}$ & 2 a $4 \mathrm{mmHg}$ \\
\hline Exercício físico & $\begin{array}{l}\text { Habituar-se à prática regular de atividade física } \\
\text { aeróbica, como caminhadas por, pelo menos, } 30 \\
\text { minutos por dia, } 3 \text { a } 5 \text { vezes/semana }\end{array}$ & 4 a 9 mmHg \\
\hline
\end{tabular}


desnatados (B); busca de forma prazerosa e palatável de preparo dos alimentos: assados, crus e grelhados (D); plano alimentar que atenda às exigências de uma alimentação saudável, do controle do peso corporal, das preferências pessoais e do poder aquisitivo do indivíduo/família (D).

\section{Suplementação de potássio}

A suplementação de potássio promove redução modesta da pressão arterial $^{111}$ (A). Sua ingestão na dieta pode ser aumentada pela escolha de alimentos pobres em sódio e ricos em potássio, como feijões, ervilha, vegetais de cor verdeescuro, banana, melão, cenoura, beterraba, frutas secas, tomate, batata inglesa e laranja.

É razoável a recomendação de níveis de ingestão de potássio de 4,7 g/dia. Para a população saudável com função renal normal, a ingestão de potássio pode ser superior a 4,7 $\mathrm{g} /$ dia sem oferecer riscos, porque o excesso será excretado pelos rins. Entretanto, para indivíduos com função renal diminuída (taxa de filtração glomerular $<60 \mathrm{ml} / \mathrm{min}$ ), é apropriada a ingestão de potássio inferior a 4,7 g/dia pelos riscos de hiperpotassemia ${ }^{102}$.

Recomenda-se cautela com medicamentos à base de potássio, como expectorantes, em indivíduos suscetíveis à hiperpotassemia, principalmente pacientes com insuficiência renal ou em uso de inibidor da ECA, antagonista do receptor AT1 ou diuréticos poupadores de potássio ${ }^{102}$.

\section{Suplementação de cálcio e magnésio}

Dieta com frutas, verduras e laticínios de baixo teor de gordura apresenta quantidades apreciáveis de cálcio, magnésio e potássio, proporcionando efeito favorável em relação à redução da pressão arterial e de acidente vascular cerebral ${ }^{107,112,113}$ (A).

Não existem dados suficientes para recomendar suplementação de cálcio ou magnésio como medida para baixar a pressão arterial, se não houver hipocalcemia ou hipomagnesemia. Além disso, suplementação de cálcio excedendo $1 \mathrm{~g} /$ dia pode aumentar o risco de litíase renal ${ }^{114,115}$.

\subsection{Redução do consumo de sal}

Inúmeras evidências mostram benefícios na restrição do consumo de sal ${ }^{116-120}$ : a) redução da pressão arterial $(\mathrm{A})$; b) menor prevalência de complicações cardiovasculares (B); c) menor incremento da pressão arterial com o envelhecimento (B); d) possibilidade de prevenir a elevação da pressão arterial (B); e) regressão de hipertrofia miocárdica B.

Estudos randomizados comparando dieta hipossódica com a dieta habitual, com ou sem redução de peso, demonstram efeito favorável, embora modesto, na redução da pressão arterial com a restrição de sal ${ }^{121}$. Há evidências de que a pressão arterial varia diretamente com o consumo de sal tanto em normotensos como em hipertensos. Portanto, mesmo reduções modestas no consumo diário podem produzir benefícios.

A dieta habitual contém de 10 a $12 \mathrm{~g} /$ dia de sal $(\mathrm{A})^{122}$. É saudável uma pessoa ingerir até $6 \mathrm{~g}$ de sal por dia $(100 \mathrm{mmol}$ ou 2,4 g/dia de sódio), correspondente a quatro colheres de café ( $4 \mathrm{~g}$ ) rasas de sal adicionadas aos alimentos, que contêm 2 g de sal. Para tanto, recomenda-se reduzir o sal adicionado aos alimentos, evitar o saleiro à mesa e reduzir ou abolir os alimentos industrializados, como enlatados, conservas, frios, embutidos, sopas, temperos, molhos prontos e salgadinhos ${ }^{123}$. Por outro lado, a redução excessiva do consumo de sal também deve ser evitada, principalmente em pacientes em uso de diuréticos, podendo provocar hiponatremia, hipovolemia e hemoconcentração.

O uso de cloreto de potássio em lugar do sal, como forma de redução do consumo de sódio ou suplementação de potássio, pode ser recomendado, porém é absolutamente contraindicado em pacientes com risco de hiperpotassemia ${ }^{102}$.

\subsection{Moderação no Consumo de Bebidas Alcoólicas}

Recomenda-se limitar o consumo de bebidas alcoólicas a, no máximo, $30 \mathrm{~g} /$ dia de etanol ${ }^{102}$ para homens e $15 \mathrm{~g} /$ dia para mulheres ou indivíduos de baixo peso (Tabela 2). Aos pacientes que não se enquadrarem nesses limites de consumo, sugere-se o abandono.

\subsection{Exercício físico}

A prática regular de exercícios físicos ${ }^{124-127}$ é recomendada para todos os hipertensos, inclusive aqueles sob tratamento medicamentoso, porque reduz a pressão arterial sistólica/diastólica em 6,9/4,9 $\mathrm{mmHg}$ (Tabela 3). Além disso, o exercício físico pode reduzir o risco de doença arterial coronária, acidentes vasculares cerebrais e mortalidade geral ${ }^{128}$ (A).

\begin{tabular}{|c|c|c|c|c|}
\hline Bebida & $\begin{array}{c}\text { \% de etanol } \\
\text { (o GL Gay Lussac) }\end{array}$ & $\begin{array}{l}\text { Quantidade de etanol (g) } \\
\text { em } 100 \mathrm{ml}\end{array}$ & $\begin{array}{c}\text { Volume para } 30 \mathrm{~g} \text { de } \\
\text { etanol }\end{array}$ & $\begin{array}{c}\text { Consumo máximo } \\
\text { tolerado }\end{array}$ \\
\hline Cerveja & $\sim 6 \%(3-8)$ & $6 \mathrm{~g} / 100 \mathrm{ml} \times 0,8^{*}=4,8 \mathrm{~g}$ & $625 \mathrm{ml}$ & $\begin{array}{l}\sim 2 \text { latas }(350 \times 2=700 \\
\mathrm{ml}) \text { ou } 1 \text { garrafa }(650 \mathrm{ml})\end{array}$ \\
\hline Vinho & 12\% (5-13) & $12 \mathrm{~g} / 100 \mathrm{ml} \times 0,8^{*}=9,6 \mathrm{~g}$ & $312,5 \mathrm{ml}$ & $\begin{array}{c}\sim 2 \text { taças de } 150 \mathrm{ml} \mathrm{ou} \\
1 \text { taça de } 300 \mathrm{ml}\end{array}$ \\
\hline $\begin{array}{l}\text { Uísque, vodka, } \\
\text { aguardente }\end{array}$ & $\sim 40 \%(30-50)$ & $40 \mathrm{~g} / 100 \mathrm{ml} \times 0,8^{*}=32 \mathrm{~g}$ & $93,7 \mathrm{ml}$ & $\begin{array}{c}\sim 2 \text { doses de } 50 \mathrm{ml} \mathrm{ou} \\
3 \text { doses de } 30 \mathrm{ml}\end{array}$ \\
\hline
\end{tabular}




\section{Diretriz}

Tabela 3 - Recomendação de atividade física

\section{Recomendação populacional ${ }^{130,131}$}

Todo adulto deve realizar pelo menos 30 minutos de atividades físicas moderadas de forma contínua ou acumulada em pelo menos 5 dias da semana (A).

\section{Recomendação individual}

Fazer exercícios aeróbicos (caminhada, corrida, ciclismo, dança, natação) (A).

Exercitar-se de 3 a 5 vezes por semana (B).

Exercitar-se por, pelo menos, 30 minutos (para emagrecer, fazer 60 minutos) (B).

Realizar exercício em intensidade moderada (B), estabelecida:

a) pela respiração: sem ficar ofegante (conseguir falar frases compridas sem interrupção) (D);

b) pelo cansaço subjetivo: sentir-se moderadamente cansado no exercício $(\mathrm{C})$;

c) pela freqüência cardíaca (FC) medida durante o exercício (forma mais precisa), que deve se manter dentro da faixa de freqüência cardíaca de treinamento ( $F C$ treino) $(B)$, cujo cálculo é feito da seguinte forma: $F_{\text {treino }}=\left(F_{\text {máxima }}-F_{\text {repouso }}\right) \times$ \% + $\mathrm{FC}_{\text {repouso' }}$ em que:

$\mathrm{FC}_{\text {máxima }}$ : deve ser preferencialmente estabelecida em um teste ergométrico máximo. Na sua impossibilidade, pode-se usar a fórmula: $\mathrm{FC}_{\text {máxima }}=220$ - idade, exceto em indivíduos em uso de betabloqueadores e/ou inibidores de canais de cálcio nãodiidropiridínicos ${ }^{132}$.

$\mathrm{FC}_{\text {repouso }}$ : medida após 5 minutos de repouso deitado.

\%: são utilizadas duas porcentagens, uma para o limite inferior e outra para o superior da faixa de treinamento. Assim, para sedentários: 50\% e 70\%; para condicionados: $60 \%$ e $80 \%$, respectivamente.

Realizar também exercícios resistidos (musculação) (B). No caso dos hipertensos, estes devem ser feitos com sobrecarga de até 50\% a $60 \%$ de 1 repetição máxima (1 RM = carga máxima que se consegue levantar uma única vez) e o exercício deve ser interrompido quando a velocidade de movimento diminuir (antes da fadiga concêntrica, momento que o indivíduo não consegue mais realizar o movimento) (C).

Antes de iniciarem programas regulares de exercício físico, os hipertensos devem ser submetidos a avaliação clínica especializada, exame pré-participação (para eventual ajuste da medicação) e recomendações médicas relacionadas aos exercícios. Hipertensos em estágio 3 só devem iniciar o exercício após controle da pressão arterial ${ }^{129}$.

\subsection{Abandono do tabagismo}

O tabagismo deve ser agressivamente combatido e eliminado ${ }^{133,134}$. Hipertensos podem usar com segurança terapias reposicionais com nicotina para abandono do tabagismo. Eventual descontrole de peso observado com a abolição do tabaco, embora transitório e de pequeno impacto no risco cardiovascular, não deve ser negligenciado ${ }^{134}$.

\subsection{Controle do estresse psicoemocional}

Estudos experimentais demonstram elevação transitória da pressão arterial em situações de estresse, como o estresse mental, ou elevações mais prolongadas, como nas técnicas de privação do sono. Estudos mais recentes evidenciam o efeito do estresse psicoemocional na reatividade cardiovascular e da pressão arterial $^{135}$ (B), podendo contribuir para hipertensão arterial sustentada $^{136}$ (B). Estudos com treinamento para controle do estresse emocional com diferentes técnicas mostraram benefícios no controle ${ }^{91}$ (B) e na redução da variabilidade da pressão arterial (C), podendo ser utilizado como medida adicional na abordagem não-farmacológica de pacientes hipertensos ${ }^{137}$ (C). Além disso, a abordagem de aspectos piscoemocionais e psicossociais pode ser útil na melhora da adesão do paciente a medidas terapêuticas não-medicamentosas e medicamentosas. 


\section{Tratamento Medicamentoso}

\subsection{Objetivos}

O objetivo primordial do tratamento da hipertensão arterial é a redução da morbidade e da mortalidade cardiovasculares $^{138,139}$. Assim, os anti-hipertensivos devem não só reduzir a pressão arterial, mas também os eventos cardiovasculares fatais e não-fatais. As evidências provenientes de estudos de desfechos clinicamente relevantes, com duração relativamente curta, de três a quatro anos, demonstram redução de morbidade e mortalidade em maior número de estudos com diuréticos ${ }^{140-142}(\mathrm{~A})$, mas também com betabloqueadores ${ }^{140,141,143,144}(\mathrm{~A})$, inibidores da $\mathrm{ECA}^{144-149}(\mathrm{~A})$, bloqueadores do receptor AT1 150,151 (A) e com bloqueadores dos canais de cálcio ${ }^{145,149,152-154}(\mathrm{~A})$, embora a maioria dos estudos utilize, no final, associação de anti-hipertensivos.

O tratamento medicamentoso associado ao nãomedicamentoso objetiva a redução da pressão arterial para valores inferiores a $140 \mathrm{mmHg}$ de pressão sistólica e 90 mmHg de pressão diastólica ${ }^{138,139,155}$ (A), respeitandose as características individuais, a presença de doenças ou condições associadas ou características peculiares e a qualidade de vida dos pacientes. Reduções da pressão arterial para níveis inferiores a 130/80 mmHg podem ser úteis em situações específicas, como em pacientes de alto risco cardiovascular $^{79,156,157}$ (A), diabéticos - principalmente com microalbuminúria ${ }^{156-160}(A)$, insuficiência cardíaca ${ }^{161}(A)$, com comprometimento renal ${ }^{160}(\mathrm{~A})$ e na prevenção de acidente vascular cerebral ${ }^{148,162}(\mathrm{~A})$.

\subsection{Princípios Gerais do Tratamento Medicamentoso}

Os aspectos importantes na escolha do anti-hipertensivo estão na tabela 1. Deve-se explicar, detalhadamente, aos pacientes a ocorrência de possíveis efeitos adversos, a possibilidade de eventuais modificações na terapêutica instituída e o tempo necessário para que o efeito pleno dos medicamentos seja obtido.

Tabela 1 - Características importantes do anti-hipertensivo

Ser eficaz por via oral.

Ser bem tolerado.

Permitir a administração em menor número possível de tomadas, com preferência para dose única diária.

Ser iniciado com as menores doses efetivas preconizadas para cada situação clínica, podendo ser aumentadas gradativamente, pois quanto maior a dose, maiores serão as probabilidades de efeitos adversos.

Não ser obtido por meio de manipulação, pela inexistência de informações adequadas de controle de qualidade, bioequivalência e/ou de interação química dos compostos.

Ser considerado em associação para os pacientes com hipertensão em estágios 2 e 3 que, na maioria das vezes, não respondem à monoterapia.

Ser utilizado por um período mínimo de 4 semanas, salvo em situações especiais, para aumento de dose, substituição da monoterapia ou mudança das associações em uso.

\subsection{Escolha do Medicamento}

Qualquer medicamento dos grupos de anti-hipertensivos (Tabela 2), com exceção dos vasodilatadores de ação direta (D), pode ser utilizado para o controle da pressão arterial em monoterapia inicial, especialmente para pacientes com hipertensão arterial em estágio 1 que não responderam às medidas não-medicamentosas (Tabela 3). Para pacientes em estágios 2 e 3, pode-se considerar o uso de associações fixas (Tabela 4) de medicamentos anti-hipertensivos como terapia inicial.

Tabela 2 - Classes de anti-hipertensivos para uso clínico

Diuréticos

Inibidores adrenérgicos

Ação central - agonistas alfa-2 centrais

Betabloqueadores - bloqueadores beta-adrenérgicos

Alfabloqueadores - bloqueadores alfa-1-adrenérgicos

Alfabloqueadores e Betabloqueadores

Bloqueadores dos canais de cálcio

Inibidores da ECA

Bloqueadores do receptor AT1 da angiotensina II

Vasodilatadores diretos

Tabela 3 - Anti-hipertensivos disponíveis no Brasil

\begin{tabular}{|c|c|c|c|}
\hline \multirow{2}{*}{ Medicamentos } & \multicolumn{2}{|c|}{ Posologia (mg) } & \multirow{2}{*}{$\begin{array}{c}\text { Número de } \\
\text { Tomadas/ } \\
\text { dia }\end{array}$} \\
\hline & Mínima & Máxima & \\
\hline \multicolumn{4}{|l|}{ Diuréticos } \\
\hline \multicolumn{4}{|l|}{ Tiazídicos } \\
\hline Clortalidona & 12,5 & 25 & 1 \\
\hline Hidroclorotiazida & 12,5 & 25 & 1 \\
\hline Indapamida & 2,5 & 5 & 1 \\
\hline Indapamida SR $* * *$ & 1,5 & 5 & 1 \\
\hline \multicolumn{4}{|l|}{$A / c ̧ a$} \\
\hline Bumetamida & 0,5 & $* *$ & $1-2$ \\
\hline Furosemida & 20 & $* *$ & $1-2$ \\
\hline Piretanida & 6 & 12 & 1 \\
\hline \multicolumn{4}{|l|}{ Poupadores de potássio } \\
\hline Amilorida* & 2,5 & 5 & 1 \\
\hline Espironolactona & 50 & 200 & $1-2$ \\
\hline Triantereno* & 50 & 100 & 1 \\
\hline \multicolumn{4}{|c|}{ Inibidores adrenérgicos } \\
\hline \multicolumn{4}{|l|}{ Ação central } \\
\hline Alfametildopa & 500 & 1.500 & $2-3$ \\
\hline Clonidina & 0,2 & 0,6 & $2-3$ \\
\hline
\end{tabular}




\section{Diretriz}

\begin{tabular}{|c|c|c|c|}
\hline \multicolumn{4}{|c|}{ continuação da Tabela 3} \\
\hline Guanabenzo & 4 & 12 & $2-3$ \\
\hline Moxonidina & 0,2 & 0,6 & 1 \\
\hline Rilmenidina & 1 & 2 & 1 \\
\hline Reserpina* & 0,1 & 0,25 & $1-2$ \\
\hline \multicolumn{4}{|l|}{ Betabloqueadores } \\
\hline Atenolol & 25 & 100 & $1-2$ \\
\hline Bisoprolol & 2,5 & 10 & $1-2$ \\
\hline $\begin{array}{l}\text { Metoprolol/ } \\
\text { Metoprolol } \\
(\text { ZOK)*** }\end{array}$ & 50 & 200 & $1-2$ \\
\hline Nadolol & 40 & 120 & 1 \\
\hline $\begin{array}{l}\text { Propranolol**/ } \\
\text { Propranolol (LA)*** }\end{array}$ & $40 / 80$ & $240 / 160$ & $2-3 / 1-2$ \\
\hline Pindolol & 10 & 40 & 2 \\
\hline \multicolumn{4}{|l|}{ Alfabloqueadores } \\
\hline Doxazosina & 1 & 16 & 1 \\
\hline Prazosina & 1 & 20 & $2-3$ \\
\hline Prazosina $\mathrm{XL} * * *$ & 4 & 8 & 1 \\
\hline Terazosina & 1 & 20 & $1-2$ \\
\hline \multicolumn{4}{|c|}{ Alfabloqueadores e betabloqueadores } \\
\hline Carvedilol & 12,5 & 50 & $1-2$ \\
\hline \multicolumn{4}{|c|}{ Bloqueadores dos canais de cálcio } \\
\hline \multicolumn{4}{|c|}{ Fenilalquilaminas } \\
\hline $\begin{array}{l}\text { Verapamil Retard } \\
* * *\end{array}$ & 120 & 480 & $1-2$ \\
\hline \multicolumn{4}{|l|}{ Benzotiazepinas } \\
\hline $\begin{array}{l}\text { Diltiazem AP, SR ou } \\
\text { CD*** }\end{array}$ & 180 & 480 & $1-2$ \\
\hline \multicolumn{4}{|l|}{ Diidropiridinas } \\
\hline Anlodipino & 2,5 & 10 & 1 \\
\hline Felodipino & 5 & 20 & $1-2$ \\
\hline Isradipino & 2,5 & 20 & 2 \\
\hline Lacidipino & 2 & 8 & 1 \\
\hline Nifedipino Oros*** & 20 & 60 & 1 \\
\hline $\begin{array}{l}\text { Nifedipino } \\
\text { Retard*** }\end{array}$ & 20 & 40 & 2 \\
\hline Nisoldipino & 5 & 40 & $1-2$ \\
\hline Nitrendipino & 10 & 40 & $2-3$ \\
\hline Lercarnidipino & 10 & 30 & 1 \\
\hline Manidipino & 10 & 20 & 1 \\
\hline \multicolumn{4}{|l|}{ Inibidores da ECA } \\
\hline Benazepril & 5 & 20 & 1 \\
\hline Captopril & 25 & 150 & $2-3$ \\
\hline Cilazapril & 2,5 & 5 & 1 \\
\hline Delapril & 15 & 30 & $1-2$ \\
\hline Enalapril & 5 & 40 & $1-2$ \\
\hline
\end{tabular}

\begin{tabular}{|lccc}
\hline \multicolumn{5}{c}{ continuação da Tabela 3 } \\
\hline Fosinopril & 10 & 20 & 1 \\
\hline Lisinopril & 5 & 20 & 1 \\
\hline Perindopril & 4 & 8 & 1 \\
\hline Quinapril & 10 & 20 & 1 \\
\hline Ramipril & 2,5 & 10 & 1 \\
\hline Trandolapril & 2 & 4 & 1 \\
\hline Bloqueadores do receptor AT & & \\
\hline Candesartana & 8 & 16 & 1 \\
\hline Irbersartana & 150 & 300 & 1 \\
\hline Losartana & 25 & 100 & 1 \\
\hline Olmesartana & 20 & 40 & 1 \\
\hline Telmisartana & 40 & 80 & 1 \\
\hline Valsartana & 80 & 160 & 1 \\
\hline Vasodilatadores de ação direta & & \\
\hline Hidralazina & 50 & 200 & $2-3$ \\
\hline Minoxidil & 2,5 & 80 & $2-3$ \\
\hline * Medicamentos comercializados apenas em associações a outros anti- \\
hipertensivos. ** Dose máxima variável de acordo com a indicação \\
médica. *** Retard, SR, ZOK, Oros, XL, LA, AP, SR e CD: formas \\
farmacêuticas de liberação prolongada ou controlada.
\end{tabular}

\section{Tabela 4 - Associações fixas de anti-hipertensivos disponíveis no} Brasil

Associações Posologia (mg)

\section{Diurético + diurético}

$\begin{array}{ll}\text { Clortalidona + amilorida } & 25+5 \\ 50+5\end{array}$

\begin{tabular}{lc}
$\begin{array}{l}\text { Espironolactona }+ \\
\text { hidroclorotiazida }\end{array}$ & $50+50$ \\
\hline Furosemida + amilorida & $40+10$ \\
Furosemida + espironolactona & $20+100$ \\
\hline Furosemida + triantereno & $40+50$ \\
\hline Hidroclorotiazida + amilorida & $25+2,5$ \\
\hline Hidroclorotiazida + triantereno & $50+5$ \\
\hline
\end{tabular}

Inibidor adrenérgico + diurético

Ação central + diurético

$\begin{array}{lc}\text { Alfametildopa + hidroclorotiazida } & 250+25 \\ & 250+15 \\ \text { Reserpina + clortalidona } & 0,25+50 \\ \begin{array}{l}\text { Reserpina + diidralazina }+ \\ \text { hidroclorotiazida }\end{array} & 0,1+10+10\end{array}$

Betabloqueador + diuréticos

$$
\begin{array}{cc}
25+12,5 \\
\text { Atenolol + clortalidona } & 50+12,5 \\
100+25
\end{array}
$$




\section{continuação Tabela 4}

\begin{tabular}{|cc}
\hline $2,5+6,25$ \\
Bisoprolol + hidroclorotiazida & $5+6,25$ \\
& $10+6,25$ \\
& $50+25$ \\
& $100+25$ \\
\hline Metoprolol + hidroclorotiazida & $100+12,5$ \\
\hline Metoprolol ZOK*** & $100+12,5$ \\
hidroclortiazida & $10+5$ \\
\hline Pindolol + clopamida & $40+25$ \\
\hline Propranolol + hidroclorotiazida & $80+25$ \\
\hline
\end{tabular}

Bloqueadores do receptor $\mathrm{AT}_{1}+$ diurético

\begin{tabular}{cc}
\hline Candesartana + hidroclorotiazida & $8+12,5$ \\
& $16+12,5$ \\
\hline Ibersartana + hidroclorotiazida & $150+12,5$ \\
& $300+12,5$ \\
\hline Losartana + hidroclorotiazida & $50+12,5$ \\
& $100+25$ \\
\hline Olmesartana + hidroclorotiazida & $20+12,5$ \\
& $40+12,5$ \\
& $40+25$ \\
\hline Telmisartana + hidroclortiazida & $40+12,5$ \\
& $80+12,5$ \\
\hline Valsartana + hidroclorotiazida & $80+12,5$ \\
& $160+12,5$ \\
\hline
\end{tabular}

Inibidores da ECA + diuréticos

\begin{tabular}{|cc|}
\hline Benazepril + hidroclorotiazida & $5+6,25$ \\
\hline Captopril + hidroclorotiazida & $50+25$ \\
\hline Cilazapril + hidroclorotiazida & $5+12,5$ \\
\hline Enalapril + hidroclorotiazida & $10+25$ \\
\hline Fosinopril + hidroclorotiazida & $20+12,5$ \\
\hline Lisinopril + hidroclorotiazida & $10+12,5$ \\
\hline Ramipril + hidroclorotiazida & $10+12,5$ \\
\hline Bloqueadores dos canais de cálcio + betabloqueador & $20+12,5$ \\
\hline Nifedipino + atenolol & $5+12,5$ \\
\hline Anlodipino + atenolol & $20+50$ \\
\hline
\end{tabular}

Bloqueadores dos canais de cálcio + inibidores da ECA

\begin{tabular}{cc}
$2,5+10$ \\
Anlodipino + enalapril & $5+10$ \\
& $5+20$ \\
\hline Anlodipino + ramipril & $2,5+5$ \\
$5+5$ \\
Manidipino + delapril & $10+30$ \\
\hline
\end{tabular}

\section{continuação Tabela 4}

Bloqueadores dos canais de cálcio + bloqueadores do receptor $\mathrm{AT}_{1}$

$$
\begin{array}{rr}
2,5+50 \\
\text { Anlodipino + losartana } & 5+100
\end{array}
$$

\section{Diuréticos}

O mecanismo de ação anti-hipertensiva dos diuréticos relaciona-se inicialmente aos seus efeitos diurético e natriurético, com diminuição do volume extracelular. Posteriormente, após cerca de 4 a 6 semanas, o volume circulante praticamente se normaliza e há redução persistente da resistência vascular periférica. São eficazes no tratamento da hipertensão arterial, tendo sido comprovada sua eficácia na redução da morbidade e da mortalidade cardiovasculares ${ }^{140-142}$ (A). Como anti-hipertensivos, são preferidos os diuréticos tiazídicos e similares, em baixas doses. Os diuréticos de alça são reservados para situações de hipertensão associada a insuficiência renal com taxa de filtração glomerular abaixo de $30 \mathrm{ml} / \mathrm{min} / 1,73$ $\mathrm{m}^{2}$ (D) e na insuficiência cardíaca com retenção de volume. Os diuréticos poupadores de potássio apresentam pequena eficácia diurética, mas, quando associados aos tiazídicos e aos diuréticos de alça, são úteis na prevenção e no tratamento de hipopotassemia. Seu uso em pacientes com redução da função renal poderá acarretar hiperpotassemia.

\section{Reações adversas principais}

Hipopotassemia, por vezes acompanhada de hipomagnesemia, que pode induzir arritmias ventriculares, e hiperuricemia. O emprego de baixas doses diminui o risco de efeitos adversos, sem prejuízo da eficácia anti-hipertensiva. Os diuréticos também podem provocar intolerância à glicose, além de promoverem aumento de triglicérides, em geral dependente da dose. É um evento transitório e de importância clínica ainda não comprovada, e o seu uso tem-se mostrado seguro e eficaz em pacientes portadores de diabetes melito ${ }^{163}(\mathrm{~A})$.

\section{Ação central}

Atuam estimulando os receptores alfa-2-adrenérgicos pré-sinápticos no sistema nervoso central, reduzindo o tônus simpático, como fazem a alfametildopa, a clonidina e o guanabenzo, e/ou os receptores imidazolidínicos, como a moxonidina e a rilmenidina.

Seu efeito hipotensor como monoterapia é, em geral, discreto (B). Entretanto, eles podem ser úteis quando utilizados em associação com medicamentos de outros grupos, particularmente no caso de evidência de hiperatividade simpática.

A experiência favorável em relação ao binômio mãe-feto recomenda a alfametildopa como agente de escolha para tratamento da hipertensa grávida (vide capítulo 7, item 7.5), única situação clínica em que esse medicamento pode ser utilizado como monoterapia.

Não interferem na resistência periférica à insulina ou no perfil lipídico. 


\section{Diretriz}

\section{Reações adversas principais}

Decorrentes da ação central, como sonolência, sedação, boca seca, fadiga, hipotensão postural e disfunção sexual. A freqüência é um pouco menor com os inibidores de receptores imidazolidínicos.

A alfametildopa pode provocar, ainda, embora com pequena freqüência, galactorréia, anemia hemolítica e lesão hepática. Ela é contra-indicada na presença de disfunção hepática.

No caso da clonidina, destaca-se a hipertensão rebote, quando da suspensão brusca da medicação, e a ocorrência mais acentuada de boca seca.

\section{Alfabloqueadores}

Apresentam efeito hipotensor discreto em longo prazo como monoterapia, devendo, portanto, ser associados com outros anti-hipertensivos. Podem induzir o aparecimento de tolerância medicamentosa, o que exige o uso de doses gradativamente crescentes. Têm a vantagem de propiciar melhora discreta no metabolismo lipídico e dos sintomas de pacientes com hipertrofia prostática benigna.

\section{Reações adversas principais}

Hipotensão postural, mais evidente com a primeira dose, sobretudo se a dose inicial for alta, palpitações e, eventualmente, astenia. No estudo ALLHAT, a comparação entre o alfabloqueador doxazosina, freqüentemente usado em hipertrofia prostática benigna, com a clortalidona resultou em maior ocorrência de eventos cardiovasculares no grupo doxazosina, especialmente de insuficiência cardíaca congestiva, reforçando a idéia de que alfabloqueadores não são fármacos de primeira escolha para o tratamento da hipertensão ${ }^{167}(\mathrm{~A})$.

\section{Betabloqueadores}

Seu mecanismo anti-hipertensivo envolve diminuição inicial do débito cardíaco, redução da secreção de renina, readaptação dos barorreceptores e diminuição das catecolaminas nas sinapses nervosas.

São eficazes no tratamento da hipertensão arterial. Entretanto, a redução da morbidade e da mortalidade cardiovasculares é bem documentada em grupos de pacientes com idade inferior a $60 \operatorname{anos}^{140,141,143,144}$ (A). Estudos e metanálises recentes não têm apontado redução de desfechos relevantes, principalmente acidente vascular cerebral, em pacientes com idade superior a 60 anos, situação em que o uso dessa classe de medicamentos seria reservado para situações especiais, como coronariopatia, pacientes com disfunção diastólica, arritmias cardíacas ou infarto do miocárdio prévio $^{164-166}$ (A). Mostram-se igualmente úteis em pacientes com tremor essencial, síndromes hipercinéticas, cefaléia de origem vascular e naqueles com hipertensão portal.

\section{Reações adversas principais}

Broncoespasmo, bradicardia excessiva (inferior a 50 bpm), distúrbios da condução atrioventricular, vasoconstrição periférica, insônia, pesadelos, depressão psíquica, astenia e disfunção sexual.
Podem acarretar também intolerância à glicose, hipertrigliceridemia com elevação do LDL-c e redução da fração HDL-c. Esse efeito está relacionado à dose e à seletividade, sendo quase inexistente com o uso de baixas doses de betabloqueadores cardiosseletivos. A importância clínica das alterações lipídicas induzidas por betabloqueadores ainda não está comprovada.

A suspensão brusca dos betabloqueadores pode provocar hiperatividade simpática, com hipertensão rebote e/ou manifestações de isquemia miocárdica, sobretudo em hipertensos com pressão arterial prévia muito elevada. Os betabloqueadores são formalmente contra-indicados a pacientes com asma brônquica, DPOC e bloqueio atrioventricular de 2 o e 3 o graus. Devem ser utilizados com cautela em pacientes com doença vascular de extremidade.

\section{Bloqueadores dos canais de cálcio}

A ação anti-hipertensiva decorre da redução da resistência vascular periférica por diminuição da concentração de cálcio nas células musculares lisas vasculares. Apesar do mecanismo final comum, esse grupo é dividido em três subgrupos, com características químicas e farmacológicas diferentes: fenilalquilaminas, benzotiazepinas e diidropiridinas.

São anti-hipertensivos eficazes e reduzem a morbidade e a mortalidade cardiovasculares ${ }^{145,149,152-154,166}$ (A). Em comparação com outros anti-hipertensivos, levam a menor redução nas taxas de hospitalização por insuficiência cardíaca e infarto do miocárdio ${ }^{168}$. Deve-se dar preferência aos bloqueadores dos canais de cálcio de ação de longa duração intrínseca ou por formulação galênica que permita uma liberação controlada. Não são recomendados agentes de curta duração.

Estudos recentes reafirmaram a eficácia, a tolerabilidade e a segurança do uso dessa classe de medicamentos no tratamento da hipertensão arterial ${ }^{166,169,170}$. No estudo ASCOTT LLA, verificou-se interação favorável entre o bloqueador de canal de cálcio e a vastatina ${ }^{171}$, provavelmente pelo sinergismo desses medicamentos na liberação de óxido nítrico pela célula endotelial ${ }^{172}$.

\section{Reações adversas principais}

Cefaléia, tontura, rubor facial - mais freqüentes com diidropiridínicos de ação curta - e edema de extremidades. Esses efeitos adversos são, em geral, dose-dependentes. Mais raramente, podem induzir hipertrofia gengival. Os diidropiridínicos de ação curta provocam importante estimulação simpática reflexa, sabidamente deletéria para o sistema cardiovascular. Verapamil e diltiazem podem provocar depressão miocárdica e bloqueio atrioventricular. A obstipação intestinal é observada, sobretudo, com verapamil

\section{Inibidores da ECA}

Agem fundamentalmente pela inibição da ECA, bloqueando a transformação da angiotensina I em II no sangue e nos tecidos, embora outros fatores possam estar envolvidos neste mecanismo de ação.

São eficazes no tratamento da hipertensão arterial reduzindo a morbidade e a mortalidade cardiovasculares nos hipertensos ${ }^{145,146,148}(\mathrm{~A})$, pacientes com insuficiência cardíaca ${ }^{173,174}(\mathrm{~A})$, pacientes com infarto agudo do miocárdio, 
em especial quando apresentam baixa fração de ejeção ${ }^{147}$ (A), pacientes de alto risco para doença aterosclerótica ${ }^{147}(\mathrm{~A})$, sendo também úteis na prevenção secundária do acidente vascular cerebral ${ }^{148}$ (A). Quando administrados em longo prazo, os inibidores da ECA retardam o declínio da função renal em pacientes com nefropatia diabética ou de outras etiologias $^{175-178}$ (A).

\section{Reações adversas principais}

Tosse seca, alteração do paladar e, mais raramente, reações de hipersensibilidade com erupção cutânea e edema angioneurótico.

Em indivíduos com insuficiência renal crônica, podem eventualmente agravar a hiperpotassemia. Em pacientes com hipertensão renovascular bilateral ou unilateral associada a rim único, podem promover redução da filtração glomerular com aumento dos níveis séricos de uréia e creatinina.

Seu uso em pacientes com função renal reduzida pode causar aumento de até 30\% dos níveis séricos de creatinina ${ }^{179}$, mas, em longo prazo, prepondera seu efeito nefroprotetor. Em associação a diurético, a ação anti-hipertensiva dos inibidores da ECA é magnificada, podendo ocorrer hipotensão postural. Seu uso é contra-indicado na gravidez pelo risco de complicações fetais. Desta forma, seu emprego deve ser cauteloso e freqüentemente monitorado em adolescentes e mulheres em idade fértil.

\section{Bloqueadores do receptor $\mathrm{AT}_{1}$}

Antagonizam a ação da angiotensina II por meio do bloqueio específico de seus receptores AT . São eficazes no tratamento da hipertensão. Estudos recentes comprovam seu efeito benéfico em insuficiência cardíaca congestiva ${ }^{180,181}$ (B). No tratamento da hipertensão arterial, foram testados, basicamente, em populações de alto risco cardiovascular ou com comorbidades. São nefroprotetores no paciente diabético tipo 2 com nefropatia estabelecida ${ }^{158,159,165}$ (A). Entretanto, contrariamente aos inibidores da ECA, não reduziram a mortalidade total nessa população $^{182}$. Em hipertensos idosos com hipertrofia ventricular esquerda ${ }^{150,151}$ (A), foi demonstrado que a losartana diminui a mortalidade e a morbidade cardiovasculares de forma superior à observada com o atenolol, especialmente acidente vascular cerebral. Em outro ensaio clínico ${ }^{169}$ comparando valsartana com anlodipino em hipertensos de alto risco, o desfecho primário foi semelhante nos dois grupos, havendo excesso de infarto do miocárdio e acidente vascular cerebral no grupo valsartana, com menor incidência de diabetes melito nesse mesmo grupo. Mais recentemente, metanálise envolvendo 21 estudos clínicos randomizados (16 com inibidores da ECA e 5 com bloqueadores do receptor $\mathrm{AT}_{1}$ ) constatou redução de eventos coronarianos apenas com os inibidores da ECA $^{183,184}$. $\mathrm{O}$ tratamento com bloqueadores do receptor $\mathrm{AT}_{1}$, assim como o uso de inibidores da ECA, vem sendo associado a menor incidência de novos casos de diabetes melito do tipo $2^{150,166,185,186}$ (A). Os bloqueadores do receptor $\mathrm{AT}_{1}$ apresentam bom perfil de tolerabilidade.

\section{Reações adversas principais}

Tontura e, raramente, reação de hipersensibilidade cutânea (rash). As precauções para seu uso são semelhantes às descritas para os inibidores da ECA.

\section{Vasodilatadores diretos}

Atuam sobre a musculatura da parede vascular, promovendo relaxamento muscular com conseqüente vasodilatação e redução da resistência vascular periférica. Pela vasodilatação arterial direta, promovem retenção hídrica e taquicardia reflexa, o que contra-indica seu uso como monoterapia. São utilizados em associação a diuréticos e/ou betabloqueadores. Hidralazina e minoxidil são dois dos principais representantes desse grupo.

\subsection{Esquemas Terapêuticos}

\section{Monoterapia}

Os anti-hipertensivos preferenciais para a realização do controle da pressão arterial em monoterapia inicial são: diuréticos ${ }^{140-142}(\mathrm{~A})$; betabloqueadores ${ }^{140,141,143,144}(\mathrm{~A})$; bloqueadores dos canais de cálcio ${ }^{145,149,152-154}(\mathrm{~A})$; inibidores da $\mathrm{ECA}^{144-149}(\mathrm{~A})$; bloqueadores do receptor $\mathrm{AT}_{1}{ }_{150,151}(\mathrm{~A})$.

O tratamento deve ser individualizado e a escolha inicial do medicamento como monoterapia deve basear-se em: a) capacidade do agente a ser escolhido de reduzir a morbidade e a mortalidade cardiovasculares; b) perfil de segurança do medicamento (potencial de reações adversas, interação medicamentosa e comodidade ao paciente); c) mecanismo fisiopatogênico predominante; d) características individuais; e) doenças associadas; f) condições socioeconômicas do paciente.

\section{Posologia}

A dose deve ser ajustada até que se consiga redução da pressão arterial a um nível considerado satisfatório para cada paciente, mas inferior a 140/90 mmHg $138,139,155$ (A). Pressão arterial mais baixa (inferior a 130/80 mmHg) deve ser considerada como meta para pacientes: a) de alto risco cardiovascular $^{79,156,157}(\mathrm{~A})$; b) diabéticos (A); c) com nefropatia, mesmo que em fase incipiente (taxa de filtração glomerular > $90 \mathrm{ml} / \mathrm{min} / 1,73 \mathrm{~m}^{2(156-160)}(\mathrm{A})$; d) em prevenção primária' ${ }^{162}$ (B) e secundária ${ }^{148}$ (A) de acidente vascular cerebral.

Se o objetivo terapêutico não for conseguido com a monoterapia inicial, três condutas são possíveis: a) se o resultado for parcial ou nulo, mas sem reação adversa, recomenda-se aumentar a dose do medicamento em uso ou associar anti-hipertensivo de outro grupo terapêutico; b) quando não se obtiver efeito terapêutico na dose máxima preconizada, ou se surgirem eventos adversos, recomenda-se a substituição do anti-hipertensivo utilizado como monoterapia; c) se ainda assim a resposta for inadequada, devem-se associar dois ou mais medicamentos (Figura 1).

\section{Terapêutica anti-hipertensiva combinada}

Com base em evidências de estudos recentes mostrando que, em cerca de $2 / 3$ dos casos, a monoterapia não foi suficiente para atingir as reduções de pressão previstas, e diante da necessidade de controle mais rigoroso da pressão arterial, há clara tendência atual para a introdução mais 


\section{Diretriz}

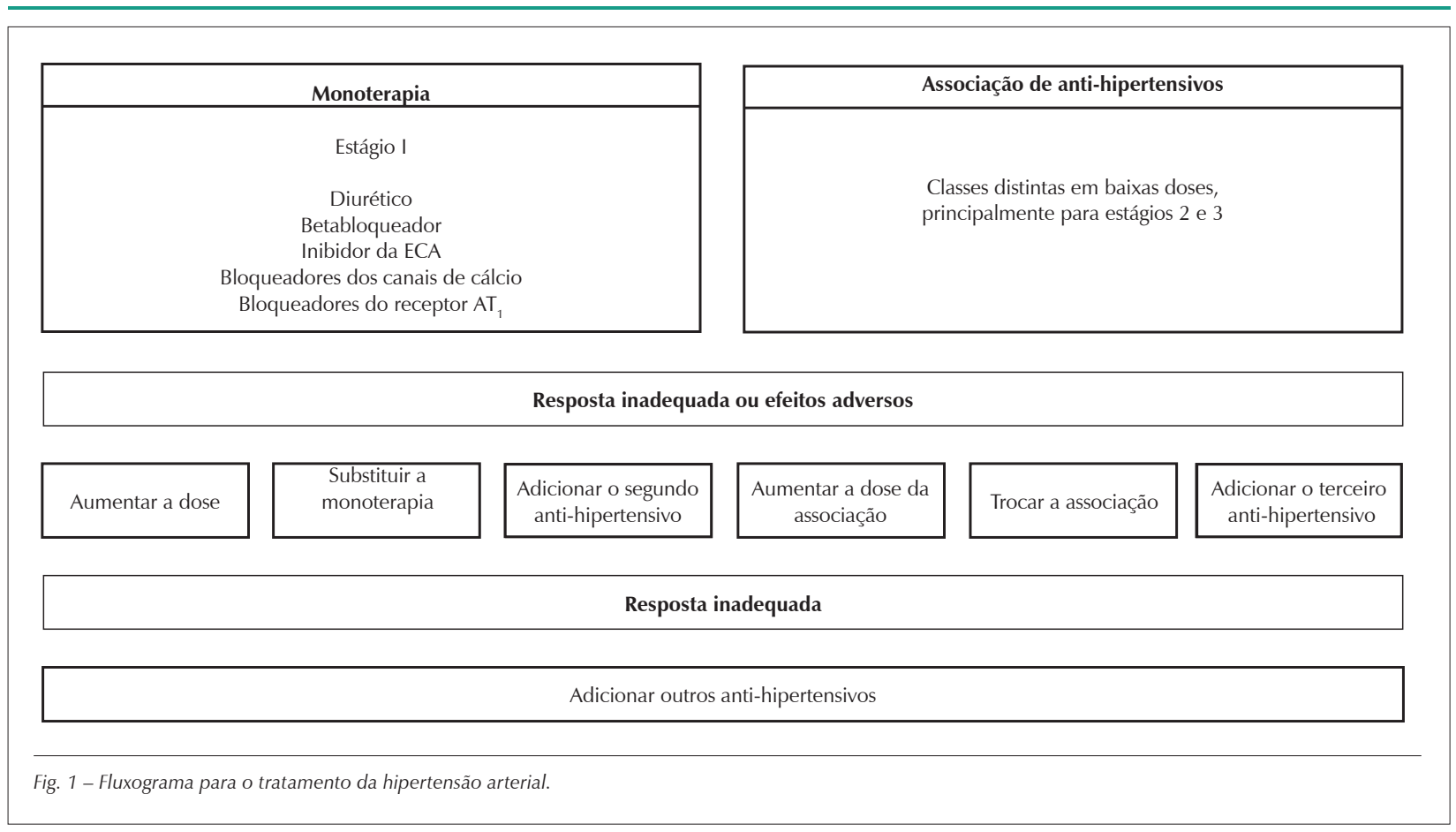

precoce de terapêutica combinada de anti-hipertensivos como primeira medida medicamentosa, principalmente para pacientes com hipertensão em estágios 2 e $3^{79,157}$ (D).

$\mathrm{O}$ esquema anti-hipertensivo instituído deve manter a qualidade de vida do paciente, de modo a estimular a adesão às recomendações prescritas. Após longo período de controle da pressão, pode ser tentada, criteriosamente, a redução progressiva das doses dos medicamentos em uso.

Existem evidências de que, para hipertensos com pressão arterial controlada, a associação de ácido acetilsalicílico em baixas doses diminui a ocorrência de complicações cardiovasculares, desde que não haja contra-indicação ${ }^{157}(\mathrm{~A})$.

Devemos estimular o SUS, dada a necessidade de tratamento crônico da hipertensão arterial, a garantir o fornecimento contínuo de medicamentos de pelo menos quatro dos grupos de anti-hipertensivos recomendados ${ }^{79}(\mathrm{~A})$. As associações de anti-hipertensivos (Tabela 4) devem seguir a lógica de não combinar medicamentos com mecanismos de ação similares, com exceção da combinação de diuréticos tiazídicos e de alça com poupadores de potássio. Tais associações de antihipertensivos podem ser feitas por meio de medicamentos em separado ou por associações em doses fixas.

Associações reconhecidas como eficazes: diuréticos e diuréticos de diferentes mecanismos de ação; medicamentos de ação central e diuréticos; betabloqueadores e diuréticos; bloqueadores do receptor $\mathrm{AT}_{1}$ e diuréticos; inibidores da ECA e diuréticos; bloqueadores dos canais de cálcio e betabloqueadores; bloqueadores dos canais de cálcio e inibidores da ECA; bloqueadores dos canais de cálcio e bloqueadores do receptor $\mathrm{A} \mathrm{T}_{1}{ }^{79}(\mathrm{~A})$.

As associações assinaladas também estão disponíveis no mercado (Tabela 4) em doses fixas. Seu emprego, desde que seja criterioso, pode ser útil por simplificar o esquema posológico, reduzindo o número de comprimidos administrados e, assim, estimulando a adesão ao tratamento.

Na hipertensão resistente à dupla terapia, podem ser prescritos três ou mais medicamentos. Nessa situação, o uso de diuréticos é fundamental. Em casos ainda mais resistentes, a adição de minoxidil ao esquema terapêutico tem-se mostrado útil.

\subsection{Interações Medicamentosas}

É importante conhecer as principais interações de antihipertensivos e medicamentos de uso contínuo que podem ser prescritos para o paciente hipertenso (Tabela 5). Para os antihipertensivos lançados mais recentemente, essa possibilidade tem sido avaliada de forma sistemática, o que nem sempre ocorre com os medicamentos mais antigos.

\subsection{Complicações Hipertensivas Agudas}

Pressão arterial muito elevada, acompanhada de sintomas, caracteriza uma complicação hipertensiva aguda e requer avaliação clínica adequada, incluindo exame físico detalhado e exame de fundo de olho.

\section{Urgências hipertensivas}

Há elevação importante da pressão arterial, em geral pressão arterial diastólica $>120 \mathrm{mmHg}$, com condição clínica estável, sem comprometimento de órgãos-alvo. A pressão arterial deverá ser reduzida em pelo menos 24 horas, em geral com medicamentos por via oral (D) (Tabela 6).

Embora a administração sublingual de nifedipina de ação rápida tenha sido amplamente utilizada para esse fim, foram descritos efeitos adversos graves com esse uso. A dificuldade de controlar o ritmo e o grau de redução da pressão arterial, 


\begin{tabular}{|c|c|c|}
\hline Anti-hipertensivo & Medicamentos & Efeitos \\
\hline \multicolumn{3}{|l|}{ Diuréticos } \\
\hline \multirow[t]{4}{*}{ Tiazídicos e de alça } & Digitálicos & Intoxicação digitálica por hipopotassemia \\
\hline & Antiinflamatórios esteróides e não-esteróides & Antagonizam o efeito diurético \\
\hline & Hipoglicemiantes orais & Efeito diminuído pelos tiazídicos \\
\hline & Lítio & Aumento dos níveis séricos do lítio \\
\hline Poupadores de potássio & Suplementos de potássio e inibidores da ECA & Hiperpotassemia \\
\hline \multicolumn{3}{|l|}{ Inibidores adrenérgicos } \\
\hline Ação central & Antidepressivos tricíclicos & Redução do efeito anti-hipertensivo \\
\hline \multirow[t]{9}{*}{ Betabloqueadores } & Insulina e hipoglicemiantes orais & $\begin{array}{l}\text { Redução dos sinais de hipoglicemia e } \\
\text { bloqueio da mobilização de glicose }\end{array}$ \\
\hline & Amiodarona quinidina & Bradicardia \\
\hline & Cimetidina & $\begin{array}{c}\text { Reduz a depuração hepática de propranolol } \\
\text { e metoprolol }\end{array}$ \\
\hline & Cocaína & Potencializam o efeito da cocaína \\
\hline & Vasoconstritores nasais & $\begin{array}{l}\text { Facilitam o aumento da pressão } \\
\text { pelos vasoconstritores nasais }\end{array}$ \\
\hline & Diltiazem, verapamil & $\begin{array}{c}\text { Bradicardia, depressão sinusal e } \\
\text { atrioventricular }\end{array}$ \\
\hline & Dipiridamol & Bradicardia \\
\hline & Antiinflamatórios esteróides e não-esteróides & Antagonizam o efeito hipotensor \\
\hline & $\begin{array}{l}\text { Diltiazem, verapamil, betabloqueadores e } \\
\text { medicamentos de ação central }\end{array}$ & Hipotensão \\
\hline \multicolumn{3}{|l|}{ Inibidores da ECA } \\
\hline & $\begin{array}{l}\text { Suplementos e diuréticos poupadores de } \\
\text { potássio }\end{array}$ & Hiperpotassemia \\
\hline & Ciclosporina & Aumento dos níveis de ciclosporina \\
\hline & Antiinflamatórios esteróides e não-esteróides & Antagonizam o efeito hipotensor \\
\hline & Lítio & Diminuição da depuração do lítio \\
\hline & Antiácidos & Reduzem a biodisponibilidade do captopril \\
\hline \multicolumn{3}{|c|}{ Bloqueadores dos canais de cálcio } \\
\hline & Digoxina & $\begin{array}{l}\text { Verapamil e diltiazem aumentam os níveis de } \\
\text { digoxina }\end{array}$ \\
\hline & Bloqueadores de $\mathrm{H} 2$ & $\begin{array}{l}\text { Aumentam os níveis dos bloqueadores dos } \\
\text { canais de cálcio }\end{array}$ \\
\hline & Ciclosporina & $\begin{array}{l}\text { Aumento do nível de ciclosporina, a exceção } \\
\text { de } \\
\text { anlodipino e felodipino }\end{array}$ \\
\hline & Teofilina, prazosina & Níveis aumentados com verapamil \\
\hline & Moxonidina & Hipotensão \\
\hline \multicolumn{3}{|c|}{ Bloqueadores do receptor AT1 } \\
\hline & Moxonidina & Hipotensão com losartana \\
\hline
\end{tabular}

quando intensa, pode ocasionar acidentes vasculares; o risco de importante estimulação simpática secundária e a existência de alternativas eficazes e mais bem toleradas tornam o uso da nifedipina de curta duração (cápsulas) não recomendável nessa situação. O uso desse medicamento, sobretudo de forma abusiva, foi recentemente analisado em parecer técnico do Conselho Regional de Medicina do Estado de São Paulo (http://www.sbn.org.br).

\section{Emergências hipertensivas}




\section{Diretriz}

Tabela 6 - Medicamentos indicados para uso oral nas urgências hipertensivas

\begin{tabular}{|c|c|c|c|c|}
\hline \multirow{2}{*}{ Medicamentos } & \multirow{2}{*}{ Dose } & \multicolumn{2}{|c|}{ Ação } & \multirow{2}{*}{ Efeitos adversos e precauções } \\
\hline & & Início & Duração & \\
\hline Nifedipino & $10-20$ mg VO & $5-15 \min$ & $3-5 h$ & $\begin{array}{l}\text { Redução abrupta da pressão, hipotensão } \\
\text { Cuidados especiais em idosos }\end{array}$ \\
\hline Captopril & $\begin{array}{l}\text { 6,25-25 mg VO } \\
\text { (repetir em } 1 \text { h se } \\
\text { necessário) }\end{array}$ & $15-30 \mathrm{~min}$ & $6-8 \mathrm{~h}$ & $\begin{array}{l}\text { Hipotensão, hiperpotassemia, insuficiência renal, } \\
\text { estenose bilateral de artéria renal ou rim único } \\
\text { com estenose de artéria renal }\end{array}$ \\
\hline Clonidina & $0,1-0,2 \mathrm{mg} \vee \mathrm{h} / \mathrm{h}$ & $30-60 \mathrm{~min}$ & $6-85 \mathrm{~h}$ & $\begin{array}{l}\text { Hipotensão postural, } \\
\text { sonolência, boca seca }\end{array}$ \\
\hline
\end{tabular}

Condição em que há elevação crítica da pressão arterial com quadro clínico grave, progressiva lesão de órgãos-alvo e risco de morte, exigindo imediata redução da pressão arterial com agentes por via parenteral (D) (Tabela 7).

Resultam de elevação abrupta da pressão arterial, com perda da auto-regulação do fluxo cerebral e evidências de lesão vascular, com quadro clínico de encefalopatia hipertensiva, lesões hemorrágicas dos vasos da retina e papiledema. Habitualmente, apresentam-se com pressão arterial muito elevada em pacientes com hipertensão crônica ou menos elevada em pacientes com doença aguda, como em eclâmpsia, glomerulonefrite aguda, e em uso de drogas ilícitas, como cocaína. Emergências hipertensivas podem também cursar com pressão arterial muito elevada, acompanhada de sinais que indicam lesões em órgãos-alvo em progressão, tais como acidente vascular cerebral (vide capítulo 7, item 7.9), edema pulmonar agudo, síndromes isquêmicas miocárdicas agudas (infarto agudo do miocárdio, crises repetidas de angina) e dissecção aguda da aorta. Nesses casos, há risco iminente à vida ou de lesão orgânica grave.

Depois de obtida a redução imediata da pressão arterial, deve-se iniciar a terapia anti-hipertensiva de manutenção e interromper a medicação parenteral. A hidralazina é contraindicada nos casos de síndromes isquêmicas miocárdicas agudas e de dissecção aguda de aorta por induzir ativação simpática, com taquicardia e aumento da pressão de pulso. Em tais situações, indica-se o uso de betabloqueadores e de nitroglicerina $(\mathrm{C})$.

Na fase aguda de acidente vascular cerebral, a redução da pressão arterial deve ser gradativa e cuidadosa, evitando-se reduções bruscas e excessivas. Embora saiba-se que a redução da pressão arterial, nessas condições, deva ser feita de forma gradual e não abrupta, não há consenso para se estabelecer a pressão arterial ideal.

É comum, ainda, a ocorrência de situações de estresse psicológico agudo e de síndrome do pânico associadas à pressão arterial elevada, não caracterizando complicações hipertensivas agudas. Recomenda-se terapêutica do estresse psicológico e tratamento ambulatorial da hipertensão arterial.

\subsection{Adesão ao Tratamento}

A adesão ao tratamento pode ser definida como o grau

\begin{tabular}{|c|c|c|c|c|c|}
\hline \multirow{2}{*}{ Medicamentos } & \multirow{2}{*}{ Dose } & \multicolumn{2}{|c|}{ Ação } & \multirow{2}{*}{ Efeitos adversos e precauções } & \multirow{2}{*}{ Indicações } \\
\hline & & Início & Duração & & \\
\hline $\begin{array}{l}\text { Nitroprussiato } \\
\text { de sódio }\end{array}$ & $\begin{array}{c}0,25-10 \mathrm{mg} / \mathrm{kg} / \mathrm{min} \\
\mathrm{EV}\end{array}$ & Imediato & $1-2 \min$ & $\begin{array}{c}\text { Náuseas, vômitos, intoxicação por cianeto. } \\
\text { Cuidado na insuficiência renal e hepática e } \\
\text { na pressão intracraniana alta. } \\
\text { Hipotensão grave }\end{array}$ & $\begin{array}{l}\text { Maioria das } \\
\text { emergências } \\
\text { hipertensivas }\end{array}$ \\
\hline Nitroglicerina & $5-100 \mathrm{mg} / \mathrm{min} \mathrm{EV}$ & $2-5 \min$ & $3-5 \min$ & $\begin{array}{l}\text { Cefaléia, taquicardia, taquifilaxia, flushing, } \\
\text { meta-hemoglobinemia }\end{array}$ & $\begin{array}{l}\text { Insuficiência } \\
\text { coronariana }\end{array}$ \\
\hline Hidralazina & $\begin{array}{l}10-20 \text { mg EV ou } 10- \\
40 \mathrm{mg} \mathrm{IM} 6 / 6 \mathrm{~h}\end{array}$ & $\begin{array}{l}10-30 \\
\min \end{array}$ & $3-12 \mathrm{~h}$ & $\begin{array}{c}\text { Taquicardia, cefaléia, vômitos. Piora da } \\
\text { angina e do infarto. Cuidado com pressão } \\
\text { intracraniana elevada }\end{array}$ & Eclâmpsia \\
\hline Metoprolol & $\begin{array}{l}5 \text { mg EV (repetir } \\
\text { 10/10 min, se } \\
\text { necessário) até } 20 \\
\text { mg }\end{array}$ & $\begin{array}{l}5-10 \\
\min \end{array}$ & $3-4 \mathrm{~h}$ & $\begin{array}{c}\text { Bradicardia, bloqueio atrioventricular } \\
\text { avançado, insuficiência cardíaca, } \\
\text { broncoespasmo }\end{array}$ & $\begin{array}{c}\text { Insuficiência } \\
\text { coronariana } \\
\text { Aneurisma } \\
\text { dissecante de aorta }\end{array}$ \\
\hline Furosemida & $\begin{array}{l}20-60 \mathrm{mg} \text { (repetir } \\
\text { após } 30 \mathrm{~min} \text { ) }\end{array}$ & $2-5 \min$ & $\begin{array}{l}30-60 \\
\min \end{array}$ & Hipopotassemia & $\begin{array}{l}\text { Insuficiência } \\
\text { ventricular esquerda. } \\
\text { Situações de } \\
\text { hipervolemia }\end{array}$ \\
\hline
\end{tabular}


de coincidência entre a prescrição e o comportamento do paciente. Vários são os determinantes da não-adesão ao tratamento ${ }^{187-189}$ (Tabela 8). Os percentuais de controle de pressão arterial são muito baixos, apesar das evidências de que o tratamento anti-hipertensivo é eficaz em diminuir a morbidade e a mortalidade cardiovasculares, em razão da baixa adesão ao tratamento. Estudos isolados apontam controle de 20\% a $40 \%, 190,191$. A taxa de abandono, grau mais elevado de falta

Tabela 8 - Principais determinantes da não-adesão ao tratamento anti-hipertensivo

1. Falta de conhecimento do paciente sobre a doença ou de motivação para tratar uma doença assintomática e crônica.

2. Baixo nível socioeconômico, aspectos culturais e crenças erradas adquiridas em experiências com a doença no contexto familiar e baixa auto-estima.

3. Relacionamento inadequado com a equipe de saúde.

4. Tempo de atendimento prolongado, dificuldade na marcação de consultas, falta de contato com os faltosos e com aqueles que deixam o serviço.

5. Custo elevado dos medicamentos e ocorrência de efeitos indesejáveis.

6. Interferência na qualidade de vida após o início do tratamento. de adesão, é crescente conforme o tempo decorrido após o início da terapêutica. A tabela 9 indica sugestões para melhorar a adesão às prescrições para os hipertensos.

A relação médico-paciente deve ser a base de sustentação para o sucesso do tratamento anti-hipertensivo. A participação de vários profissionais da área da saúde, com uma abordagem multidisciplinar ao hipertenso pode facilitar a adesão ao tratamento e, conseqüentemente, aumentar o controle ${ }^{192}$.

Tabela 9 - Principais sugestões para melhor adesão ao tratamento anti-hipertensivo

1. Educação em saúde, com especial enfoque nos conceitos de hipertensão e suas características.

2. Orientações sobre os benefícios dos tratamentos, incluindo mudanças de estilo de vida.

3. Informações detalhadas e compreensíveis pelos pacientes sobre os eventuais efeitos adversos dos medicamentos prescritos e necessidades de ajustes posológicos com o passar do tempo.

4. Cuidados e atenções particularizadas de conformidade com as necessidades.

5. Atendimento médico facilitado, sobretudo no que se refere ao agendamento de consultas. 


\section{Diretriz}

\section{Situações Especiais}

\subsection{Afrodescendente e Miscigenados}

Os afrodescendentes apresentam maior prevalência e gravidade da hipertensão relacionadas a fatores étnicos e/ou socioeconômicos ${ }^{193}$ (B). Os miscigenados, predominantes em nosso país, podem diferir dos afrodescendentes quanto às características da hipertensão. Como não há evidências de ação diferenciada dos medicamentos anti-hipertensivos em nossa população, a escolha do anti-hipertensivo deve ser norteada pela presença de comorbidades e eficácia em atingir as metas ${ }^{194}(\mathrm{~A})$.

\subsection{Idosos}

Estima-se que pelo menos 60\% dos idosos brasileiros, indivíduos com 60 anos ou mais, são hipertensos. A maioria apresenta elevação isolada ou predominante da pressão sistólica, aumentando a pressão de pulso, que mostra forte relação com eventos cardiovasculares (B). A prevalência de outros fatores de risco, como a síndrome metabólica, também aumenta com a idade, elevando ainda mais o risco cardiovascular (B).

Os aspectos relacionados à medida de pressão arterial e os critérios diagnósticos estão no capítulo 2, tabelas 1 e 7 .

O objetivo do tratamento é a redução gradual da pressão arterial para valores abaixo de $140 / 90 \mathrm{mmHg}$. Em pacientes com valores muito elevados de pressão sistólica, podem ser mantidos inicialmente níveis de até $160 \mathrm{mmHg}$ (A). Não está bem estabelecido o nível mínimo tolerável da pressão diastólica, mas estudos sugerem que redução abaixo de 65 $\mathrm{mmHg}$ identifica o grupo de pior prognóstico ${ }^{195}$ (B).

$\mathrm{O}$ tratamento não-medicamentoso é recomendado para os idosos ${ }^{121}(\mathrm{~A})$. Quando o tratamento medicamentoso for necessário, a dose inicial deve ser mais baixa, e o incremento de doses ou a associação de novos medicamentos deve ser feito com mais cuidado, especialmente em idosos frágeis (D). Grande parte dos idosos tem outros fatores de risco, lesão de órgão-alvo ou doença cardiovascular associada, fatores que devem nortear a escolha do anti-hipertensivo inicial. A maioria, porém, necessita de terapia combinada, principalmente para o controle adequado da pressão sistólica (B).

Estudos controlados demonstraram melhora da morbidade e da mortalidade com diferentes agentes: diuréticos tiazídicos, betabloqueadores em combinação, bloqueadores de canais de cálcio de ação longa, inibidores da ECA e bloqueadores do receptor $\mathrm{AT}_{1}{ }_{1}^{142,152,196-198}$ (A). Evidências sugerem que o tratamento da hipertensão no idoso reduz a incidência de déficit cognitivo e demência ${ }^{199}$ (B).

O tratamento de hipertensos com mais de 80 anos sem comorbidades cardiovasculares deve ser individualizado, considerando estado clínico e motivação do paciente. As evidências disponíveis, oriundas da análise de subgrupos, sugerem redução de eventos sem impacto sobre a mortalidade $^{200}$ (B). Outro grupo que deve ter seu tratamento cuidadosamente individualizado é o dos idosos portadores de múltiplas comorbidades não cardiovasculares, situação não representada nos grandes ensaios clínicos.

\subsection{Crianças e Adolescentes}

A medida da pressão arterial deve ser avaliada em toda consulta médica a partir de 3 anos de idade e, nas crianças abaixo dessa idade, quando houver antecedentes ou condições clínicas de risco, tais como prematuridade e nefropatia ${ }^{51}$.

Os aspectos relacionados à medida da pressão arterial e os critérios diagnósticos estão no capítulo 2, tabelas 1, 2, 8 a 11. Quanto mais altos forem os valores da pressão arterial e mais jovem o paciente, maior é a possibilidade da hipertensão arterial ser secundária, com maior prevalência das causas renais ${ }^{201}$. A ingestão de álcool, o tabagismo, o uso de drogas ilícitas e a utilização de hormônios esteróides, hormônio do crescimento, anabolizantes e anticoncepcionais orais devem ser considerados possíveis causas de hipertensão ${ }^{51}$.

O objetivo do tratamento é atingir valores de pressão arterial sistólica e diastólica abaixo do percentil 95 para sexo, altura e faixa etária na hipertensão arterial não complicada, e abaixo do percentil 90 na hipertensão complicada por comorbidades. O tratamento não-medicamentoso deve ser recomendado a partir do percentil 90 de pressão arterial sistólica ou diastólica (hipertensão limítrofe).

O emprego de anti-hipertensivos deve ser considerado nos que não respondem ao tratamento não-medicamentoso, naqueles com evidência de lesão em órgãos-alvo ou fatores de risco conhecidos, como diabetes, tabagismo e dislipidemia, e na hipertensão sintomática ou hipertensão secundária. Não há estudos em longo prazo sobre o uso de anti-hipertensivos na infância ou na adolescência. A escolha dos medicamentos obedece aos critérios utilizados para adultos. A utilização de inibidores da ECA ou de bloqueadores do receptor $\mathrm{AT}_{1}$ deve ser evitada em adolescentes do sexo feminino, exceto quando houver indicação absoluta, em razão da possibilidade de gravidez.

\subsection{Anticoncepcionais Orais e Terapia de Reposição Estrogênica}

A hipertensão é duas a três vezes mais comum em usuárias de anticoncepcionais orais, especialmente entre as que possuem mais de 35 anos e obesas. Em mulheres hipertensas com mais de 35 anos e fumantes, o anticoncepcional oral está contra-indicado ${ }^{202}$ (B). Deve também ser evitado em portadoras de síndrome metabólica pelo aumento potencial do risco cardiovascular203. O aparecimento de hipertensão arterial durante o uso de anticoncepcional oral impõe a interrupção imediata da medicação, o que, em geral, normaliza a pressão arterial em alguns meses. Outro método contraceptivo deverá ser rapidamente instituído para evitar gravidez indesejada.

A reposição estrogênica após a menopausa não está contra-indicada para mulheres hipertensas, pois tem pouca interferência sobre a pressão arterial ${ }^{204}$ (A). A via transdérmica parece ser a melhor opção ${ }^{205}$ (B). Em mulheres de alto risco cardiovascular, a reposição hormonal é contra-indicada ${ }^{206}$ (A). Como um pequeno número de mulheres apresenta elevação da pressão arterial, há necessidade de avaliação periódica da pressão após o início da reposição. Por causa do aumento de risco de eventos coronarianos, cerebrovasculares e tromboembolismo venoso, a terapia de reposição hormonal não deve ser utilizada com o intuito de promover proteção $\operatorname{cardiovascular}^{205}(\mathrm{~A})$. 


\subsection{Gravidez}

Considera-se hipertensão na gravidez quando o nível da pressão arterial for maior ou igual a 140/90 $\mathrm{mmHg}$, sendo a pressão diastólica identificada na fase $\mathrm{V}$ de Korotkoff. Duas formas de hipertensão podem complicar a gravidez: hipertensão preexistente (crônica) e hipertensão induzida pela gravidez (pré-eclâmpsia/eclâmpsia), podendo ocorrer isoladamente ou de forma associada.

\section{Hipertensão arterial crônica}

Corresponde a hipertensão de qualquer etiologia, presente antes da gravidez ou diagnosticada até a vigésima semana da gestação. As mulheres com pressão arterial superior a 159/99 $\mathrm{mmHg}$ devem receber tratamento medicamentoso. Gestantes com pressão arterial inferior a 159/99 $\mathrm{mmHg}$ e/ou portadoras de diabetes melito, obesidade, gravidez gemelar, nulíparas, idade superior a 40 anos e antecedentes pessoais ou familiares de pré-eclâmpsia merecem avaliação periódica em razão da possibilidade de rápida elevação da pressão ou surgimento de proteinúria e podem receber tratamento medicamentoso com valores mais baixos, entre 120/80 e 159/99 mmHg, visando à proteção materno-fetal.

Pacientes sob anti-hipertensivos podem ter a medicação reduzida ou suspensa em virtude da hipotensão. A alfametildopa é a droga preferida por ser a mais bem estudada e não haver evidência de efeitos deletérios para o feto ${ }^{207}$ (B). Opções aditivas ou alternativas incluem betabloqueadores, que podem estar associados a crescimento fetal restrito, outros bloqueadores adrenérgicos, bloqueadores de canais de cálcio e diuréticos.

Os inibidores da ECA e os bloqueadores do receptor AT são contra-indicados durante a gravidez ${ }^{208}(\mathrm{~A})$.

\section{Pré-eclâmpsia/eclâmpsia}

A pré-eclâmpsia/eclâmpsia ocorre geralmente após 20 semanas de gestação. Caracteriza-se pelo desenvolvimento gradual de hipertensão e proteinúria. A interrupção da gestação é o tratamento definitivo na pré-eclâmpsia e deve ser considerado em todos os casos com maturidade pulmonar fetal assegurada. Se não houver maturidade pulmonar fetal pode-se tentar prolongar a gravidez, mas a interrupção deve ser indicada se houver deterioração materna ou fetal. A hipertensão arterial grave é freqüentemente tratada com hidralazina endovenosa (vide capítulo 6, tabela 7). O nifedipino tem sido também utilizado, entretanto, sua associação com o sulfato de magnésio, droga de escolha no tratamento e, possivelmente, na prevenção da convulsão eclâmptica, pode provocar queda súbita e intensa da pressão arterial. Em raras circunstâncias, o nitroprussiato de sódio pode ser utilizado se a hidralazina e o nifedipino não forem efetivos. O ácido acetilsalicílico em baixas doses tem pequeno efeito na prevenção da pré-eclâmpsia, enquanto a suplementação oral de cálcio em pacientes de alto risco e com baixa ingestão de cálcio parece reduzir a incidência de pré-eclâmpsia.

\subsection{Síndrome Metabólica e Obesidade}

É a condição representada por um conjunto de fatores de risco cardiovascular usualmente relacionados à obesidade central e à resistência à insulina, aumentando a mortalidade

geral em 1,5 vez e a cardiovascular em 2,5 vezes ${ }^{209}$. É necessária a presença de pelo menos três componentes para firmar o diagnóstico (Tabela 1).

Tabela 1 - Componentes da síndrome metabólica (I Diretriz Brasileira de Diagnóstico e Tratamento da Síndrome Metabólica ${ }^{210}$ )

Componentes

Obesidade central

Triglicérides

HDL-C

Pressão arterial

Glicemia de jejum

A presença de diabetes melito não exclui o diagnóstico de síndrome metabólica.

Redução do peso corporal superior a 5\% do valor inicial e incremento da atividade física atuam favoravelmente sobre todos os elementos dessa síndrome.

No tratamento medicamentoso da obesidade, o orlistat melhora o perfil metabólico e não interfere na pressão arterial. A sibutramina, embora possa elevar a pressão arterial e a freqüência cardíaca, tem-se mostrado um agente seguro para o tratamento da obesidade em hipertensos tratados (B). Derivados anfetamínicos estão contra-indicados em hipertensos.

O tratamento da hipertensão arterial em indivíduos obesos deve priorizar o uso dos inibidores da ECA (por aumentarem a sensibilidade à insulina), dos bloqueadores dos receptores

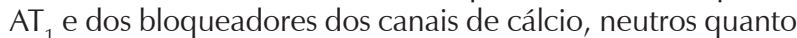
aos efeitos metabólicos (B). Diuréticos tiazídicos podem ser utilizados em doses baixas isoladamente ou em combinação com bloqueadores do SRAA.

\subsection{Diabetes melito}

A freqüente associação entre hipertensão arterial e diabetes tem como conseqüência grande aumento no risco cardiovascular. Em pacientes com diabetes tipo 1, existe evidente relação entre hipertensão e desenvolvimento da nefropatia diabética, enquanto no diabetes tipo 2, a hipertensão arterial faz parte da síndrome metabólica. O tratamento da hipertensão arterial é importante nos pacientes diabéticos, tanto para a prevenção da doença cardiovascular quanto para minimizar a progressão da doença renal e da retinopatia diabética ${ }^{156}(\mathrm{~A})$.

Recomenda-se que a pressão arterial seja reduzida a valores inferiores a 130/80 mmHg 157 (A) e a 125/75 mmHg, se houver proteinúria $>1 \mathrm{~g} / 24 \mathrm{~h}^{210}(\mathrm{~A})$, por serem pacientes de alto risco para eventos cardiovasculares.

Todos os agentes anti-hipertensivos podem ser utilizados em pacientes diabéticos; na maioria das vezes, dois ou três deles precisam ser associados para que se atinjam os objetivos. O uso de associações de medicamentos já no início do tratamento pode ser útil para reduzir de forma mais eficiente os níveis de pressão arterial em menor período de tempo. 


\section{Diretriz}

Os diuréticos devem ser utilizados em baixas doses. Os betabloqueadores em hipertensos aumentam o risco de desenvolvimento de diabetes ${ }^{211}$ (A). Esses agentes devem ser utilizados quando houver indicação específica, como na doença arterial coronariana. Existem vantagens na inclusão de inibidores da ECA ou de bloqueadores dos receptores $\mathrm{AT}_{1}$ no esquema terapêutico, tanto para prevenir o aparecimento da microalbuminúria ${ }^{212}$ (A) como para impedir a progressão da doença renal e cardiovascular $151,158,175,213$ (A).

Na vigência de microalbuminúria ou proteinúria, o bloqueio do SRAA é comprovadamente a medida mais eficiente para deter a progressão da doença renal ${ }^{158,175,214,215}$ (A). A redução da excreção de proteínas é crucial para a proteção renal e requer o controle rígido da pressão arterial e a utilização de doses máximas dos bloqueadores do SRAA, algumas vezes em combinação, para obtenção do máximo efeito antiproteinúrico, mesmo em pacientes normotensos ou com pressão arterial controlada $^{214,215}(\mathrm{~A})$.

\subsection{Dislipidemias}

Níveis elevados de colesterol, juntamente com hipertensão arterial, representam mais que $50 \%$ do risco atribuível para doença coronária. Indivíduos hipertensos beneficiam-se de forma incontestável da diminuição do colesterol, e as intervenções terapêuticas para reduzir conjuntamente a hipertensão arterial e o colesterol são capazes de diminuir a morbidade e a mortalidade em diversas condições de $\operatorname{risco}^{216}(\mathrm{~A})$.

Inibidores da ECA, bloqueadores dos receptores $\mathrm{AT}_{1}$, bloqueadores dos canais de cálcio e diuréticos em doses baixas não interferem na lipemia. Os betabloqueadores podem aumentar temporariamente os níveis de triglicérides e reduzir o HDL-c.

O tratamento das dislipidemias tem como prioridade a diminuição do LDL-c, e as metas de HDL-c e triglicérides são secundárias, com exceção dos indivíduos com hipertrigliceridemia grave, em que ocorre risco de pancreatite aguda $^{217}$. O uso de hipolipemiantes, especialmente de vastatinas, demonstrou grande benefício sobre a morbidade e a mortalidade cardiovasculares, independentemente da presença de hipertensão arterial, síndrome metabólica, diabetes ou doença aterosclerótica (A). Associações com outros hipolipemiantes, como ezetimiba ou ácido nicotínico, podem ser necessárias para obtenção das metas, com menores doses de vastatinas em caso de efeitos colaterais.

O benefício da redução do LDL-c será tanto maior quanto maior for o risco absoluto de eventos coronários. A estratificação do risco deverá ser feita com base na presença ou não de doença aterosclerótica, de diabetes e no risco absoluto de eventos coronários em dez anos calculado pelos escores de risco de Framingham ${ }^{218}$.

O diagnóstico, as metas lipídicas e o tratamento da dislipidemia em pacientes hipertensos assemelham-se em tudo aos dos não-hipertensos. As metas propostas segundo as I Diretrizes Brasileiras de Síndrome Metabólica estão na tabela 2. Na impossibilidade de atingir as metas, recomendase redução de pelo menos $30 \%$ a $40 \%$ do LDL-c dos níveis basais $^{218}$. Os fibratos e o ácido nicotínico têm importante papel na dislipidemia da síndrome metabólica, melhorando o perfil aterogênico.

Nos pacientes com concentrações de triglicérides $\geq 200$ $\mathrm{mg} / \mathrm{dl}$, é importante calcular o colesterol não-HDL (colesterol total - HDL-c). Este parâmetro reflete o colesterol carregado pelas lipoproteínas aterogênicas, englobando o LDL-c, o VLDL-c e os seus remanescentes. Os valores a serem atingidos são $30 \mathrm{mg} / \mathrm{dl}$ acima da meta do LDL-c para cada nível de risco. Exemplo: paciente de alto risco, meta de LDL-c $<100 \mathrm{mg} / \mathrm{dl}$ corresponde a uma meta de colesterol não-HDL < $130 \mathrm{mg} / \mathrm{dl}$. Devemos enfatizar que nos portadores de diabetes melito, deve ser obtido o controle glicêmico antes de agir sobre os valores de triglicérides e HDL-c.

\subsection{Acidente Vascular Cerebral}

\section{Prevenção primária e secundária}

A relação entre hipertensão arterial e acidente vascular cerebral é ainda maior do que aquela observada no infarto do miocárdio $^{1}$ (A). O tratamento da hipertensão arterial, inclusive da hipertensão sistólica isolada, é eficaz para a redução do risco de acidente vascular cerebral ${ }^{219}$ (A). A utilização de diuréticos, betabloqueadores, bloqueadores dos canais de

Tabela 2 - Metas lipídicas propostas para a prevenção da doença aterosclerótica

\begin{tabular}{|c|c|c|c|c|}
\hline & Baixo risco & Médio risco & Alto risco & Risco muito alto \\
\hline & $<10 \%$ em 10 anos & $\begin{array}{l}\text { 10\%-20\% em } 10 \\
\text { anos }\end{array}$ & $\begin{array}{l}\geq 20 \% \text { em } 10 \text { anos, } \\
\text { ou diabetes ou } \\
\text { aterosclerose clínica }\end{array}$ & $\begin{array}{l}\text { Aterosclerose clínica associada a: } \\
\text { diabetes melito, tabagismo persistente, } \\
\text { HDL-c baixo, triglicérides elevados, } \\
\text { colesterol não-HDL-c alto, síndromes } \\
\text { coronárias agudas }\end{array}$ \\
\hline LDL-c (mg/dl) (A) & $<160^{*}$ & $<130(<100)^{* *}$ & $<100$ & $<70$ \\
\hline HDL-c (mg/dl) (B) & $>40$ & $>40$ & $\begin{array}{l}>40(>45 \text { se } \\
\text { diabetes melito })\end{array}$ & $>40$ (> 45 se diabetes melito) \\
\hline $\begin{array}{l}\text { Triglicérides } \\
(\mathrm{mg} / \mathrm{dl})(\mathrm{B})\end{array}$ & $<150$ & $<150$ & $<150$ & $<150$ \\
\hline
\end{tabular}


cálcio e inibidores da ECA é benéfica na prevenção primária do acidente vascular cerebral ${ }^{145}$ (A). Em pacientes hipertensos com hipertrofia ventricular esquerda que receberam losartana (bloqueadores do receptor $\mathrm{AT}_{1}$ ), observou-se redução maior do risco de acidente vascular cerebral do que os que receberam atenolol (betabloqueador) (A). Em hipertensos ou normotensos que sofreram acidente vascular cerebral ou ataque isquêmico transitório, a utilização de um inibidor da ECA (perindoprila) associado a um diurético (indapamida) foi capaz de reduzir novos acidentes vasculares cerebrais ${ }^{148}$. Houve superioridade do eprosartan, bloqueador do receptor $\mathrm{AT}_{1}$, quando comparado com nitrendipina, bloqueador de canal de cálcio, para a prevenção secundária de acidente vascular cerebral ${ }^{220}(\mathrm{~A})$.

\section{Fase aguda do acidente vascular cerebral isquêmico}

A elevação da pressão arterial observada na fase aguda do acidente vascular cerebral isquêmico é freqüente e transitória, mesmo em pacientes previamente normotensos, podendo ser observado um declínio dos níveis de pressão arterial, sem intervenção medicamentosa, durante os primeiros dias após o evento ${ }^{221}$ (B). Na fase aguda do acidente vascular cerebral isquêmico, pode haver um importante comprometimento da auto-regulação cerebral, tornando o fluxo sangüíneo dependente da pressão de perfusão cerebral e extremamente sensível a alterações da pressão arterial, principalmente na área de penumbra. Redução excessiva da pressão arterial diastólica (> 25\%), espontânea ou por meio de intervenção medicamentosa, também pode estar associada com um prognóstico neurológico desfavoráve ${ }^{222}(\mathrm{C})$. Valores de pressão sistólica excessivamente baixos ou elevados estão associados a pior prognóstico, representando uma curva em $U$, na qual os níveis sistólicos entre $150 \mathrm{mmHg}$ e $180 \mathrm{mmHg}$ parecem estar associados a melhor prognóstico 223 (B).

No evento agudo isquêmico cerebral, não devem ser administrados anti-hipertensivos, a não ser em condições clínicas específicas (isquemia miocárdica, insuficiência renal e cardíaca ou dissecção de aorta) ou na presença de níveis de pressão arterial extremamente elevados (pressão sistólica maior que 220 mmHg e diastólica maior que $120 \mathrm{mmHg}$ ), obtidos por medidas repetidas da pressão arterial (vide capítulo 6, item 6.6).

A pressão arterial deve ser mantida em torno de 180/100 $\mathrm{mmHg}$ nos pacientes com hipertensão arterial prévia e entre 160-180/90-100 mmHg nos pacientes não-hipertensos ${ }^{224}$ (C). Pacientes submetidos à trombólise devem manter a pressão arterial abaixo de 180/110 $\mathrm{mmHg}^{22} 5$ (C).

\subsection{Hematoma Cerebral}

Níveis de pressão arterial sistólica $\geq 160 \mathrm{mmHg}$ foram relacionados com a expansão do hematoma ${ }^{226}(\mathrm{C})$. A redução da pressão arterial média abaixo de $130 \mathrm{mmHg}$ e a manutenção acima de $90 \mathrm{mmHg}$ na fase aguda do hematoma intraparenquimatoso visam reduzir o risco de ressangramento ${ }^{227}$ (D) (vide capítulo 6, item 6.6).

\subsection{Cardiopatia Isquêmica}

Em hipertensos com doença arterial coronária, objetivase o controle gradual da pressão arterial até atingir níveis inferiores a 140/90 mmHg. É fundamental o controle de outros fatores de risco, bem como o uso de ácido acetilsalicílico ${ }^{228}$ (A). Os betabloqueadores são os mais indicados por sua ação antiisquêmica. Os bloqueadores dos canais de cálcio, exceto os de ação rápida, podem ser utilizados como recurso alternativo. Agentes hipotensores que aumentam a freqüência cardíaca, como a hidralazina, devem ser evitados. Em portadores de doença arterial coronariana, foi demonstrada redução de eventos com o uso do inibidor da ECA ramipril, mesmo sem hipertensão arterial ${ }^{147}$. Nos pacientes que já sofreram infarto agudo do miocárdio, devem ser utilizados um betabloqueador sem atividade simpaticomimética intrínseca e um inibidor da $\mathrm{ECA}^{147}(\mathrm{~A})$. No infarto agudo do miocárdio sem onda $Q$ com função sistólica preservada, podem ser utilizados diltiazem ou verapamil 229 (A).

\subsection{Insuficiência Cardíaca}

A hipertensão arterial pode promover alterações estruturais no ventrículo esquerdo, com ou sem isquemia coronária, contribuindo para o desenvolvimento de insuficiência cardíaca, com função sistólica preservada ou não. É fundamental o tratamento adequado da hipertensão prevenindo a insuficiência cardíaca, uma vez que, mesmo com a evolução do tratamento, a insuficiência cardíaca ainda tem alta morbimortalidade (A). Em pacientes com 65 anos ou mais, a insuficiência cardíaca é a primeira causa de internação, segundo o DATASUS ${ }^{230}(\mathrm{C})$.

Medidas não-medicamentosas são muito importantes, como a restrição de sal e, em alguns casos, de água, além da prática de atividade física supervisionada. Os diuréticos devem ser usados para o controle da hipertensão ou para evitar a retenção hídrica, nem sempre sendo necessário o uso de diurético de alça, salvo em pacientes com insuficiência renal.

Em presença de disfunção sistólica, os inibidores da ECA devem ser utilizados em doses plenas, mesmo que a pressão arterial esteja controlada, pois diminuem a morbidade e a mortalidade ${ }^{231}$ (A). Bloqueadores do receptor $\mathrm{AT}_{1}$ podem ser utilizados também em doses plenas como alternativa ${ }^{232}$ (A) ou em associação ${ }^{233}(\mathrm{~A})$ aos inibidores da ECA.

O betabloqueador carvedilol, associado ao inibidor da ECA, mostrou-se benéfico no tratamento da insuficiência cardíaca, reduzindo a mortalidade, em pacientes de diferentes classes funcionais (A). Benefícios semelhantes foram demonstrados com o uso de metoprolol ${ }^{234} \mathrm{e}$ bisoprolol $^{235}(\mathrm{~A})$, mas não com bucindolol ${ }^{236}(\mathrm{~A})$.

Entre os bloqueadores dos canais de cálcio, para controle da angina de peito ou da hipertensão arterial, em pacientes com insuficiência cardíaca, apenas o anlodipino ${ }^{237}$ ou o felodipino ${ }^{238}$ pode ser adicionado com segurança (A).

A adição de um antagonista da aldosterona, espironolactona ${ }^{239}$ ou eplerenona ${ }^{240}$, demonstrou redução significativa de mortalidade (A) em insuficiência cardíaca avançada. Seu uso, porém, pode estar associado a maior incidência de hiperpotassemia (C).

\subsection{Hipertrofia do Ventrículo Esquerdo}

A hipertrofia ventricular esquerda pode se associar à hipertensão arterial e é um indicador independente de risco 


\section{Diretriz}

cardiovascular. O tratamento medicamentoso é imperativo, devendo-se também recomendar a restrição de sódio e o controle do peso. Todos os anti-hipertensivos, à exceção dos vasodilatadores de ação direta, reduzem a hipertrofia ventricular esquerda, sendo os bloqueadores do SRAA considerados os mais eficazes ${ }^{241}$. Evidências sugerem que a regressão da hipertrofia ventricular esquerda está associada à diminuição da morbidade cardiovascular (B). Em pacientes diabéticos, a redução da glicemia pode se associar à regressão da hipertrofia ventricular esquerda.

\subsection{Síndrome da Apnéia Obstrutiva do Sono}

É uma condição comum e freqüentemente não diagnosticada (vide capítulo 8, item 8.9; capítulo 9, item 9.5). Em casos de hipertensão de difícil controle, deve-se pesquisar a ocorrência de apnéia do sono. 


\section{Hipertensão Arterial Secundária}

Apresenta causa identificável, passível ou não de correção. Sua prevalência, em torno de $3 \%$ a $10 \%$, depende da experiência de quem investiga e dos recursos diagnósticos disponíveis.

As situações em que se deve investigar a possibilidade de hipertensão arterial secundária estão na tabela 1.

Entretanto, antes de se prosseguir na investigação, deve-se fazer o diagnóstico diferencial com as seguintes possibilidades: medida inadequada da pressão arterial; hipertensão do avental branco; tratamento inadequado; não-adesão ao tratamento; progressão da doença; presença de comorbidades; interação com medicamentos.

\subsection{Hiperaldosteronismo Primário}

Caracteriza-se por produção aumentada de aldosterona pela supra-renal, originada por hiperplasia da glândula, adenoma, carcinoma ou por formas genéticas. A prevalência nos hipertensos varia de $3 \%$ a $22 \%$, sendo mais alta nos hipertensos de difícil controle ${ }^{242}$. Em geral, os pacientes têm hipertensão arterial estágio 2 ou 3, podendo ser refratária ao tratamento. Atualmente, sabe-se que a prevalência de hipopotassemia no hiperaldosteronismo primário varia de $9 \%$ a $37 \%$ dos casos.

A abordagem do hiperaldosteronismo primário inclui quatro etapas principais: rastreamento, confirmação do diagnóstico, diagnóstico diferencial entre hiperplasia e

Tabela 1 - Achados que sugerem hipertensão arterial secundária

\begin{tabular}{|c|c|c|}
\hline Achados & Suspeita diagnóstica & Estudos diagnósticos adicionais \\
\hline Ronco, sonolência diurna, obesidade & Apnéia obstrutiva do sono & Polissonografia \\
\hline $\begin{array}{l}\text { Hipertensão resistente ao tratamento ou } \\
\text { Hipertensão com hipopotassemia ou } \\
\text { Hipertensão com tumor abdominal }\end{array}$ & Hiperaldosteronismo primário & Relação aldosterona/renina \\
\hline $\begin{array}{l}\text { Sódio plasmático normal alto, } \\
\text { hipopotassemia }\end{array}$ & Aldosteronismo & $\begin{array}{c}\text { Relação aldosterona/renina, tomografia de } \\
\text { adrenais }\end{array}$ \\
\hline $\begin{array}{l}\text { Insuficiência renal, doença cardiovascular } \\
\text { aterosclerótica, edema, uréia elevada, } \\
\text { creatinina elevada, proteinúria/hematúria }\end{array}$ & Doença renal parenquimatosa & $\begin{array}{c}\text { Taxa de filtração glomerular, ultra- } \\
\text { sonografia renal }\end{array}$ \\
\hline $\begin{array}{l}\text { Sopro sistólico/diastólico abdominal, } \\
\text { edema pulmonar súbito, alterações de } \\
\text { função renal por medicamentos }\end{array}$ & Doença renovascular & $\begin{array}{l}\text { Angiografia por ressonância magnética } \\
\text { ou tomografia computadorizada, ultra- } \\
\text { sonografia com Doppler, } \\
\text { renograma, arteriografia renal }\end{array}$ \\
\hline $\begin{array}{l}\text { Uso de simpaticomiméticos, peri- } \\
\text { operatório, estresse agudo, taquicardia }\end{array}$ & Catecolaminas em excesso & $\begin{array}{c}\text { Confirmar normotensão em ausência de } \\
\text { catecolaminas }\end{array}$ \\
\hline $\begin{array}{l}\text { Pulsos em femorais reduzidos ou } \\
\text { retardados, raios X de tórax anormal }\end{array}$ & Coartação da aorta & $\begin{array}{c}\text { Doppler ou tomografia computadorizada } \\
\text { de aorta }\end{array}$ \\
\hline $\begin{array}{l}\text { Ganho de peso, fadiga, fraqueza, } \\
\text { hirsutismo, amenorréia, face em } \\
\text { "lua cheia", "corcova" dorsal, estrias } \\
\text { purpúricas, obesidade central, } \\
\text { hipopotassemia }\end{array}$ & Síndrome de Cushing & $\begin{array}{l}\text { Cortisol basal e após teste de supressão } \\
\text { com dexametasona }\end{array}$ \\
\hline $\begin{array}{l}\text { Uso de medicamentos/substâncias pró- } \\
\text { hipertensivas }\end{array}$ & Efeito adverso de medicamento/substância & Eliminar uso do medicamento, se possível \\
\hline $\begin{array}{l}\text { Ingestão elevada de sal, abuso de álcool, } \\
\text { obesidade }\end{array}$ & Efeitos de estilos de vida & Tentar modificação dietética \\
\hline $\begin{array}{l}\text { Hipertensão paroxística, cefaléias, } \\
\text { sudorese, palpitações, taquicardia }\end{array}$ & Feocromocitoma & $\begin{array}{l}\text { Catecolaminas e metabólitos de } \\
\text { catecolaminas em sangue e urina }\end{array}$ \\
\hline $\begin{array}{l}\text { Fadiga, ganho de peso, perda de cabelo, } \\
\text { hipertensão diastólica, fraqueza muscular }\end{array}$ & Hipotireoidismo & Dosagem de TSH \\
\hline $\begin{array}{l}\text { Intolerância ao calor, perda de peso, } \\
\text { palpitações, hipertensão sistólica, } \\
\text { exoftalmia, tremores, taquicardia }\end{array}$ & Hipertireoidismo & Dosagem de TSH \\
\hline $\begin{array}{l}\text { Litíase urinária, osteoporose, depressão, } \\
\text { letargia, fraqueza muscular }\end{array}$ & Hiperparatireoidismo & Dosagem do cálcio sérico e níveis de PTH \\
\hline $\begin{array}{l}\text { Cefaléias, fadiga, problemas visuais, } \\
\text { aumento de mãos, pés e língua }\end{array}$ & Acromegalia & Dosagem do hormônio do crescimento \\
\hline
\end{tabular}




\section{Diretriz}

adenoma e tratamento (Figura 1$)^{243,245}$. O rastreamento deve ser realizado em todo hipertenso com hipocalemia espontânea ou provocada por diuréticos, em hipertensos resistentes aos tratamentos habituais e em hipertensos com tumor abdominal pela determinação da relação aldosterona sérica/atividade de renina plasmática $(A / R)$. Relação $A / R \geq 30 \mathrm{ng} / \mathrm{dl} / \mathrm{ng}$, com aldosterona sérica superior a $15 \mathrm{ng} / \mathrm{dl}$, é achado considerado positivo e sugestivo de hiperaldosteronismo primário.

Paciente com rastreamento positivo para hiperaldosteronismo primário deve ter este diagnóstico confirmado pela determinação de aldosterona após sobrecarga de sal realizada pela administração endovenosa de soro fisiológico (2 I em 4 horas) ou pela administração via oral, durante quatro dias, de acetato de fludrocortisona $(0,1 \mathrm{mg} \mathrm{6/6}$ horas), além de dieta rica em sal. Pacientes com concentrações de aldosterona $\geq 5$ $\mathrm{ng} / \mathrm{dl} \mathrm{e} \geq 6 \mathrm{ng} / \mathrm{dl}$, após o final do primeiro e do segundo testes, respectivamente, têm o diagnóstico de hiperaldosteronismo primário confirmado.

O terceiro passo no diagnóstico do hiperaldosteronismo primário é fazer a diferenciação entre hiperplasia e adenoma, essencial para o tratamento adequado dessas duas condições. Isso pode ser feito a partir de dados clínicos, laboratoriais, radiológicos e, finalmente, da determinação da aldosterona nas veias adrenais por cateterismo das adrenais, que indica se existe lateralização na produção de aldosterona ou se ela é bilateral. Do ponto de vista clínico e laboratorial, pacientes portadores de adenoma são, em geral, mais jovens, têm hipocalemia mais acentuada e concentrações mais elevadas de aldosterona (> $25 \mathrm{ng} / \mathrm{dl})^{244}$.

A investigação radiográfica do hiperaldosteronismo primário tem o objetivo de indicar a presença ou a ausência de tumor. Deve ser feita pela tomografia computatorizada ou pela ressonância magnética das adrenais. Entretanto, cerca de $20 \%$ dos adenomas são tumores menores que um centímetro e podem não ser visualizados.

\subsection{Feocromocitoma}

São tumores neuroendócrinos da medula adrenal ou de paragânglios extra-adrenais (paragangliomas), com prevalência de $0,1 \%$ a $0,6 \%$. O tumor pode se apresentar como esporádico ou associado a síndromes genéticas familiares (20\% dos casos), em que predominam a de Von-Hippel-Lindau, neoplasia endócrina múltipla tipo $2 \mathrm{~A}$ e 2B, neurofibromatose tipo 1 e paragangliomas, com pelo menos seis genes de suscetibilidade (RET, VHL, NF1, SDHB,

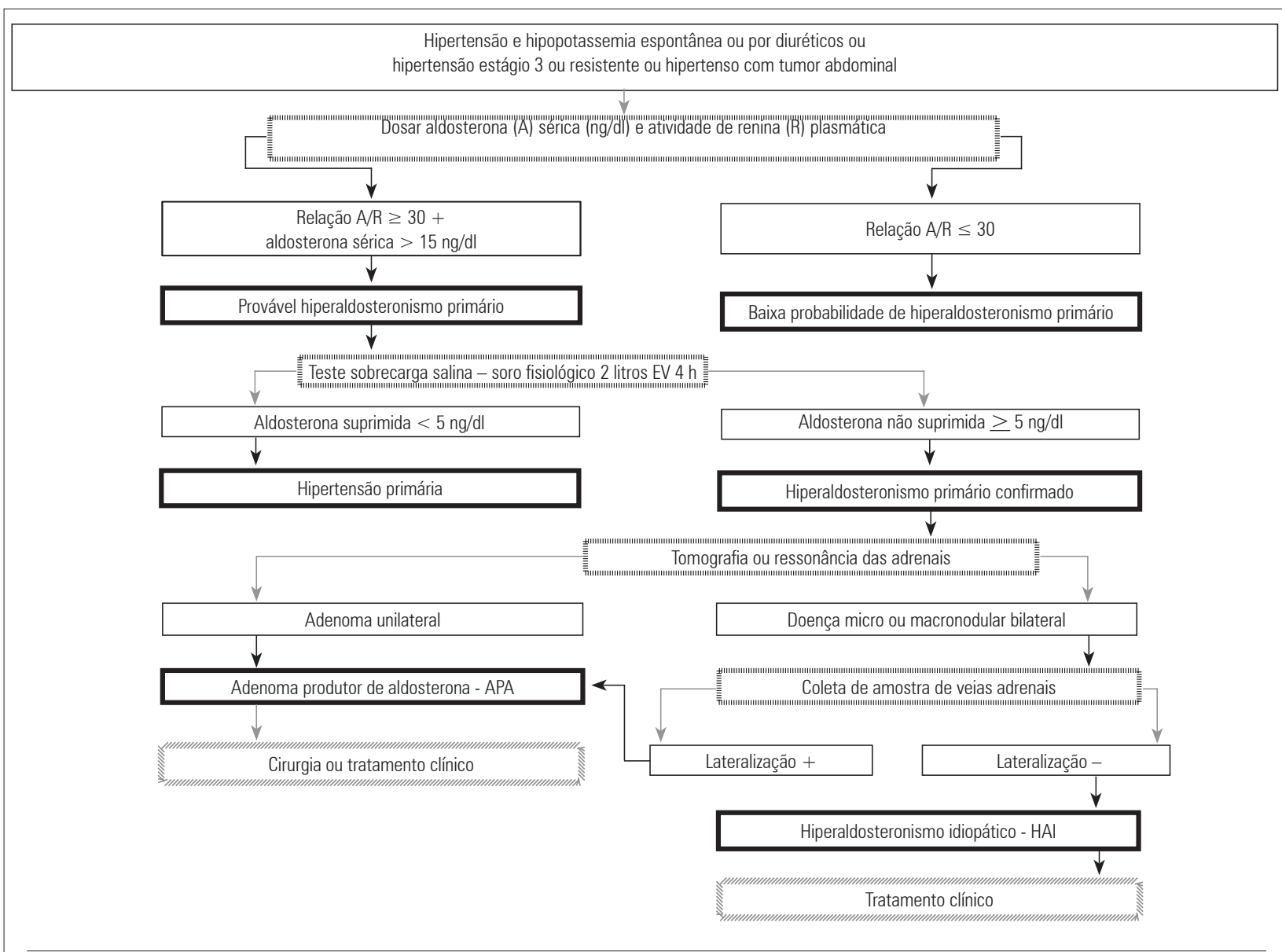

Fig. 1 - Fluxograma para investigação de hiperaldosteronismo primário $(A / R=$ relação aldosterona/atividade renina plasmática). 
SDHD e SDHC). Geralmente, o tumor é adrenal unilateral, mas pode ser bilateral (síndromes familiares), múltiplo e extra-adrenal, benigno ou maligno ( $5 \%$ a $26 \%$ dos casos). A hipertensão paroxística (30\% dos casos) ou sustentada (50\% a $60 \%$ dos casos) e os paroxismos são acompanhados principalmente de cefaléia $(60 \%$ a $90 \%)$, sudorese $(55 \%$ a $75 \%$ ) e palpitações (50\% a 70\%). O diagnóstico é baseado na dosagem de catecolaminas plasmáticas ou de seus metabólitos no sangue e na urina (Tabela 2) e na identificação de mutações nos genes envolvidos. No Brasil, não se dispõe de dosagem sérica de metanefrina no sangue, mas pode-se fazê-la na urina.

Tabela 2 - Percentuais de sensibilidade e especificidade com os respectivos intervalos de confiança dos testes bioquímicos para diagnóstico do feocromocitoma

\begin{tabular}{|c|c|c|}
\hline Teste bioquímico & Sensibilidade & Especificidade \\
\hline \multicolumn{3}{|l|}{ Plasma } \\
\hline $\begin{array}{l}\text { Metanefrinas } \\
\text { livres }\end{array}$ & $99 \%(96 \%-100 \%)$ & $89 \%(87 \%-92 \%)$ \\
\hline Catecolaminas & $84 \%(78 \%-89 \%)$ & $81 \%(78 \%-84 \%)$ \\
\hline \multicolumn{3}{|l|}{ Urina } \\
\hline $\begin{array}{l}\text { Metanefrinas } \\
\text { fracionadas }\end{array}$ & $97 \%(92 \%-99 \%)$ & $69 \%(64 \%-72 \%)$ \\
\hline Catecolaminas & 86\% (80\%-91\%) & $88 \%(85 \%-91 \%)$ \\
\hline $\begin{array}{l}\text { Metanefrinas } \\
\text { - Total }\end{array}$ & $77 \%(68 \%-85 \%)$ & $93 \%(89 \%-97 \%)$ \\
\hline $\begin{array}{l}\text { Ácido } \\
\text { vanilmandélico }\end{array}$ & $64 \%(55 \%-71 \%)$ & $95 \%(93 \%-97 \%)$ \\
\hline
\end{tabular}

Para o diagnóstico topográfico dos tumores e, eventualmente, de metástases, os métodos de imagens recomendados são: tomografia computadorizada e ressonância magnética, ambas com sensibilidade próxima a 100\% para tumores adrenais e mapeamento de corpo inteiro com metaiodobenzilguanidina, com sensibilidade de 56\% (tumores malignos) a $85 \%$ e alta especificidade. Octreoscan, mapeamento ósseo e PET com diferentes marcadores podem ser decisivos quando os exames de localização anteriores são negativos ou na investigação de doença maligna. O tratamento preferencial é cirúrgico. No tratamento farmacológico pré-operatório ou crônico, são utilizados alfabloqueadores (prazosina, doxazocina e dibenzilina), combinados ou não a outros agentes como inibidores da ECA, bloqueadores dos canais de cálcio, betabloqueadores, sempre após alfabloqueio efetivo e, principalmente em tumores inoperáveis, alfametiltirosina (Demser $\left.{ }^{\circledR}\right)$. Para a intervenção cirúrgica, recomenda-se controle da hipertensão arterial e reposição volêmica. Em crises agudas e durante a cirurgia, nitroprussiato de sódio e antiarrítmicos são agentes freqüentemente utilizados (vide capítulo 6, item 6.6). O seguimento do paciente é essencial para a detecção de recorrências ou metástases. No rastreamento familiar recomenda-se a detecção de mutações dos genes envolvidos e de outros exames relativos às síndromes ${ }^{245,246}$.

\subsection{Hipotireoidismo}

É relativamente comum, principalmente em mulheres, com prevalência de aproximadamente $8 \%$ na população geral.

Hipertensão, principalmente diastólica, atinge 40\%. Outros achados são: ganho de peso, queda de cabelos e fraqueza muscular. Pode ser diagnosticado precocemente pela elevação dos níveis séricos de TSH e confirmado com a diminuição gradativa dos níveis de T4 livre. Caso persista hipertensão arterial após a correção com tiroxina, está indicado o tratamento com medicamentos anti-hipertensivos ${ }^{247}(\mathrm{C})$.

\subsection{Hipertireoidismo}

A prevalência das formas clínica e subclínica em adultos varia de $0,5 \%$ a $5 \%$. A suspeita clínica é feita em presença de hipertensão arterial sistólica isolada ou sistodiastólica acompanhada de sintomas como intolerância ao calor, perda de peso, palpitações, exoftalmia, tremores e taquicardia. O diagnóstico é feito pela identificação do TSH baixo e elevação dos níveis de T4 livre. A correção geralmente se acompanha de normalização da pressão $\operatorname{arterial}^{248}(\mathrm{C})$.

\subsection{Hiperparatireoidismo}

A suspeita clínica deve ser feita em casos de hipertensão arterial acompanhada de história de litíase renal, osteoporose, depressão, letargia e fraqueza muscular. O diagnóstico é feito pela dosagem dos níveis plasmáticos de cálcio e PTH. A correção do hiperparatireoidismo não necessariamente se acompanha de normalização da pressão arterial.

\subsection{Hipertensão Arterial Renovascular}

Caracteriza-se por aumento de pressão arterial decorrente do estreitamento único ou múltiplo das artérias renais. Entretanto, a simples identificação de uma estenose de artéria renal não faz o diagnóstico de hipertensão arterial renovascular. Geralmente, o diagnóstico é confirmado após a correção da estenose e o desaparecimento ou a melhora da hipertensão arterial ${ }^{249}$ (Figura 2).

A prevalência é de $4 \%$ na população geral, mas pode ser mais alta em paciente com doença arterial coronária e periférica ${ }^{250,251}$. Estima-se que $12 \%$ dos pacientes em programa de diálise apresentem doença renovascular ${ }^{252}$.

A estenose de artéria renal pode ser causada por aterosclerose $(90 \%)$ ou por displasia fibromuscular ${ }^{253}$. As outras causas de estenose de artéria renal incluem aneurisma de artéria renal, arterite de Takayasu, tromboembólica, síndrome de Williams, neurofibromatose, dissecção espontânea de artéria renal, malformações arteriovenosas, fístulas, trauma e radiação abdominal prévia. Os indicadores clínicos de probabilidade de hipertensão arterial renovascular estão apresentados na tabela $3^{254}$ (B).

\section{Tratamento da doença renovascular}

Os objetivos principais do tratamento são a cura ou a melhora da hipertensão arterial e/ou a melhora ou a preservação da função renal. O tratamento da hipertensão arterial renovascular pode ser clínico, cirúrgico ou por meio de revascularização percutânea com ou sem a colocação de próteses endovasculares (stents). 


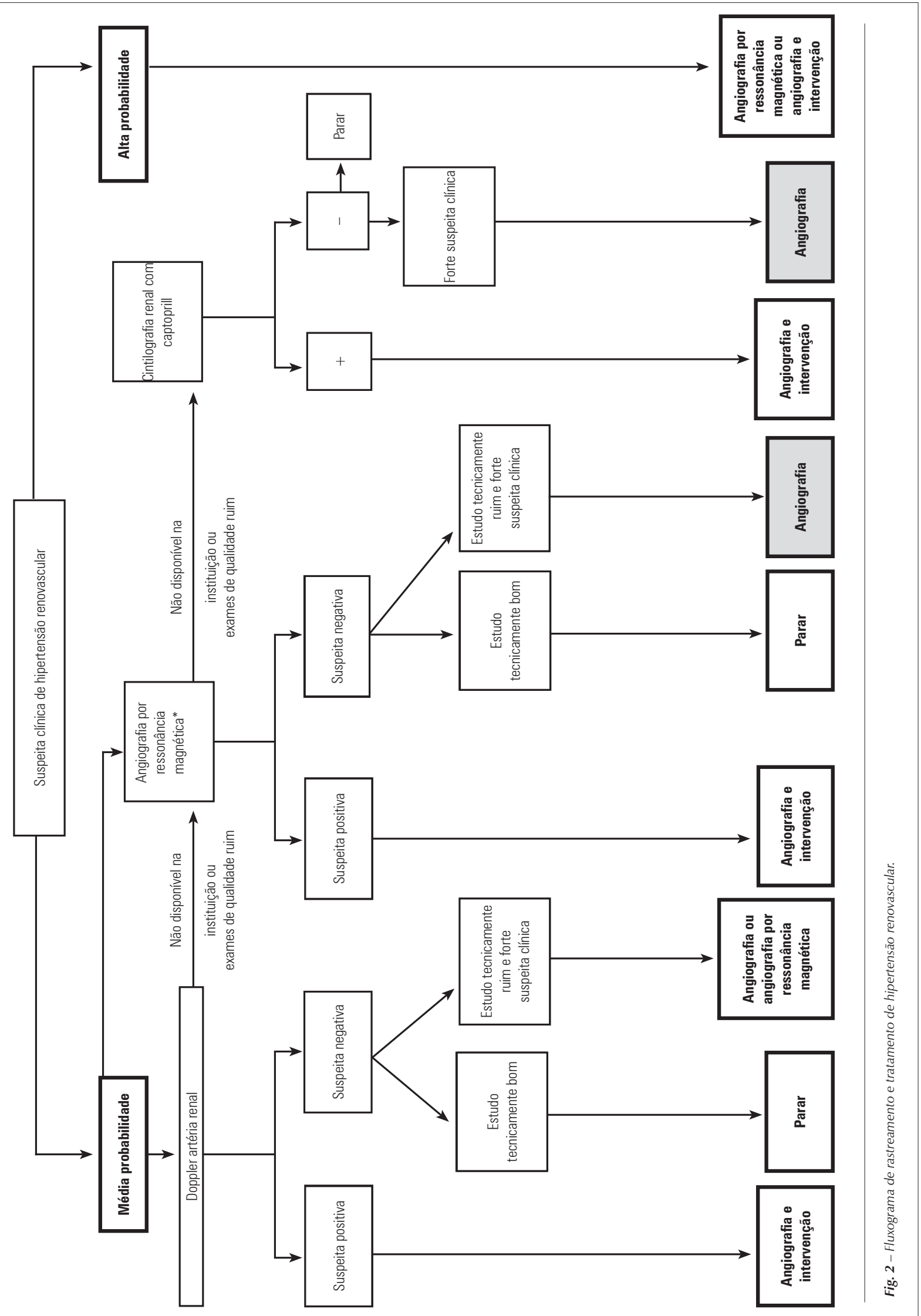


Tabela 3 - Indicadores clínicos de probabilidade de hipertensão renovascular

Baixa $(0,2 \%)$

Hipertensão estágio 1 sem complicações

Média (5\% a 15\%)

Hipertensão estágio 2 ou 3 refratária; hipertensão antes dos 30 ou após os 55 anos; sopros abdominais ou lombares, doença ateromatosa evidente em coronárias, carótidas ou vasos de extremidade em fumantes; assimetria de pulsos, insuficiência renal mal definida, edema pulmonar agudo sem causa aparente, hipotensão arterial importante com o uso de inibidores da ECA

Alta (25\%)

Hipertensão arterial maligna ou refratária com insuficiência renal progressiva; elevação da creatinina sérica com uso de inibidor da ECA, assimetria de tamanho ou função renal

\section{Tratamento clínico}

Os inibidores da ECA, os bloqueadores dos canais de cálcio e os betabloqueadores ${ }^{255,256}$ são medicamentos efetivos para o tratamento da hipertensão arterial associada à estenose unilateral de artéria renal (A). Os bloqueadores dos receptores $\mathrm{AT}_{1}$ também são efetivos para o tratamento da hipertensão arterial associada à estenose de artéria renal (B).

As indicações clínicas para correção da estenose de artéria renal por via percutânea ou por revascularização cirúrgica ${ }^{257,258}$ são: a) hipertensão resistente, hipertensão acelerada ou maligna e hipertensão com intolerância à medicação (B); b) perda progressiva da função renal com estenose bilateral ou estenose em rim único (B) ou na estenose unilateral (C); c) insuficiência cardíaca congestiva ou edema pulmonar agudo de repetição $\mathrm{O}^{259,260}(\mathrm{~B})$.

\section{Tratamento cirúrgico}

Está indicado em: a) obstrução total da artéria renal; b) grandes fístulas arteriovenosas; c) lesões de aorta englobando as artérias renais; d) insucesso do tratamento endovascular (C); e) insucesso do tratamento clínico.

A técnica a ser empregada depende da experiência e da decisão da equipe.

Tratamento por via percutânea (angioplastia isolada ou com stent) ${ }^{263}$ (B)

Salvo as indicações citadas para cirurgia, o tratamento endovascular deverá ser a abordagem inicial desde que atenda aos critérios clínicos para intervenção. O implante de stent é considerado superior ao balão no tratamento da estenose de artéria renal de etiologia aterosclerótica ${ }^{261}$, de modo que o implante de stent é recomendado para lesões ostiais ateroscleróticas ${ }^{262}$ e a angioplastia com balão para as lesões fibrodisplásicas ${ }^{264}$.

\subsection{Hipertensão em Diálise e Transplante Renal}

Hipertensão arterial é altamente prevalente nos pacientes dialisados $(60 \%$ a $80 \%)$ e nos transplantados. Os eventos cardiovasculares são os principais responsáveis pela morbidade e pela mortalidade nesses indivíduos, sendo a hipertensão arterial considerada fator de risco independente ${ }^{263}$ (B). Na fase precoce da diálise ( $<2$ anos), os níveis normais baixos de pressão arterial e os episódios de hipotensão arterial estão mais relacionados com a mortalidade do que a hipertensão arterial, o que provavelmente reflete a associação com outros estados mórbidos graves ${ }^{264}$. Em fases mais tardias e, principalmente, após cinco anos, a hipertensão arterial representa papel mais relevante para mortalidade nesses pacientes. Tem sido relatada intrigante elevação do risco de mortalidade na vigência de redução acentuada $(<110 \mathrm{mmHg})$ da pressão arterial sistólica pré-diálise. A curva de associação entre pressão arterial e mortalidade adquire padrão em forma de " $U$ ", em que os pacientes de maior risco são aqueles muito hipertensos (pressão arterial sistólica pré-diálise $>180 \mathrm{mmHg}$ ) e os muito hipotensos (pressão arterial sistólica pré-diálise < $110 \mathrm{mmHg}$ ). Sugere-se que esta condição seja evitada tanto quanto possível, assim como maior atenção deva ser dada à hipertensão arterial pós-diálise ${ }^{265}$ (A).

Hipertensos em diálise são, em geral, mal controlados, em decorrência da hipervolemia, hiperatividade simpática, alterações do SRAA, concentração de sódio do dialisato, hiperparatireoidismo, uso de eritropoietina e redução da resposta vasodilatadora dependente do endotélio, sendo a sobrecarga de volume o mais importante (A). Há evidências de que a hemodiálise diária e a CAPD estariam associadas ao melhor controle da pressão arterial ${ }^{266,267}$ (B). A monitoração ambulatorial da pressão arterial, por períodos de $48 \mathrm{~h}$, pode ser útil no período interdialítico.

A hipertensão arterial ocorre em mais da metade dos transplantados, sendo considerada um fator de risco nãoimunológico na sobrevida em longo prazo do enxerto ${ }^{268}(\mathrm{~B})$. Pode ser induzida por ciclosporina e outros imunossupressores, corticosteróides, rejeição, recidiva da doença renal, estenose de artérias renais e hipertensão arterial primária superajuntada. A terapia imunossupressora também eleva a ocorrência de dislipidemia ${ }^{269,270}(\mathrm{~B})$.

O tratamento nos pacientes em programa de diálise pode ser feito com todas as classes de medicamentos antihipertensivos, exceto os diuréticos tiazídicos e os de alça nos pacientes anéfricos ou que não apresentam diurese com os diuréticos, além da adequação da diálise (B). Nos transplantados, há evidências de que os medicamentos que bloqueiam o SRAA podem melhorar os resultados ${ }^{271}$ (B). Nos pacientes em uso de ciclosporina, os bloqueadores de canais de cálcio são indicados por reverter a vasoconstrição ocasionada pela medicação, e o verapamil e o diltiazem podem aumentar os níveis séricos de ciclosporina ${ }^{272}(\mathrm{C})$.

\subsection{Coartação da Aorta}

É causa de hipertensão secundária especialmente em crianças e adultos jovens, em que há evidência de níveis de pressão arterial mais elevados em membros superiores em relação aos inferiores ou quando há ausência ou diminuição de pulsos em membros inferiores. Os exames complementares diagnósticos indicados são ecocardiograma e angiografia por ressonância magnética. É muito importante o diagnóstico precoce, pois pode ser causa de insuficiência cardíaca na 


\section{Diretriz}

infância e há relação inversa entre o tempo de exposição à hipertensão e a reversão desta após a correção. A intervenção pode ser realizada por procedimento endovascular, principalmente em crianças, ou por cirurgia.

\subsection{Síndrome da Apnéia Obstrutiva do Sono}

É definida como a obstrução recorrente completa ou parcial das vias aéreas superiores durante o sono, resultando em períodos de apnéia, dessaturação de oxiemoglobina e despertares freqüentes com sonolência diurna. Está relacionada ao desenvolvimento de hipertensão arterial independentemente da obesidade ${ }^{273}$ (B) e alterações precoces da estrutura e da função $\operatorname{arterial}^{274}(\mathrm{C})$, sendo reconhecida como fator de risco para aterosclerose e doença cardiovascular $^{275}(\mathrm{~B})$.

A ativação simpática e as respostas humorais, como conseqüência aos episódios repetidos de hipoxemia, causam vasoconstricção, disfunção endotelial, elevação da PCR, aumento dos níveis de fibrinogênio, das citocinas e da pressão arterial.

A suspeita clínica deve ser realizada na presença dos seguintes sintomas: ronco alto, episódios de engasgo freqüentes, cansaço diurno, sonolência diurna excessiva, alterações de memória e capacidade de concentração prejudicada. Alguns achados clínicos associados auxiliam na suspeita diagnóstica, tais como obesidade, aumento da circunferência do pescoço, orofaringe pequena e eritematosa, insuficiência cardíaca congestiva, hipertensão pulmonar e cor pulmonale. Alguns pacientes podem ter apresentações clínicas atípicas, como palpitações noturnas, cefaléia matutina, tonturas, refluxo gastroesofágico e noctúria. O diagnóstico é confirmado pelo achado de cinco ou mais episódios de apnéia e/ou hipopnéia por hora de sono (índice de apnéia-hipopnéia) na polissonografia.

O tratamento inclui o uso de máscara de pressão positiva contínua (CPAP) em vias aéreas superiores por via nasal durante o sono $^{276}(\mathrm{~B})$, tratamento cirúrgico do processo obstrutivo e redução do peso em indivíduos com sobrepeso ou obesidade.

\subsection{Hipertensão Induzida por Medicamentos e Drogas}

A tabela 4 relaciona algumas classes de substâncias com seu potencial hipertensivo e sugestões de intervenção. Recomendase, em geral, avaliar a relação risco-benefício e adequar as doses e associações dos anti-hipertensivos (vide capítulos 7 e 9).

Tabela 4 - Fármacos e drogas que podem induzir hipertensão

\begin{tabular}{|lcc}
\hline Classe farmacológica & Efeito pressor e freqüência & Ação sugerida \\
\hline Imunossupressores & & Inibidor de ECA e antagonista de canal \\
\hline $\begin{array}{l}\text { Ciclosporina, tacrolimus, } \\
\text { Glicocorticóide }\end{array}$ & Intenso e freqüente & de cálcio (nifedipino/anlodipino). Ajustar \\
nível sérico. Reavaliar opções
\end{tabular}

\section{Antiinflamatórios não-esteróides, Inibidores da ciclooxigenase 1 e ciclooxigenase 2}

Inibidores da COX-1 e COX-2 Eventual, muito relevante com uso Observar função renal e informar efeitos contínuo adversos

Anorexígenos/Sacietógenos

Anfepramona e outros

Intenso e freqüente

Suspensão ou redução de dose

Sibutramina

Moderado, mas pouco relevante

Avaliar a redução da pressão arterial obtida com a redução de peso

Vasoconstritores, incluindo derivados do ergot

Variável, mas transitório

Usar por período determinado

Hormônios

Eritropoietina humana

Variável e freqüente

Avaliar hematócrito e dose semanal

Anticoncepcionais orais

Variável, prevalência de hipertensão até $5 \%$

Avaliar a substituição do método com especialista

Terapia de reposição estrogênica (estrogênios conjugados e estradiol)

Variável

Avaliar risco e custo-benefício

Hormônio de crescimento (adultos)

Variável, uso cosmético

Suspensão

\section{Antidepressivos}

Inibidores da monoaminoxidase

Intenso, infreqüente

Abordar como crises adrenérgica

Tricíclicos

Variável e freqüente

Abordar como crise adrenérgica. Vigiar interações medicamentosas

Drogas ilícitas e álcool

Anfetamina, cocaína e derivados

Álcool
Efeito agudo, intenso. Dose-dependente

Variável e dose-dependente. Muito prevalente
Abordar como crise adrenérgica

Vide tratamento não-medicamentoso 


\section{Prevenção Primária da Hipertensão e dos Fatores de Risco Associados}

A hipertensão arterial, principal fator de risco de morte entre as doenças não-transmissíveis ${ }^{277}$, mostra relação direta e positiva com o risco cardiovascular ${ }^{278,279}$. Entretanto, apesar dos progressos na prevenção, no diagnóstico, no tratamento e no controle, ainda é importante problema de saúde pública ${ }^{281}$.

Devem ser metas dos profissionais de saúde a identificação precoce e a abordagem adequada dos fatores de risco para o desenvolvimento da hipertensão arterial, principalmente na população de alto risco. Entre as medidas preventivas, destacam-se a adoção de hábitos alimentares saudáveis, a prática de atividade física e o abandono do tabagismo ${ }^{104}$.

\subsection{Hábitos Alimentares Saudáveis}

A adoção de hábitos alimentares saudáveis é um componente muito importante da prevenção primária da hipertensão arterial $^{281}$ (D), sendo necessário manter o peso adequado, reduzir o consumo de sal, moderar o de álcool, controlar o de gorduras e incluir alimentos ricos em potássio na alimentação diária (D).

Peso corporal: a manutenção do índice de massa corporal entre 18,5 e $24,9 \mathrm{~kg} / \mathrm{m}^{2}$ é o ideal ${ }^{280,281}$ (B). Além disso, é importante que a circunferência da cintura não seja superior a $102 \mathrm{~cm}$ para os homens e $88 \mathrm{~cm}$ para as mulheres 282 (B). Quando houver sobrepeso ou obesidade, a perda de 5\% a 10\% do peso inicial já traz benefícios (D). O consumo de calorias deve estar de acordo com o gasto calórico diário, incluindo o gasto com atividade física e evitando-se alimentos hipercalóricos e sem valor nutricional.

Sal: estudos realizados na população brasileira detectaram consumo de sal elevado, superior a $12 \mathrm{~g} /$ dia $^{283,284}$. Deve-se diminuir a ingestão de sódio para, no máximo, $100 \mathrm{mmol}$ ou 2,4 g/dia, o que equivale a $6 \mathrm{~g} / \mathrm{dia}$ de sal ${ }^{281,284}(\mathrm{~A})$. Para tanto, recomenda-se reduzir o sal adicionado aos alimentos, evitar o saleiro à mesa e reduzir ou abolir os alimentos industrializados, como enlatados, conservas, frios, embutidos, sopas, temperos, molhos prontos e salgadinhos ${ }^{123}$ (B) (vide capítulo 1, item 1.5; capítulo 5, item 5.3). A redução da ingestão excessiva de sódio e/ou a perda de peso pode prevenir a hipertensão arterial em 20\% (B).

Álcool: deve-se limitar o consumo de bebida alcoólica a, no máximo, $30 \mathrm{ml} /$ dia de etanol para homens e $15 \mathrm{ml} /$ dia para mulheres ou indivíduos de baixo peso (vide capítulo 5, tabela 2). Quem não consome bebidas alcoólicas não deve ser estimulado a fazê-lo ${ }^{281}$ (A) (vide capítulo 1, item 1.5; capítulo 5, item 5.4).

Gordura: no máximo 30\% do valor calórico total da dieta deve ser de gorduras, sendo a saturada até $10 \%$ e o colesterol até $300 \mathrm{mg} /$ dia. Deve-se evitar a gordura vegetal hidrogenada contida em bolachas doces recheadas, margarinas duras, produtos com massa folhada, dar preferência ao uso dos óleos vegetais insaturados ${ }^{284}$ e fazer uso de margarinas cremosas ou light com até $40 \%$ de lípides (A) (vide capítulo 1; capítulo 5, item 5.2).

Potássio: deve-se garantir o consumo de $75 \mathrm{mmol}$ ou 4,7 g/dia de potássio, utilizando-se verduras, legumes, frutas, principalmente cruas, e leguminosas como feijões, ervilha, lentilha, grão-de-bico, soja ${ }^{281}$ (A) (vide capítulo 5, item suplementação de potássio).

\section{Dieta DASH e dieta do Mediterrâneo}

Todos os preceitos enumerados anteriormente são preconizados nas dietas DASH (Dietary Approaches to Stop Hypertension) ${ }^{108}$ (A) e do Mediterrâneo 285,286 (B), que trazem vários benefícios à saúde, destacando-se a queda da pressão arterial com a dieta DASH (A). A alimentação balanceada com verduras, frutas, legumes, cereais, tubérculos, leguminosas, carnes magras, leite e derivados desnatados e óleos vegetais está associada à redução do risco de desenvolvimento de hipertensão arterial pelo impacto da ação isolada ou combinada de seus nutrientes ${ }^{284}(\mathrm{~A})$.

É importante que esses cuidados nutricionais sejam adotados desde a infância e a adolescência ${ }^{104,284,287}$ (D). Sua adoção deve levar em conta os aspectos culturais, sociais, regionais, ambientais e a realidade econômica de cada paciente para que haja maior adesão ${ }^{104,288}$ (D) (vide capítulo 1, item 1.5; capítulo 5, item 5.2).

\subsection{Atividade Física}

Há relação inversa entre quantidade total de atividade física (qualquer movimento humano) e incidência de hipertensão $\operatorname{arterial}^{24,126}(\mathrm{C})$, sendo essa relação mais evidente com o envolvimento em atividades de lazer e vigorosas ${ }^{24}$. Entretanto, ganhos substanciais já são obtidos com atividades acumuladas e moderadas ${ }^{130,131}$.

$\mathrm{Na}$ população geral, a prática regular de exercícios (movimentos estruturados) aeróbicos reduz a pressão arterial casual na clínica (-3,0/2,4 mmHg) (A) e a ambulatorial (-3,3/3,5 $\mathrm{mmHg})^{127}(B)$, sendo o efeito hipotensor maior quanto maior for a pressão arterial inicial ${ }^{126,127}$ (A). Os exercícios resistidos (musculação) também reduzem a pressão arterial na população geral $^{26,126}(B)$, mas têm resultados limitados e controversos em hipertensos ${ }^{26}$. A atividade física auxilia também no controle de outros fatores de risco, como o peso corporal, a resistência à insulina e a dislipidemia, reduzindo o risco cardiovascular geral $^{126}(\mathrm{~A})$. Atividades e exercícios físicos auxiliam na prevenção primária da hipertensão arterial, devendo ser praticados conforme as recomendações da tabela 3, capítulo 5 (vide capítulo 1, item 1.5; capítulo 5, item 5.5).

\subsection{Tabagismo}

O fumo é o único fator de risco totalmente evitável de doença e morte cardiovasculares ${ }^{289}$ (A). Evitar esse hábito, que em $90 \%$ dos casos ocorre na adolescência (C), é um dos maiores desafios em razão da dependência química causada pela nicotina. No entanto, programas agressivos de controle ao tabagismo resultam em redução do consumo individual e se associam à diminuição de mortes cardiovasculares em curto $\operatorname{prazo}^{292}(\mathrm{~A})$.

O cuidado individual do tabagista é prioritário para toda a equipe de saúde. O apoio psicoemocional incondicional ao tabagista e a prescrição de medicamentos têm-se mostrado muito eficazes ${ }^{292}$ (B). Recomenda-se a execução simultânea de 
atividades físicas e a educação alimentar para evitar o ganho excessivo de peso que pode ocorrer.

\subsection{Estresse}

Há evidências de uma relação positiva entre estresse emocional e aumento da pressão arterial ${ }^{290}$ (B) e da reatividade cardiovascular $^{135}(\mathrm{~B})$, sendo a reatividade aumentada ao estresse um fator prognóstico do desenvolvimento da hipertensão $\operatorname{arterial}^{291}(\mathrm{~A})$. O estresse crônico também pode contribuir para o desenvolvimento de hipertensão arterial (A), embora os mecanismos envolvidos não estejam claros ${ }^{292}$ (B). Assim, o controle do estresse emocional é necessário na prevenção primária da hipertensão arterial (A). O treino desse controle resulta em: redução da reatividade cardiovascular (B), redução da pressão arterial (B) e redução de variabilidade da pressão arterial $^{293}(\mathrm{C})$, sendo recomendado não só para hipertensos, mas também para aqueles com fatores de risco para hipertensão $\operatorname{arterial}^{294}(\mathrm{~A})$.

\subsection{Síndrome da Apnéia Obstrutiva do Sono}

Está bem documentada a associação causal entre a síndrome da apnéia obstrutiva do sono e a hipertensão arterial. O paciente com essa síndrome é considerado de risco para hipertensão ${ }^{276}$ (B) (vide capítulo 7, item 7.14; capítulo 8, item 8.9).

\subsection{Estratégias para a Implementação de Medidas Preventivas da Hipertensão Arterial}

As intervenções devem adotar um modelo multidimensional, multiprofissional e incorporar diversos níveis de ação ${ }^{294}$, usando e integrando recursos das sociedades científicas, da universidade, do setor público e privado e do terceiro setor (D).

\section{Políticas públicas}

- Redução dos fatores de riscos para hipertensão arterial.

- Prevenção e promoção de saúde em diferentes níveis: educacional, laboral, de lazer, comunitário e outros.

- Vigilância epidemiológica das condições de risco da hipertensão arterial no setor público e privado.

- Ações educativas utilizando todas as formas de mídia.

- Manutenção e expansão da rede de equipamentos de saúde, garantindo o acesso, a qualidade e a eficiência da atenção prestada.

- Incentivar o desenvolvimento e a implantação de programas nacional, estaduais e municipais de promoção do consumo de frutas e verduras que sejam sustentáveis e envolvam todos os setores.

- Conscientização geral acerca dos hábitos alimentares saudáveis na prevenção da hipertensão arterial.

- Exigir maior rigor na rotulagem do conteúdo nutricional dos alimentos com concomitante educação da população a respeito de sua importância.

- Estabelecer normas governamentais para reduzir o conteúdo de sódio e gorduras saturadas dos alimentos industrializados.

- Implementar políticas de conscientização da importância da atividade física para a saúde.

- Implementar programas nacional, estaduais e municipais de incentivo à prática de atividades físicas, ampliando experiências bem-sucedidas, como o programa Agita São Paulo ${ }^{295}$.

\section{Atividades comunitárias}

- Apoiar a mobilização social e a intervenção na comunidade voltadas à prevenção integrada dos fatores de risco para hipertensão arterial.

- Identificar líderes, grupos organizados e instituições para a formação de coalizões e alianças estratégicas.

- Capacitar grupos estratégicos da comunidade em questões que tratam de gerenciamento de projetos e prevenção dos fatores de risco para hipertensão arterial.

- Promover campanhas temáticas periódicas, como Dia Municipal, Estadual e/ou Nacional de prevenção à hipertensão arterial.

- Incentivar a formação de grupos comunitários para a prática de atividades físicas coletivas em locais públicos e privados.

Serviços de atenção à saúde

- Estruturar o sistema de saúde, garantindo e facilitando o acesso, objetivando o enfoque no cuidado contínuo e promoção de hábitos saudáveis de vida.

- Implementar práticas assistenciais que permitam a participação e o diálogo entre profissionais, usuários, familiares e gestores.

- Treinar e dar apoio técnico aos profissionais envolvidos sobre o planejamento comunitário e a implementação de programas.

- Capacitar e desenvolver recursos humanos, formando profissionais de saúde habilitados e capacitados para aplicar as medidas preventivas da hipertensão arterial.

- Fazer a interface entre os setores educacionais da sua área de abrangência (escolas de $1^{\circ}$ e $2^{\circ}$ grau, profissionalizantes e universidades).

- Formar parcerias com centros acadêmicos para fortalecer o componente de avaliação e ampliar a participação em pesquisas.

- Estimular a colaboração entre serviços públicos de saúde e de esportes (atividade física), visando um atendimento à comunidade mais integral para a adoção de um estilo de vida ativo. 
1. Lewington S, Clarke R, Qizilbash N, Peto R, Collins R, for the Prospective Studies Collaboration. Age-specific relevance of usual blood pressure to vascular mortality: a meta-analysis of individual data for one million adults in 61 prospective studies. Lancet 2002;360:1903-13.

2. Lotufo PA. Stroke in Brazil: a neglected disease. Sao Paulo Med J 2005; 123(1):3-4.

3. Ministério da Saúde. URL:http://www.datasus.gov. Acessado em 28 de janeiro de 2006

4. The Seventh Report of the Joint National Committee on Prevention, Detection, Evaluation, and Treatment of High Blood Pressure. The JNC 7 Report. JAMA 2003;289(19):2560-72.

5. IV Brazilian Guidelines in Arterial Hypertension. Arq Bras Cardiol 2004; 82(suppl 4):7-22.

6. Gus I, Harzheim E, Zaslavsky C, Medina C, Gus M. Prevalence, Awareness, and Control of Systemic Arterial Hypertension in the State of Rio Grande do Sul. Arq Bras Cardiol 2004;83(5):429-33.

7. Matos AC, Ladeia AM. Assessment of Cardiovascular Risk Factors in a Rural Community in the Brazilian State of Bahia. Arq Bras Cardiol 2003;81(3):297-302

8. Vasan RS, Larson MG, Leip EP, Kannel WB, Levy D. Assessment of frequency of progression to hypertension in non-hypertensive participants in the Framingham Heart Study: a cohort study. Lancet 2001;358:1682-86.

9. Franklin SS, Pio JR, Wong ND, Larson MG, Leip EP, Vasan RS, Levy D. Predictors of new-onset diastolic and systolic hypertension: the Framingham Heart Study. Circulation 2005;111:1121-27.

10. Firmo JOA, Barreto SM, Lima-Costa MF. The Bambui Health and Aging Study (BHAS): factors associated with the treatment of hypertension in older adults in the community. Cad. Saúde Pública 2003;19:817-27.

11. Kearney PM, Whelton M, Reynolds K, Muntner P, Whelton PK, He J. Global burden of hypertension: analysis of worldwide data. Lancet 2005;365:217-23.

12. Lessa I. Epidemiologia Insuficiência Cardíaca e da Hipertensão Arterial Sistêmica no Brasil. Rev Bras de Hipertensão 2001;8:383-392.

13. Drummond M, Barros MBA. Social Inequalities in Adult Mortality in Sao Paulo city. Rev Bras Epidemiol 1999;2(1/2):34-49.

14. The effects of nonpharmacologic interventions on blood pressure of persons with high normal levels. Results of the Trials of Hypertension Prevention, Phase I. Jama 1992;267:1213-20.

15. Mancilha-Carvalho Jde J.,Souza E Silva N. A. The Yanomami Indians in the INTERSALT Study. Arq Bras Cardiol 2003;80:289-300.

16. World Health Organization. Obesity. Preventing and managing the global epidemic. WHO/NUT/NCD 98.1. Genebra, jun 1997.

17. Niskanen L, Laaksonen DE, Nyyssonen K, Punnonen K, Valkonen VP, Fuentes R, Tuomainen TP, Salonen R, Salonen JT. Inflammation, Abdominal Obesity, and Smoking as Predictors of Hipertensión. Hypertension 2004;44:859-865.

18. Carneiro G, Faria AN, Ribeiro Filho FF, Guimaraes A, Lerario D, Ferreira SR, Zanella MT. Influência da distribuição da gordura corporal sobre a prevalência de hipertensão arterial e outros fatores de risco cardiovascular em indivíduos obesos. Rev Assoc Med Bras 2003; 49(3):306-311.

19. de Simone G, Devereux RB, Chinali M, Roman MJ, Best LG, Welty TK, Lee ET, Howard BV; Strong Heart Study Investigators. Risk factors for arterial hypertension in adults with initial optimal blood pressure: the Strong Heart Study. Hypertension 2006;47(2):162-7. Epub 2005 Dec 27.

20. Neter JE, Stam BE, Kok FJ, Grobbee DE, and Geleijnse JM. Influence of weight reduction on blood pressure: a meta-analysis of randomized controlled trials. Hypertension 2003;42:878-84.

21. Stranges S, Wu T, Dorn JM, Freudenheim JL, Muti P, Farinaro E, Russel M, Nochajski TH, Trevisan M. Relationship of alcohol drinking pattern to risk of hypertension: a population-based study. Hypertension 2004;44:813-19.

22. Xin X, He J, Frontini MG, Ogden LG, Motsamai OI, Whelton PK. Effects of Alcohol Reduction on Blood Pressure: A Meta-Analysis of Randomized Controlled Trials. Hypertension 2001;38:1112-17.

23. Paffenbarger RS Jr, Jung DL, Leung RW, Hyde RT. Physical activity and hypertension: an epidemiological view. Ann Med 1991;23:319-327.

24. Fagard RH. Physical activity, physical fitness and the incidence of hypertension. J Hypertens 2005;23:265-7.

25. Whelton SP, Chin A, Xin X, He J. Effect of aerobic exercise on blood pressure: a meta-analysis of randomized, controlled trials. Ann Intern Med 2002:136:493-503.

26. Cornelissen VA, Fagard RH. Effect of resistance training on resting blood pressure: a meta-analysis of randomized controlled trials. J Hypertens $2005 ; 23: 251-59$

27. Wilson PW, Kannel WB, Silbershatz H,D'agostino RB. Clustering of metabolic factors and coronary heart disease. Arch Intern Med 1999;159:1104-9.

28. Knuiman MW, Divitini ML, Welborn TA,Bartholomew HC. Familial correlations, cohabitation effects, and heritability for cardiovascular risk factors. Ann Epidemiol 1996;6:188-94.

29. Vanhala MJ, Pitkajarvi TK, Kumpusalo EA,Takala JK Obesity type and clustering of insulin resistance-associated cardiovascular risk factors in middle-aged men and women. Int J Obes Relat Metab Disord 1998;22:369-74.

30. Perloff D, Grim C, Flack J, Frohlich ED, Hill M, McDonald M, Morgenstern BZ. Human blood pressure determination by sphygmomanometry. Circulation $1993 \cdot 88: 2460-2470$

31. Petrie JC, O'Brien ET, Littler WA, de Swiet M. Recommendations on blood pressure measurement. Br Med J 1986;293:611-615.

32. O'Brien E. Will mercury manometers soon be obsolete? J Human Hypertens 1995;9:933-934

33. Mion Jr D, Pierin AMG. How accurate are sphygmomanometers? Journal of Human Hypertension 1998;12:245-248.

34. O'Brien E, Waeber B, Parati G, Staessen J, Myers MG. Blood pressure measuring devices: recommendations of the European Society of Hypertension. BMJ 2001;322:531-536.

35. O'Brien E, Petrie J, Littler W, de Swiet M, Padfield PL, O'Malley K, Jamieson M, Altman D, Bland M, Atkins N. The British Hypertension Society protocol for the evaluation of automated and semi-automated blood pressure measuring devices with special reference to ambulatory systems. J Hypertens 1990:8:607-619.

36. White WB, Berson AS, Robbins C, Jamieson MJ, Prisant LM, Roccella E, Sheps SG. National Standard for measurement of resting and ambulatory blood pressures with Automated Sphygmomanometers. Hypertension 1993:21:504-509.

37. Pickering TG, Hall JE, Lawrence JÁ, Falkner BE, Graves J, Hill MN Recommendation for blood pressure measurement in humans and experimental animals. Part 1: Blood pressure measurement in humans. A statement for professionals from the subcommittee of professional and public education of the American Heart Association Council on High Blood Pressure Research. Circulation 2005;45:142-161.

38. Hemmelgarn BR, Zarnke KB, Campbell NR, Feldman RD, McKay DW McAlister FA, Khan N, Schiffrin EL, Myers MG, Bolli P, Honos G, Lebel M Levine M, Padwal R. The 2004 Canadian Hypertension Education Program 
recommendations for the management of hypertension: Part 1 - Blood pressure measurement, diagnosis and assessment of risk. Can J Cardiol 2004;20(1):31-40.

39. O'Brien E, Asmar R, Beilin L, Imai Y, Mallion JM, Mancia G, Mengden T, Myers M, Padfield P, Palatini P, Parati G, Pickering T, Redon J, Staessen J, Stergiou G, Verdecchia P. European Society of Hypertension recommendations for conventional, ambulatory and home blood pressure measurement. J Hypertens 2003;21:821-848.

40. European Society of Hypertension Working Group on Blood Pressure Monitoring. Practice guidelines of the European Society of Hypertension for clinic, ambulatory and self blood pressure measurement. J Hypertens 2005;23:697-701

41. Myers MG, Tobe SW, McKay DW, Bolli P, Hemmelgarn BR, McAlister FA, on behalf of the Canadian Hypertension Education Program. New Algorithm for the Diagnosis of Hypertension. Am J Hypertens 2005;18:1369-74.

42. Verdecchia P. Prognostic value of ambulatory blood pressure. Current evidence and clinical implications. Hypertens 2000;35:844-51.

43. Sega R, Trocino G, Lanzarotti A, Carugo S, Cesana G, Schiavina R, Valagussa F, Bombelli M, Giannattasio C, Zanchetti A, Mancia G. Alterations in cardiac structures in patients with isolated officce ambulatory or home hypertension. Data from the PAMELA study. Circulation 2001;104:1385-92.

44. Verdecchia P, Reboldi GP, Angeli F, Schillaci G, Schwartz JE, Pickering TG, Imai Y, Ohkubo T, Kario K. Short and long term incidence of stroke in whitecoat hypertension. Hypertens 2005;45:203-8.

45. Bombelli M, Sega R, Facchetti R, Corrao G, Friz HP, Vertemati AM, Sanvito R, Banfi E, Carugo S, Primitz L, Mancia G. Prevalence and clinical significance of a greater ambulatory versus office blood pressure ('reversed white coat' condition) in a general population J Hypertens 2005;23:513-520.

46. IV Diretriz para uso da monitorização ambulatorial da pressão arterial / II Diretriz para o uso da monitorização residencial da pressão arterial. Arq Bras Cardiol 2005;85(supl. II):5-18.

47. Ohkubo T, Imai Y, Tsuji I, Nagai K, Kato J, Kikuchi N, Nishiyama A, Aihara A, Sekino M, Kikuya M, Ito S, Satoh $\mathrm{H}$, Hisamichi S. Home blood pressure measurement has a stronger predictive power for mortality than does screening blood pressure measurement: a population-based observation in Ohasama , Japan. J Hypertens 1998;16:971-5.

48. Thijs L, Staessen JA, Celis H, de Gaudemaris R, Imai Y, Julius S, Fagard $R$. Reference values for self-recorded blood pressure. A meta-analysis of summary data. Arch Intern Med 1998;158:481-8.

49. Staessen JA, Thijs L, Fagard R, O'Brien ET, Clement D, de Leeuw PW, Mancia G, Nachev C, Palatini P, Parati G, Tuomilehto J, Webster J. Predicting cardiovascular risk using conventional vs ambulatory blood pressure in older patients with systolic hypertension. JAMA 1999;282:539-46.

50. Clement DL, De Buyzere ML, De Bacquer DA, de Leeuw PW, Duprez DA, Fagard RH, Gheeraert PJ, Missault LH, Braun JJ, Six RO, Van Der Niepen $\mathrm{P}, \mathrm{O}^{\prime}$ Brien E. Prognostic value of ambulatory blood-pressure recordings in patients with treated hypertension. N Engl J Med 2003;348:2407-15.

51. The fourth report on the diagnosis, evaluation, and treatment of high blood pressure in children and adolescents. National High Blood Pressure Education Program Working Group on High Blood Pressure in Children and Adolescents. Pediatrics 2004;114:555-76.

52. Sgambatti MS, Pierin A, Mion Jr D. A medida da pressão arterial no idoso. Rev Bras Hipertensão 2000;7:65-70.

53. Messerli FH, Ventura HO, Amodeo C. Osler's maneuver and pseudohypertension. N Engl J Med 1985;312:1548-51.

54. Junqueira SM. Medida da pressão arterial na gestante. Rev Bras Hipertensão 2000;7:59-64.

55. Pouliot MC, Després JP, Lemieux S Morjani S, Bouchard C, TremblayA, Nakeau A, Lupien PJ. Waist circumference and abdominal sagital diameter: best simple anthropometric indexes of abdominal visceral adipose tissues accumulation and related cardiovascular risk in men and women. Am J
Cardiol 1994;73(7):460-8

56. Beckman JA, Higgins CO, Gerhard-Herman. Automated oscillometric determination of the ankle-brachial index provides accuracy necessary for Office practice. Hypertension 2006; 47:35-8

57. Cockroft DW, Gault MH. Prediction of creatinine clearance from serum creatinine. Nephron 1976;16(1):31-41.

58. Volpe $\mathrm{M}$, Consentino F, Ruilope LM. Is it to measure microalbuminuria in hypertension. J Hypertens 2003;21:1213-20.

59. Palaniappan L, Carnethon M, Fortmann SP. Association between microalbuminuria and the metabolic syndrome: NHANES III. Am J Hypertens 2003,16:952-8.

60. Ruilope LM, van Veldhuisen DJ, Ritz E, Luscher TF. Renal function: the cinderella of cardiovascular risk profile. J. Am Coll Cardiol 2001;38:1782-7.

61. Martinez MA, Sancho T, Armada E, Rubio JM, Anton IL, Torre A, Palau J, Seguido P, Gallo J, Saenz I, Polo E, Torres R, Oliver J, Puig JG. Prevalence of left ventricular hypertrophy in patients with mild hypertension in primary care: impact of echocardiography on cardiovascular risk stratification. Am J Hypertens 2003;16:556-63.

62. Yeh ET. High-sensitivity C-reactive protein as a risk assessment tool for cardiovascular disease. Clin Cardiol 2005;28 (9):408-12.

63. King DE, Egan BM, Mainous AG 3rd, Geesey ME. Elevation of C-reactive protein in people with prehypertension. J Clin Hypertens 2004;6(10):562-8.

64. Vasan RS, Larson MG, Leip EP, Evan JC, O'Donnell CJ, Kanel WB, Levy D. Imoact of high-normal blood pressure on the risk of cardiovascular disease. N Engl J Med 2001; 345(18):1291-7

65. Kshisagar AV, Carpenter M, Bang H, Wyatt SB, Colindres RE. Blood pressure usually considered normal is associated with an elevated risk of cardiovascular disease. Am J Med 2006;119:133-141.

66. Cole KD, Waite MS, Nichols LO. Organizational structure, team process, and future directions of interprofessional health care teams. Gerontol Geriatri Educ 2003,24(2):35-92.

67. Ciampone MHT, Peduzzi M. Trabalho em equipe e trabalho em grupo no Programa de Saúde da Família. Rev Bras Enferm 2000;53(supl):143-7.

68. Hall P \& Weaver L. Interdisciplinary education and teamwork: a long and winding road. Medical Education 2001;35:867-875

69. Peduzzi, M. Equipe multiprofissional de saúde: conceito e tipologia. Revista de Saúde Pública, São Paulo 2001; 35(1):103-109.

70. Jardim PCBV. A Relação Médico-Paciente-Equipe de Saúde. In Rodrigues Branco RFG a Relação com o Paciente. Teoria, Ensino e Prática. Rio de Janeiro: Ed. Guanabara Koogan, 1a Ed. 2003, p. 253-256.

71. Teamworking in Primary Healthcare - Shared aims in patient care Forum on Teamworking in Primary Healthcare. Joint initiative of the Royal Pharmaceutical Society, the British Medical Association, the Royal College of Nursing, the National Pharmaceutical Association and the Royal College of General Practitioners. Final Report, October 2000, 50 p.

72. Boulware E, Daumit GL, Frick KD, Minkovitz CS, Lawrence RS, Powe NR. An Evidence-Based Review of Patient-Centered Behavioral Interventions for Hypertension, Am J Prev Med 2001;21(3):221-32.

73. Júnior AJC, Labbadia EM. Hipertensão arterial e atendimento multiprofissional. Sociedade Brasileira de Clínica Médica - Regional São Paulo (matéria do site http://www.brasilmedicina.com/especial/clinicam_ t1s1.asp).

74. Jardim PCV, Sousa ALL, Monego ET. Atendimento multiprofissional ao paciente hipertenso. Rev Medicina Ribeirão Preto, 1996; 29(2/3): 232-8.

75. Giorgi DMA. Estratégias especiais para melhoria da adesão/Equipes multiprofissionais e o papel da pré e da pósconsultas, Adesão ao tratamento: o grande desafio da hipertensão, Nobre F, Pierin A, Mion Jr D. São Paulo: Lemos Editorial, pg 71, 2001.

76. Grueninger UJ. Arterial hypertension: lessons from patient education. Patient 
Education and Counseling 1995;26:37-55.

77. Grueninger UJ, Goldstein MG, Duffy FD. Patient Education in Hypertension: five essential steps. J Hypertens 1989;7(suppl. 3):S93-S98,

78. Miller NH, Hill M, Kottke T, Ockene IS. The Multilevel Compliance Challenge: Recommendations for a Call to Action. A Statment for Healthcare Professionals. Circulation 1997;95:1085-90.

79. World Health Organization - International Society of Hypertension Guidelines for the Management of Hypertension J Hypertens 1999;17:15183.

80. Scholes J \& Vaughan B. Cross-boundary working: implications for the multiprofessional team. J Clin Nurs 2002;11(3):399-408.

81. Ketola E, Sipilä R, Mäkelä M, Klockars M. Quality improvement programme for cardiovascular disease risk factor recording in primary care. Quality in Health Care 2000;9:175-180

82. Gleichmann SI, Gleichmann UM, Mannebach HJ, Mellwig KP, Philippi $\mathrm{HH}$. Educating Nurses in Blood Pressure Measurement and Hypertension Control. J Hypertens 1989;7(suppl. 3):S99-S102.

83. Sousa ALL, Jardim PCBV. A Enfermagem e o Paciente Hipertenso em uma Abordagem Multiprofissional. Rev Latino-Americana de Enfermagem 1994;2:5-7.

84. Peduzzi M, Anselmi ML. O Auxiliar e o Técnico de Enfermagem: categorias profissionais diferentes e trabalhos equivalentes. Revista Brasileira de Enfermagem, Brasília-DF 2004;57(4):425-429.

85. Kvarnström S, Cedersund E. Discursive patterns in multiprofessional healthcare teams. J. of Advanced Nursing 2006;53(2):244.

86. Dell'Acqua MC, Pessuto J. Bocchi SC, dos Anjos RC. Communication between the patient care team and patient with hypertension. Rev Lat Am Enfermagem 1997;5(3):43-88.

87. Labrunie MCL, Mattos MSR, Braga JCF, Labrunie A. Controle dietoterápico ambulatorial. Rev Soc Cardiol Estado de São Paulo 1997;7(4):465-74.

88. Thomas JA. Drug - nutrient interaction. Nutr Rev 1995;53(10):271-82.

89. Feldman EB. Role of nutrition in primary care. Nutrition 2000;16(78):649-51.

90. Monego ET, Maggi C Gastronomia na promoção da saúde dos pacientes hipertensos. Rev. Bras. Hipertens 2004;11:105-8.

91. Lipp MN, Alcino AB, Bignotto MM, Malagris LN. O treino de controle de stress para hipertensos. Estudos de Psicologia, 1998;15(3):59-66.

92. Lipp MN, Anderson DE. Cardiovascular Reactivity to Simulated Social Stress. Stress Medicine 15:249-57.

93. Lima AS, Zanetti ML, Miyar LO, Machado MPS. Fatores facilitadores / dificultadores para a implementação de um programa educativo por equipe multidisciplinar. Arq Bras Endocrin e Metabol 2003;47(5):568-578.

94. Marcus BH, Dubbert PM, Forsyth L, McKenzie TL, Dunn A, Blair SN. Physical Activity Behavior Change: Issues in Adoption and Maintenance. Health Psychology 2000;19(1):32-41.

95. Gleichmann UM, Philippi HH, Gleichmann SI, Laun R, Mellwing KP, Frohnapfel F, Liebermann A. Group Exercise Improves Patients Compliance in Mild to Moderate Hypertension. J Hypertens 1989;7(suppl.3):S77-80.

96. Erikson SR, Slaughter R, Halapy H. Pharmacists' Ability to Influence Outcomes of Hypertension Therapy Pharmacotherapy 1997;7(1):140-7.

97. Westphal MF, Bogus CM, Faria MM. Grupos Focais: Experiências Precursoras em Programas Educativos em Saúde no Brasil. Bol Sanit Panam 1996:120(6):472-81.

98. Wildman RP, Gu D, Muntner P, Huang G, Chen J, Duan X, He J. Alcohol intake hypertension subtypes in Chinese man J Hypertens 2005;23:737-743.

99. Ross R, Janssen I, Dawson J, Kungl AM, Kuk JL, Wong SL, Nguyen-Duy TB, Lee S, Kilpatrick K, Hudson R. Exercise-induced reduction in obesity and insulin resistance in women: a randomized controlled trial. Obes Res 2004:12(5):789-798

100. Katzmarzyk PT, Church TS, Blair SN. Cardiorrespiratory fitness attenuates the effects of the metabolic syndrome on all-cause and cardiovascular disease mortality in men. Arch Intern Med 2004;164:1092-1097.

101. Organização Pan-Americana de Saúde/Organização Mundial de Saúde. Doenças crônico-degenerativas e obesidade: Estratégia mundial sobre alimentação saudável, atividade física e saúde. Brasília, 2003. (http://www. who.int/hpr/gs.facts.shtml).

102. Appel LJ, Brands MW, Daniels SR, Karanja N, Elmer PJ, Sacks FM. Dietary Approaches to Prevent and Treat Hypertension: A Scientific Statement From the American Heart Association. Hypertension 2006;47:296-308.

103. Millen BE, Quatromoni PA, Copenhafer DL, Demissie S, O'Horo CE, D'Agostino RB. Validation of a dietary pattern approach for evaluating nutritional risk: the Framingham Nutrition Studies. Jr Am Diet Assoc 2001;101:187-94.

104. Waxman A. WHO global strategy on diet, physical activity and health. Food Nutr Bull. 2004:25:292-302.

105. Ministério da Saúde. Secretaria de Assistência à Saúde. Coordenação Geral da Política de Alimentação e Nutrição. Guia Alimentar para a População Brasileira, 2005. Disponível em <www.saude/alimentacaoenutricao/ documentos>.

106. Conlin PR, Erlinger TP, Bohannon A, Miller ER 3rd, Appel LJ, Svetkey LP, Moore TJ. The DASH diet enchains the blood pressure response to losartan in hypertensive patients. AJA 2003;16:337-342.

107. Appel LJ, Moore TJ, Obarzanek E, Vollmer WM, Svetkey LP, Sacks FM, Bray GA, Vogt TM, Cutler JA, Windhauser MM, Lin PH, Karanja N. A clinical trial of the effects of dietary patterns on blood pressure. N Engl J Med 1997:336:1117.

108. Sacks FM, Svetkey LP, Vollmer WM, Appel LJ, Bray GA, Harsha D, Obarzanek E, Conlin PR, Miller ER 3rd, Simons-Morton DG, Karanja N, Lin PH. Effects on blood pressure of reduced dietary sodium and the Dietary Approaches to Stop Hypertension (DASH) diet. DASH-Sodium Collaborative Research Group. N Engl J Med 2001;344:3-10.

109. Margetts BM, Beilin LV, Vandongen R, Armstrong BK. Vegetarian diet in mild hypertension: a randomized controlled trial. Br Med J 1986; 293: 1468

110. Whelton SP, Hyre AD, Pedersen B, Yi Y, Whelton PK, He J. Effect of dietary fiber intake on blood pressure: a meta-analysis of randomised control led trials. J Hypertens 2005;23:475.

111. Whelton PK, He J, Cutler JÁ, Brancati FL, Appel LJ, Follmann D, Klag MJ. Effects of oral potassium on blood pressure. Meta-analysis of randomized controlled clinical trials. J Am Med Assoc 1997; 277(20):1624-32.

112. He FJ, Markandu ND, Coltart R, Barron J, MacGregor GA. Effect of shortterm supplementation of potassium chloride and potassium citrate on blood pressure in hypertensives. Hypertension 2005;45:571.

113. Moore TJ, Vollmer WM, Appel LI, Sacks FM, Svetkey LP, Vogt TM, Conlin PR, Simons-Morton DG, Carter-Edwards L, Harsha DW. Effect of dietary patterns on ambulatory blood pressure. Results from the Dietary Approaches to Stop Hypertension (DASH) Trial. Hypertension 1999;34:472-77.

114. Griffith LE, Guyatt GH, Cook RJ, Bucher HC, Cook DJ. The influence of dietary and nondietary calcium supplementation on glood pressure. Am J Hypertens 1999;12:84

115.Curhan GC, Willett WC, Speizer FE, Spiegelman D, Stampfer MJ. Comparison of dietary calcium with supplemental calcium and other nutrients as factors affecting the risk for kidney stones in women. Ann Intern Med 1997:126:497.

116.Jones DW. Dietary sodium and blood pressure. Hypertension 2004; 43:932.

117. He F, MacGregor G. Effect of longer-term modest salt reduction on blood pressure. Cochrane Database Syst Rev 2004;3:CD004937. 
118. Chobanian AV, Hill M. National Heart, Lung, and Blood Institute Workshop on Sodium and Blood Pressure: A critical review of curret scientific evidence. Hypertension 2000;35:858-63.

119. Jula AM, Karanko HM. Effects on left ventricular hyperthrophy on long-term non pharmacological treatment with sodium restriction in mild-to-moderate essential hypertension. Circulation 1994;89:1023.

120. He FJ, Markandu ND, Mac Gregor A. Modest Salt Reduction Lowers Blood Pressure in Isolated Systolic Hypertension and Combined Hypertension. Hypertension 2005;46:66-70

121. Whelton PK, Appel LJ, Espeland MA, Applegate WB, Ettinger WH Jr, Kostis JB, Kumanyika S, Lacy CR, Johnson KC, Folmar S, Cutler JA. Sodium reduction and weight loss in the treatment of hypertension in older people: a randomized controlled trial of nonpharmacologic interventions in the elderly (TONE). TONE Collaborative Research Group. JAMA 1998;279:839-46.

122. US Department of Health and Human Services, National Institutes of Health, National Heart, Lung and Blood Institute. Complete Report: The Seventh Report of the Joint National Committee on Prevention, Detection, Evaluation, and Treatment of High Blood Pressure. August, 2004.

123. Mattes RD, Donnelly D. Relative contributions of dietary sodium sources. J Am Coll Nutr 1991:10:383-93.

124. Whelton SP, Chin A, Xin X, HeJ. Effects of aerobic exercise on blood pressure: A meta-analysis of randomized controlled trials. Ann/intern Med 2002;136 493-503.

125. Kelley GA, Kelley KS. Progressive resistance exercise and resting blood pressure: A meta-analysis of randomized controlled trials. Hypertension, 2000; 35: 838-43.

126. Pescatello LS, Franklin BA, Fagard R, Farquhar WB, Kelley GA, Ray CA. American College os Sports Medicine position stand. Exercise and hypertension. Med Sci Sports Exerc 2004;36(3):533-553.

127. Cornelissen VA, Fagard RH. Effects of endurance training on blood pressure, blood pressure-regulating mechanisms, and cardiovascular risk factors. Hypertension 2005;46:667-75.

128. Myers J, Prakash M, Froelicher V, Do D, Partington S, Atwood JE. Exercise capacity and mortality among men referred for exercise testing. N Engl J Med 2002;346(11):793-801.

129. Woo KS, Chool P, Yu CW, Sung RY, Qiao M, Leung SS, Lam CW, Metreweli C, Celermajer DS. Effects of diet and exercise on obesity-related vascular dysfunction in children. Circulation 2004;109(16):1981-1986.

130. Dunn AL, Marcus BH, KampertJB, Garcia ME, Kohl HW, Blair SN. Comparison of lifestyle and structured interventions to increase physical activity and cardiorespiratory fitness: a ransomized trial. JAMA 1999;281:327-34.

131. Padilla J, Wallace JP, Parks S. Accumulation of physical activity reduces blood pressure in pre- and hypertension. MSSE 2005,37:1264-75.

132. Carvalho T, Cortez AA, Ferraz A, Nóbrega ACL, Brunetto AF, Herdy AH, Hossri CAC, Neder CA, Negrão CE, Araújo CGS, Brito FS, Drummond FA Roselino F, Nogueira GA, Umeda ILK, Oliveira Filho JA, Teixeira JAC, Lazzoli JK, Mastrocolla LE, Benetti M, Leitão MB, Zager M, Alves MJNN, Grinberg M, Godoy M, Silva OB, Stein R, Costa RV, Meneghelo RS, Moraes RS, Serra SM, Ramos S. Reabilitação cardiopulmonar e metabólica: aspectos práticos e responsabilidades. Arq Bras Cardiol 2006;83(5):448-452.

133. Reaven G, Tsao PS. Insulin resistance and compensatory hyperinsulinemia: the key player between cigarrette smoking and cardiovascular disease? J Am Coll Cardiol 2003;41:1044-1047.

134. Janzon E, Hedblad B, Berglund G, Engström G. Changes in body weight following smoking cessation in women. J Intern Med 2004;255:266-272.

135. Lipp MEN. Blood pressure reactivity to social stress in an experimental situation. Revista de Ciências Médicas 2005;14(4):317-326 (B).

136. Unger T, Parati G. Acute stress and long lasting blood pressure elevation: a possible cause of established hypertension? J Hypertension 200;23:261263 (B).
137. Touyz RM, Campbell N, Logan A, Gledhil N, Petrella R, Padwal R. Canadian Hypertension Education Program. The 2004 Canadian recommendations for the management of hypertension: Part III-Lifestyle modifications to preventa nd control hypertension. Can J Cardiol 2004;20(1):55-59 (C).

138. Kannel WB. Blood pressure as a cardiovascular risk factor: prevention and treatment. JAMA 1996;273:1571-6.

139. Padwal R, Straus SE, McAlister FA. Cardiovascular risk factors and their impact on decision to treat hypertension:an evidence-based review. BMJ 2001;322:977-80.

140. Psaty BM, Smith NL, Siscovick DS, Koepsell TD, Weiss NS, Heckbert SR, Lemaitre RN, Wagner EH, Furberg CD. Health outcomes associated with antihpertensive therapies used as firstline agents. A systematic review and meta-analysis. JAMA 1977;277:739-45.

141. Wright JM, Lee C-H, Chamber GK. Systematic review of antihypertensive therapies: does the evidence assist in choosing a first-line drug. CMAJ 1999;161:25-32.

142. SHEP-Cooperative Research Group. Prevention of stroke by antihypertensive drug treatment in older persons with isolated systolic hypertension: final results of the Systolic Hypertension in the Elderly Program (SHEP). JAMA 1991;265:3255-64.

143. Medical Research Council Working Party. MRC trial of treatment of hypertension: rincipal results. BMJ 1985;291:97-104.

144. UK Prospective Diabetes Study Group. Efficacy of atenolol and captopril in reducing risk of macrovascular and microvascular complications in type 2 diabetes. UKPDS 39. BMJ 1998;317:713-20.

145. Neal B, MacMahon S, Chapman N, for the Blood Pressure Lowering Treatment Trialists'Collaboration. Effects of ACE inhibitors, calcium antagonists, and other blood-pressure-lowering drugs: results of prospectively designed overviews of randomised trials. Lancet 2000;355:1955-1964.

146. Hansson L, Lindholm LH, Niskanen L, Lanke J, Hedner T, Niklason A, Luomanmaki K, Dahlof B, de Faire U, Morlin C, Karlberg BE, Wester PO, Bjorck JE. Effect of angiotensin converting enzyme inhibition compared with conventional therapy on cardiovascular morbidity and mortality on hypertension: the Captopril Prevention Project (CAPPP) randomized trial. Lancet 1999;353:611-6.

147. Yusuf S; Sleight P; Pogue J; Bosch J; Davies R; Dagenais G. Effects of an angiotensin-converting-enzyme inhibitor, ramipril, on cardiovascular events in high-risk patients. The Heart Outcomes Prevention Evaluation Study Investigators. N Engl J Med 2000;342(3):145-53.

148. PROGRESS Collaborative Group. Randomized Trial of a perindopril-basedblood pressure-lowering regimen among 6,105 individuals with previous stroke or transient ischaemic attack. Lancet, 2001;35:1033-41.

149. Hansson L, Lindholm LH, Ekbom T, Dahlof B, Lanke J, Schersten B, Wester PO, Hedner T, de Faire U. Randomized trial of old and new antihypertensive drugs in elderly patients: cardiovascular mortality and morbidity. The Swedish Trial in Old Patients with Hypertension-2 study. Lancet 1999;34:1129-33.

150. Dahlof B, Devereux RB, Kjeldsen SE, Julius S, Beevers G, de Faire U, Fyhrquist F, Ibsen H, Kristiansson K, Lederballe-Pedersen O, Lindholm LH, Nieminen MS, Omvik P, Oparil S, Wedel H. Cardiovascular morbidity and mortality in the losartan intervention or endpoint reduction in hypertension study (LIFE): a randomized trial against atenolol. Lancet 2002,359:995-1003.

151. Lindholm LH, Ibsen H, Dahlof B, Devereux RB, Beevers G, de Faire U, Fyhrquist F, Julius S, Kjeldsen SE, Kristiansson K, Lederballe-Pedersen O, Nieminen MS, Omvik P, Oparil S, Wedel H, Aurup P, Edelman J, Snapinn S. Cardiovascular morbidity and mortality in patients with diabetes in the Losartan Intervention For Endpoint reduction in hypertension study (LIFE): a randomized trial against atenolol. Lancet 2002;359:1004-10.

152. Stassen JÁ, Fagard R, Thijs L. Randomized double-blind comparison of placebo and active treatment for older patients with isolated systolic hypertension. The Systolic hypertension in Europe (SYST-EUR). Lancet 1997;350:757-64. 
153. Brown MJ, Palmer CR, Castaigne A, de Leeuw PW, Mancia G, Rosenthal T, Ruilope LM. Morbidity and mortality in patients randomized to doubleblind treatment with long-acting calcium-channel blocker or diuretic in the International Nifedipine GITS study: Intervention as a Goal in Hypertension Treatment (INSIGHT). Lancet 2000;356:366-72.

154. Hansson L, Hedner T, Lund-Johansen P, Kjeldsen SE, Lindholm LH, Syvertsen JO, Lanke J, de Faire U, Dahlof B, Karlberg BE. Randomized trial of effects of calcium antagonists compared with diuretics and alpha-blockers on cardiovascular morbidity and mortality in hypertension: the Nordic Diltiazen (NORDIL) study. Lancet 2000;356:359-65.

155. Sykowsky PA, D'Agostino RB, Belanger AJ, Kannel WB. Secular Trends in Long Term Sustained Hypertension, Long Term Treatment and Cardiovascular Morbidity. The Framingham Heart Study 1950 to 1990. Circulation 1996;93:697-703

156. UK Prospective Diabetes Study Group. Tight blood pressure control and the risk of macrovascular and microvascular complications in type diabetes. UKPDS 38. BMJ 1998:317:703-13.

157. Hansson L, Zanchetti A, Carruthers SG, Dahlof B, Elmfeldt D, Julius S, Menard J, Rahn KH, Wedel H, Westerling S. Effects of intensive bloodpressure lowering and low-dose aspirin in patients with hypertension: principal results of the Hypertension Optimal Treatment (HOT) randomized trial. Lancet 1998;351:1755-62.

158. Lewis EJ, Hunsicker LG, Clarke WR. Renoprotective effect of the angiotensin receptor antagonist irbesartan in patients with nephropathy due to type 2 diabetes. N Eng J Med 2001;345:851-60.

159. Brenner BM, Cooper ME, Zeeuw D. Effects of losartan on renal and cardiovascular outcomes in patients with type 2 diabetes and nephropathy N Engl J Med 2001;345:861-9.

160. Peterson JC, Adler S, Burkart JM, Greene T, Hebert LA, Hunsicker LG, King AJ, Klahr S, Massry SG, Seifter JL. Blood pressure control, proteinuria, and the progression of renal disease. The modification of Diet in Renal Disease Study (MDRD) Ann Intern Med 1995;123:754-62.

161. Krumholz HM, Parent EM, Tu N, Vaccarino V, Wang Y, Radford MJ, Hennen J. Readmission after hospitalization for congestive heart failure among Medicare beneficiares. Arch Intern Med 1997;157(1):99-104.

162. Du X, Cruickshank K, McNamee R, Saraee M, Sourbutts J, Summers A, Roberts N, Walton E, Holmes S. Case-Control of stroke and quality of hypertension control in north west England. BMJ 1997;341:272-6.

163. Turnbull F, Neal B, Algert C, Chalmers J, Chapman N, Cutler J, Woodward M, MacMahon S; Blood Pressure Lowering Treatment Trialists' Collaboration. Effects of different blood pressure-lowering regimens on major cardiovascular events in individuals with and without diabetes mellitus: results of prospectively designed overviews of randomized trials. Arch Intern Med 2005;165:1410-9

164. Calberg B ,Samyuelson O, Lindholm LH. Atenolol in hypertension: is it a wise choice? Lancet 2004;364:1684-89.

165. Lindholm LH, Calberg B, Samyuelson O. Should $\square$ blocker remain a first choice in the treatment of primary hypertension? A meta-analysis. Lancet 2005;366:1545-53.

166. Dahlof B, Sever PS, Poulter NR, Wedel H, Beevers DG, Caulfield M, Collins R, Kjeldsen SE, Kristinsson A, McInnes GT, Mehlsen J, Nieminen M, O'Brien E, Ostergren J; ASCOT Investigators. Prevention of cardiovascular events with an antihypertensive regimen of amlodipine adding perindopril as required versus atenolol adding bendroflumethiazide as required, in the Anglo-Scandinavian Cardiac Outcomes Trial-Blood Pressure Lowering Arm (ASCOT-BPLA): a multicentre randomised controlled trial. Lancet 2005;366:895-906

167. The ALLHAT Officers and Coordinators for the ALLHAT Collaborative Reserach Group. Major cardiovascular events in hypertensive patients randomized to doxazosin vs chlorthalidone. The Antihypertensive and Lipid- LoweringTreatment to prevent Heart Attack Trial (ALLHAT). JAMA 2000:283:1967-75.
168. Pahor M, Psaty BM, Alderman MH et al. Health outcomes associated with calcium antagonists compared with other first-line antihypertensive therapies: a meta-analyses of randomized controlled trials. Lancet 2000;356:1949-54.

169. Julius S, Kjeldsen SE, Weber M, Brunner HR, Ekman S, Hansson L, Hua T, Laragh J, McInnes GT, Mitchell L, Plat F, Schork A, Smith B, Zanchetti A VALUE trial group. Outcomes in hypertensive patients at high cardiovascular risk treated with regimens based on valsartan or amlodipine: the VALUE randomised trial. Lancet 2004;363(9426):2022-31.

170. Lubsen J, Wagener G, Kirwan BA, de Brouwer S, Poole-Wilson PA; ACTION (A Coronary disease Trial Investigating Outcome with Nifedipine GITS investigators. Effect of long-acting nifedipine on mortality and cardiovascular morbidity in patients with symptomatic stable angina and hypertension: the ACTION trial. J Hypertens 2005;23(3):641-8.

171. Sever PS, Dahlof B, Poulter NP, Wedel H. Anglo-Scandinavian Cardiac Outcomes Trial: Lipid Lowering Arm (ASCOT LLA) revisited: interaction of antihypertensive and lipid lowering therapy. Circulation 2005;112(Suppl II):134-134.

172. Mason PR. A rationale for combination therapy in risk factor management: a mechanistic perspective. Amer J Med 2005;118(12A),54S-61S

173. Flather MD, Yusuf S, Kober L, Pfeffer M, Hall A, Murray G, Torp-Pedersen C, Ball S, Pogue J, Moye L, Braunwald E. Long term ACE-inhibitor therapy in patients with heart failure or left ventricular dysfunction: a systematic overview of data from individual patients. Lancet 2000;355:1575-81

174. Garg R, Yussuf S. Colaborative Group on ACE-inhibitor Trials. Overview of randomized trials of angiotensin converting enzyme inhibitors on mortality and morbidity in patients with heart failure. JAMA 1995;273:1450-6.

175. Lewis EJ, Hunsicker LG, Bain RP, Rohde RD. The effect of angiotensinconverting-enzyme inhibition on diabetic nephropathy. The Collaborative Study Group. N Engl J Med 1993; 329:1456-562.

176. Gansevoort RT, Sluiter WJ, Hemmelder MH, de Zeeuw D, de Jong PE. Antiproteinuric effect of blood-pressure-lowering agents: a meta-analysis of comparative trials. Nephrol Dial Transplant 1995;10:1963-74.

177. Maschio G, Alberti D, Janin G, Locatelli F, Mann JF, Motolese M, Ponticelli C, Ritz E, Zucchelli P. Effect of the angiotensin-converting-enzyme inhibitor benazepril on the progression of chronic renal insufficiency. N Engl J Med 1996:334:939-45.

178. Giatra I, Lau J, Levey AS. Effect of angiotensin-converting enzyme inhibitors on the progression of non-diabetic renal disease: a meta-analysis of randomized trials. Ann Intern Med 1997;127:337-45.

179. Bakris GL, Weir MR. Angiotensin-converting enzyme inhibitor-associated elevations in serum creatinine: is this a cause for concern? Arch Intern Med 2000;160(5):685-93

180. Pitt B, Poole-Wilson PA, Segal R, Martinez FA, Dickstein K, Camm AJ, Konstam MA, Riegger G, Klinger GH, Neaton J, Sharma D, Thiyagarajan B. Effects of losartan compared with captopril on mortality in patients with symptomatic heart failure: randomized trial- the Losartan Heart Failure Survival Study - ELITE II. Lancet 2000;355:1582-7.

181. Cohn JN, Tognoni G on behalf of Valsartan Heart Failure Trial Investigators. A randomized trial of the angiotensinreceptor blocker valsartan in chronic heart failure. N Engl J Med 2001;345:167-75.

182. Strippoli GF, Craig M, Deeks JJ, Schena FP, Craig FC. Effects of angiotensin convert enzime inhibitors and angiotensin II receptor antagonists on mortality and renal outcomes in diabetic nephropathy: systematic review. BMJ 2004:9:329.

183. Strauss MH, Lonn EM, Verma S. Is the jury out? Class specif differences on coronary coutcomes with ACE-Inhibitors and ARBs: Insight form metaanlysis and the Blood Pressure Lowreing Treatment Trialist Clollaboration Eur Heart J 2005;26:2351-53.

184. Turnbull F. Blood pressure-independet effects for agents inhibiting the renin-angiotens system. Program and abstracts from the Fifteenth European Meeting on Hypertension, June 17-21, Milan, Italy. Plenary Session (http:// 
www.medscape.com/viewarticle/507293,2005).

185. Cheung BM, Cheung GT, Lauder IJ, Lau CP, Kumana CR. Meta-analysis of large outcome trials of angiotensin receptor blockers in hypertension. J Hum Hypertens 2006; 20:37-43.

186. Abuissa H, Jones PG, Marso SP, O'Keefe JH Jr. Angiotensin-converting enzyme inhibitors or angiotensin receptor blockers for prevention of type 2 diabetes: a meta-analysis of randomized clinical trials. J Am Coll Cardiol 2005;46:821-6.

187. Busnello RG, Melchior R, Faccin C, Vettori D, Petter J, Moreira LB, Fuchs FD. Características associadas ao abandono do acompanhamento de pacientes hipertensos atendidos em um ambulatório de referência. Arq Bras Cardiol 2001;76: 349-51.

188. Pierin AMG, Mion Jr D, Fukushima J, Pinto AR, Kaminaga M. O perfil de um grupo de pessoas hipertensas de acordo com conhecimento e gravidade da doença. Rev Esc Enf USP 2001;35:11-8.

189. Lessa I, Fonseca J. Raça, aderência ao tratamento e/ou consultas e controle da hipertensão arterial. Arq Bras Cardiol 1997;68: 443-9.

190. Strelec MAM, Pierin AMG, Mion Jr D. A influência do conhecimento sobre a doenças e atitude frente à tomada dos remédios no controle da hipertensão arterial. Arq Bras Cardiol 2003;81:349-354.

191. Gus I, Harzheim E, Zaslavsky C, Medina C, Gus M. Prevalência, reconhecimento e controle da hipertensão arterial sistêmica no Estado do Rio Grande do Sul. Arq Bras Cardiol 2004;83(5):424-428.

192. Pierin AMG, Strelec MAAM, Mion Jr. D. O desafio do controle da hipertensão arterial e a adesão ao tratamento. In: Pierin AMG. Hipertensão arterial: uma proposta para o cuidar. São Paulo: Ed. Manole; 2004. p. 275-289.

193. Cooper RS; Kaufman JS. Race and hypertension: science and nescience. Hypertension 1998;32(5):813-6.

194. Brewster LM; van Montfrans GA; Kleijnen J. Systematic review: antihypertensive drug therapy in black patients. Ann Intern Med 2004;141(8):614-27.

195. Somes GW, Pahor M, Shorr RI, Cushman WC, Applegate WB. The role of diastolic blood pressure when treating isolated systolic hypertension. Arch Int Med 1999;159:2004-2009.

196. Hansson L, Lindholm LH, Ekbom T, Dahlöf B, Lanke J, Schersten B, Wester PO, Hedner T, de Faire U. STOPHypertension-2 study group. Randomised trial of old and new antihypertensive drugs in elderly patients: cardiovascular mortality and morbidity the Swedish Trial in Old Patients with Hypertension2 study. Lancet, 2000;354:1751-6.

197. The ALLHAT Officers and Coordinators for the ALLHAT Collaborative Research Group. Major outcomes in high-risk hypertensive patients randomized to angiotensin-converting enzyme inhibitor or calcium channel blocker vs diuretic: The Antihypertensive and Lipid-Lowering treatment to prevent Heart Attack Trial (ALLHAT). JAMA 2002;288:2981-2997.

198. Lithell H, Hansson L, Skogg I, Elmfeldt D, Hofman A, Olofsson B, et al. for the SCOPE Study Group. The Study on Cognition and Prognosis in the Elderly (SCOPE). Principal results of a randomised double-blind intervention trial. J Hypertens 2003;21;875-886.

199. Forette F; Seux ML; Staessen JA; Thijs L; Babarskiene MR; Babeanu S; Bossini A; Fagard R; Gil-Extremera B; Laks T; Kobalava Z; Sarti C; Tuomilehto J; Vanhanen H; Webster J; Yodfat Y; Birkenhager WH. The prevention of dementia with antihypertensive treatment: new evidence from the Systolic Hypertension in Europe (Syst-Eur) study. Arch Intern Med 2002;162(18):2046-52.

200. Gueyffier F, Bulpitt C, Boissel JP, Schron E, Ekbom T, Fagard R, et al. Antihypertensive drugs in very old people: a subgroup analysis of randomised controlled trials. Lancet 1999;353:793-796. (metanálise)

201. Rosa AA, Ribeiro FP. Hipertensão arterial na infância e adolescência: fatores de terminantes. J Pediat 1999;75:75-82.

202. Vessey M; Painter R; Yeates D. Mortality in relation to oral contraceptive use and cigarette smoking. Lancet 2003;362(9379):185-91.

203. Baillargeon JP; McClish DK; Essah PA; Nestler JE. Association between the Current Use of Low-Dose Oral Contraceptives and Cardiovascular Arterial Disease: A Meta-Analysis. J Clin Endocrinol Metab 2005;90(7):3863-70.

204. Rossouw JE; Anderson GL; Prentice RL; LaCroix AZ; Kooperberg C; Stefanick ML; Jackson RD; Beresford SA; Howard BV; Johnson KC; Kotchen JM; Ockene J. Risks and benefits of estrogen plus progestin in healthy postmenopausal women: principal results From the Women's Health Initiative randomized controlled trial. JAMA 2002;288(3):321-33.

205. Osório-Wender MC, Vitola D, Spritzer PM. Percutaneous17beta-estradiol replacement therapy in hypertensive postmenopausal women. Braz J Med Biol Res, 1998;30:1047-53.

206. Hulley S; Grady D; Bush T; Furberg C; Herrington D; Riggs B; Vittinghoff E. Randomized trial of estrogen plus progestin for secondary prevention of coronary heart disease in postmenopausal women. Heart and Estrogen/progestin Replacement Study (HERS) Research Group. JAMA 1998;280(7):605-13.

207. Report of the National High Blood Pressure Education Program Working Group on High Blood Pressure inPregnancy. Am J Obstet Gynecol 2000;183: S1-S22.

208. Briggs GG, Freeman RK, Yaffee SJ. Drugs in pregnancyand lactation: a reference guide to fetal and neonatal risk. 5th ed. Baltimore (MD): Williams and Wilkins, 1998.

209. I Diretriz Brasileira de Diagnóstico e Tratamento da Síndrome Metabólica. Arq. Bras. Cardiol 2005; 84 (Supl. I):1-28.

210. Lazarus JM, Bourgoignie JJ, Buckalew VM, Greene T, Levey AS, Milas NC, Paranandi L, Peterson JC, Porush JG, Rauch S, Soucie JM, Stollar C. Achievement and safety of a low blood pressure goal in chronic renal disease. The Modification of Diet in Renal Disease Study Group. Hypertension 1997;29:641.

211. Gress TW, Nieto FJ, Shahar E, Wofford MR, Brancati FL. Hypertension and antihypertensive therapy as risk factors for type 2 diabetes mellitus. $\mathrm{N}$ Engl J Med 2000;342: 905-12.

212. Ruggenenti, P, Fassi, A, Ilieva, AP. Preventing microalbuminuria in type 2 diabetes. N Engl J Med 2004;51:1941.

213. Parving H-H, Lehnert H, Brochner-Mortensen J, Gomis R, Andersen S, Arner $P$. The effect of irbesartan on the development of diabetic nephropathy in patients with Type 2 diabetes. N Engl J Med 2001;345:870-8 (A).

214. Atkins RC, Briganti EM, Lewis JB, Hunsicker LG, Braden G, Champion de Crespigny PJ, DeFerrari G, Drury P, Locatelli F, Wiegmann TB, Lewis EJ. Proteinuria reduction and progression to renal failure in patients with type 2 diabetes mellitus and overt nephropathy. Am J Kidney Dis. 2005;45:2817 .

215. de Zeeuw D, Remuzzi G, Parving HH, Keane WF, Zhang Z, Shahinfar S, Snapinn S, Cooper ME, Mitch WE, Brenner BM. Proteinuria, a target for renoprotection in patients with type 2 diabetic nephropathy: lessons from RENAAL. Kidney Int 2004;65:2309-20.

216. Baigent C, Keech A, Kearney PM, Blackwell L, Buck G, Pollicino C, Kirby A, Sourjina T, Peto R, Collins R, Simes R; Cholesterol Treatment Trialists' (CTT) Collaborators. Efficacy and safety of cholesterol-lowering treatment: prospective meta-analysis of data from 90,056 participants in 14 randomised trials of statins. Lancet 2005;366:1267-78.

217. III Diretrizes Brasileiras sobre dislipidemias e diretriz de prevenção da aterosclerose do departamento de aterosclerose da sociedade brasileira de cardiologia. Arq Bras Cardiol 2001;77(supl III):1-48.

218. Grundy SM, Cleeman JI, Merz CN, Brewer HB Jr, Clark LT, Hunninghake DB, Pasternak RC, Smith SC Jr, Stone NJ. NCEP Report: Implications of Recent Clinical Trials for the National Cholesterol Education Program Adult Treatment Panel III Guidelines. Circulation 2004;110:227-239.

219. Goldstein LB, Adams R, Becker K, Furberg CD, Gorelick PB, Hademenos G, Hill M, Howard G, Howard VJ, Jacobs B, Levine SR, Mosca L, Sacco RL, 
Sherman DG, Wolf PA, del Zoppo G). Primary prevention of ischemic stroke. A statement from the Stroke Council of the American Heart Association. Circulation 2001;103:163-182

220. Schrader I, Luders S, Kulschewski A, Hammersen F, Plate K, Berger J, Zidek W, Dominiak P, Diener HC; MOSES Study Group. Morbidity and Mortality After Stroke, Eprosartan Compared with Nitrendipine for Secondary Prevention: principal results of a prospective randomized controlled study (MOSES). Stroke 2005 36(6):1218-26.

221. Britton M, Carlsson A, de Faire U. Blood pressure course in patients with acute stroke and matched controls. Stroke 1986;17:861-864.

222. Oliveira-Filho I, Silva SC, Trabuco CC, Pedreira BB, Sousa EU, Bacellar A. Detrimental effect of blood pressure reduction in the first 24 hours of acute stroke onset. Neurology 2003;61:1047-1051.

223. Leonardi-Bee J, Bath PM, Phillips SJ, Sandercock PA. Blood pressure and clinical outcomes in the International Stroke Trial. Stroke 2002:33:13151320.

224. Toni D, Chamorro A, Kaste M, Lees K, Wahlgren NG, Hacke W. Acute treatment of ischaemic stroke. Cerebrovasc Dis 2004;17(suppl 2):30-46.

225. Mattle HP, Kappeler L, Arnold M, Fischer U, Nedeltchev K, Remonda L, Jakob SM, Schroth G. Blood pressure and vessel recanalization in the first hours after ischemic stroke. Stroke 2005;36:264-268.

226. Ohwaki K, Yano E, Nagashima H, Hirata M, Nakagomi T, Tamura A. Blood pressure management in acute intracerebral hemorrhage: relationship between elevated blood pressure and hematoma enlargement. Stroke 2004:35:1364-1367.

227. Broderick JP, Adams HP Jr, Barsan W, Feinberg W, Feldmann E, Grotta J, Kase C, Krieger D, Mayberg M, Tilley B, Zabramski JM, Zuccarello M. Guidelines for the management of spontaneous intracerebral hemorrhage: a statement for healthcare professionals from a special writing group of the Stroke Council, American Heart Association. Stroke 1999;30:905-915.

228. Baigent C, Collins R, Appleby P, Parish S, Sleight P,Peto R. ISIS-2: 10 year survival among patients with suspected acute myocardial infarction in randomisedcomparison of intravenous streptokinase, oral aspirin, both, or neither. The ISIS-2 (Second International Studyof Infarct Survival) CollaborativeGroup. BMJ, 1998;316(7141):1337-43.

229. Gibson RS, Hansen JF, Messerli F, Schechtman KB, Boden WE. Long-term effects of diltiazem and verapamil on mortality and cardiac events in non-Q-wave acute myocardial infarction without pulmonary congestion: post hoc subset analysis of the multicenter diltiazem postinfarction tria and the second danish verapamil infarction trial studies. Am J Cardiol 2000;86(3):275-9.

230. DATASUS. Morbidade Hospitalar do Sistema Único de Saúde. http://tabnet. datasus.gov.br/tabcgi.exe?sih/cnv/miuf.def. Acessado em 18 de novembro de 2005.

231. The CONSENSUS Trial Study Group. Effects of enalapril on mortality in severe congestive heartfailure. Results of the Cooperative North Scandinavian Enalapril Survival Study (CONSENSUS). N Engl J Med 1987;316(23):1429-35.

232. Pfeffer MA; McMurray JJ; Velazquez Ej; Rouleau JL; Kober L; Maggioni AP; Solomon SD; Swedberg K; Van de Werf F; White H; Leimberger JD; Henis M; Edwards S; Zelenkofske S; Sellers MA; Califf RM. Valsartan, captopril, or both in myocardial infarction complicated by heart failure, left ventricular dysfunction, or both. N Engl J Med 2003;349(20):1893-906.

233. McMurray IJ; Ostergren J; Swedberg K; Granger CB; Held P; Michelson EL; Olofsson B; Yusuf S; Pfeffer MA. Effects of candesartan in patients with chronic heart failure and reduced left-ventricular systolic function taking angiotensin-converting-enzyme inhibitors: the CHARM-Added trial. Lancet 2003;362(9386):767-71.

234. Hjalmarson A, Goldstein S, Fagerberg B, Wedel H Waagstein F, Kjekshus J, Wikstrand J. MERIT-HF Study Group. Effects of controlled-release metoprolol on total mortality, hospitalizations, and well-being in patients with heart failure. The Metoprolol CR/XL Randomized Intervention Trial in Congestive Heart Failure (MERIT-HF). JAMA, 2000;283:1295-302.
235. Leizorovicz A; Lechat P; Cucherat M; Bugnard F. Bisoprolol for the treatmen of chronic heart failure: a meta-analysis on individual data of two placebocontrolled studies--CIBIS and CIBIS II. Cardiac Insufficiency Bisoprolol Study. Am Heart J 2002;143(2):301-7.

236. A trial of the beta-blocker bucindolol in patients with advanced chronic heart failure. N Engl J Med 2001;344(22):1659-67.

237. Packer M; O'Connor CM; Ghali JK; Pressler ML; Carson PE; Belkin RN; Miller AB; Neuberg GW; Frid D; Wertheimer JH; Cropp AB; DeMets DL. Effect of amlodipine on morbidity and mortality in severe chronic heart failure. Prospective Randomized Amlodipine Survival Evaluation Study Group. N Engl J Med 1996; 335(15):1107-14.

238. Cohn JN, Ziesche S, Smith R, Anad I, Dunkman WB, Loeb H, Cintron G Boden W, Baruch L, Rochin P, Loss L. Vasodilator-Heart Failure Trial (V-HeFT) Study Group. Effect of calcium antagonist felodipine as supplementary vasodilator therapy in patients with chronic heart failure treated with enalapril: V-HeFT III. Circulation 1997;96:856-63.

239. Pitt B, Zannad F, Remme WJ, Cody R, Castaigne A, Perez A, Palensky J, Wittes J. Randomized Aldactone Evaluation Study Investigators. The effect of spironolactone on morbidity and mortality with severe heart failure. $\mathrm{N}$ Engl J Med 1999;341:709-17.

240. Pitt B; Remme W; Zannad F; Neaton J; Martinez F; Roniker B; Bittman R Hurley S; Kleiman J; Gatlin M. Eplerenone, a selective aldosterone blocker, in patients with left ventricular dysfunction after myocardial infarction. $\mathrm{N}$ Engl J Med 2003;348(14):1309-21.

241. Klingbeil AU; Schneider M; Martus P; Messerli FH; Schmieder RE. A metaanalysis of the effects of treatment on left ventricular mass in essential hypertension. Am J Med 2003;115(1):41-6.

242. Stowasser M, Gordon RD. Primary aldosteronism. Best Practice \& Research Clinical Endocrinology \& Metabolism 2003;17(4):591-605.

243. Mulatero P, Dluxhy RG, Giacchetti Getal. Diagnosis of primary aldosteronism: from screening to subtype differentiation. Trends in Endocrinology and Metabolism 2005;16(3):114-19.

244. Young WF, Stanson AW, Thompson GB, Grant CS, Farley DR, van Heerden JA. Role for adrenal venous sampling in primary aldosteronism. Surgery 2004;136(6):1227-1235.

245. Lenders JWM, Eisenhofer G, Manelli M, Pacak K. Phaeochromocytoma. Lancet 2005;366:665-75

246. Eisenhofer G, Borsntein SR, Brouwers FM et al. Endocrine-Related Cancer 2004; $11: 423-36$

247. Saito I, Kunihikol, Saruta T. Hypothyroidism as a cause of hypertension. Hypertension 1983;5:112.

248. Levey GS. Catecholamine-tyroid hormone interactions and the cardiovascular manifestations of hyperthyroidism. Am J Med 1990; 88:6.

249. Scobe JE. The epidemiology and clinical manifestations of atherosclerotic renal disease. In: Novick AC, Scoble JE, Hamilton G. eds. Renal Vascular Disease. London, UK: WB Saunders Co, Ltd. 1996:303-14

250. Uzu T, Inoue T, Fuji T, et al. Prevalence and predictors of renal artery stenosis in patients with myocardial infarction. Am J Kidney Dis 1997;29:733-8.

251. Swartbol P, Thorvinger BO, Parson $\mathrm{H}$, et al. Renal artery stenosis in patients with peripheral vascular disease and its correlation to hypertension: a retrospective study. Int Angiol 1992;11:195-9.

252. Mailloux LU, Napolitano B, Bellucci AG, et al. Renal vascular disease causing end-stage renal disease, incidence, clinical correlates, and outcomes: a 20year clinical experience. Am J Kidney Dis 1994;24:622-9.

253. Schreiber MJ, PohI MA, Novik AC. The natural history of atherosclerotic and fibrous renal artery disease. Urol Clin North Am 1984;11:383-92.

254. Safian RD, Textor SC. Renal-artery stenosis. N Engl J Med 2001;344:43142.23 .

255. Plouin PF, Chatellier G, Darne B, et al. Blood pressure outcome of 
angioplasty in atherosclerotic renal artery stenosis: a randomized trial. Essai Multicentrique Medicaments vs Angioplastie(EMMA) Study Group. Hypertension 1998;31:823-9.

256. Hollenberg NK. Medical therapy of renovascular hypertension:efficacy and safety of captopril in 269 patients. Cardiovasc Rev Repl 1983;4:852-76.

257. Mulherin Jr JL, Edwards WH. Alternative methods of renal revascularization. Ann Surg, 205:740-46, 1987.

258. Tuttle KR. Ischemic nephropathy. Curr Opin Nephrol Hypertens 2001;10:167-73

259. Pickering TG, Herman L, Devereux RB, et al. Recurrent pulmonary oedema in hypertension due to bilateral renal artery stenosis: treatment by angioplasty or surgical revascularisation. Lancet 1988;2:551-2.

260. Gray BH, Olin JW, Childs MB, et al. Clinical benefit of renal artery angioplasty with stenting for the control of recurrent and refractory congestive heart failure. Vasc Med 2002;7:275-9

261. Airoldi F, Palatresi S, Marana I, et al. Angioplasty of atherosclerotic and fibromuscular renal artery stenosis: time course and predicting factors of the effects on renal function. Am J Hypertens 2000;13:1210-7.

262. van de Ven PJ, Kaatee R, Beutler JJ, et al. Arterial stenting and balloon angioplasty in ostial atherosclerotic renovascular disease: a randomised trial. Lancet 1999;353:282-6.

263. Matthias P. Hörl et al : Hemodialysis-Associated Hypertension: Pathophysiology and Therapy. Am J Kidney Dis 39: 227-244, 2002.

264. Mazzuchi N, Carbonell E, Fernandez-Cean J. Importance of blood pressure control in hemodialysis patient survival. Kidney Int 2000;58(5):2147-54.

265. Port FK, Hulbert-Shearon TE, Wolfe RA, Bloembergen WE, Golper TA, Agodoa LYC, Young EW. Predialysis blood pressure and mortality risk in a national sample of maintenance hemodialysis patients. Am J Kidney Dis 1999;33:507-17.

266. Fagugli RM, Reboldi G, Quintaliani G, Pasini P, Ciao G, Cicconi B et al. Short daily hemodialysis: Blood pressure control and left ventricular mass reduction in Hypertensive hemodialysis patients. Am J Kidney Dis 2001;38(2):371-6

267. Ortega O, Gallar P, Carreno A, Gutierrez M, Rodriguez I, Oliet A et al. Peritoneal sodium mass removal in continuous ambulatory peritoneal dialysis and automated peritoneal dialysis: influence on blood pressure control. Am J Nephrol 2001;21(3):189-93.

268. Fernandez-Fresnedo G, Palomar R, Escallada R et al.Hypertension and longterm renal allograft survival: effect of early glomerular filtration rate. Nephro Dial Transplant, 2001;16(suppl 1):105-9.

269. Japichino GG, Bonati L, Rubini P, Capocasale E. Prevalence of atherosclerosis in renal transplant recipients. Minerva Cardioangiol 2001;49(4):229-38.

270. Quaschning T, Mainka T, Nauck M, Rump LC, Wanner C, Kramer-Guth A. Immunosuppression enhances atherogenicity of lipid profile after transplantation. Kidney Int Suppl 1999;71:S235-7.

271. Hernandez D, Lacalzada J, Salido E, Linares J, Barragem A, Lorenzo V. Regression of left ventricular hypertrophy by lisinopril after renal transplation: role of ACE gene polymorphism. Kidney Int 2000;58(2):889-97.

272. Venkat-Raman G, Feehally J, Elliott HL, Griffin P, Moore RJ, Olubodun JO, Wilkinson R. Renal and haemodynamic effects of amlodipine and nifedipine in hypertensive renal transplant recipients. Nephrol Dial Transplant 1998;13(10):2612-6.

273. Peppard PE, Young T, Palta M, Skatrud J. Prospective study of the association between sleep-disordered breathing and hypertension. N Engl J Med 2000;342:1378-1384.

274. Drager LF, Bortolotto LA, Lorenzi MC, Figueiredo AC, Krieger EM, LorenziFilho G. Early signs of atherosclerosis in obstructive sleep apnea. Am J Respir Crit Care Med 2005; 172(5):613-8.

275. Shahar E, Whitney CW, Redline S, Lee ET, Newman AB, Javier Nieto
F, O'Connor GT, Boland LL, Schwartz JE, Samet JM. Sleep-disordered breathing and cardiovascular disease: cross-sectional results of the Sleep Heart Health Study. Am J Respir Crit Care Med 2001;163:19-25.

276. Doherty LS, Kirly JL, Swan V, McNichols WT. Long term effects of nasal continuous positive airway pressure therapy on cardiovascular outcomes in sleep apnea syndrome. Chest 2005;127(6):2076-84.

277. Brundtland $\mathrm{GH}$. From the World Health Organization. Reducing risks to health, promoting healthy life. Jama 2002;288:1974.

278. Whelton PK, He J, Appel LJ, Cutler JA, Havas S, Kotchen TA, Roccella EJ, Stout R, Vallbona C, Winston MC, Karimbakas J. Primary prevention of hypertension: clinical and public health advisory from The National High Blood Pressure Education Program. Jama 2002;288:1882-8.

279. Yusuf S, Hawken S, Ounpuu S, Dans T, Avezum A, Lanas F, McQueen M, Budaj A, Pais P, Varigos J, Lisheng L. Effect of potentially modifiable risk factors associated with myocardial infarction in 52 countries (the INTERHEART study): case-control study. Lancet 2004;364:937-52.

280. He J, Whelton PK, Appel LJ, Charleston J, Klag MJ. Long-term effects of weight loss and dietary sodium reduction on incidence of hypertension. Hypertension 2000;35:544-9.

281. Krauss RM, Eckel RH, Howard B, Appel LI, Daniels SR, Deckelbaum RJ, Erdman JW, Jr., Kris-Etherton P, Goldberg IJ, Kotchen TA, Lichtenstein AH, Mitch WE, Mullis R, Robinson K, Wylie-Rosett J, St Jeor S, Suttie J, Tribble DL, Bazzarre TL. AHA Dietary Guidelines: revision 2000: A statement for healthcare professionals from the Nutrition Committee of the American Heart Association. Circulation 2000;102:2284-99.

282. Lemieux S, Prud'homme D, Bouchard C, Tremblay A, Despres JP. A single threshold value of waist girth identifies normal-weight and overweight subjects with excess visceral adipose tissue. Am J Clin Nutr 1996;64:68593.

283. Molina MCB, Cunha RS, Herkenhoff LF, Mill JG. Hipertensão arterial e consumo de sal em população urbana. Rev Saúde Pública 2003;37:743750.

284. Ministério da Saúde. Pesquisa do IBGE revela que o brasileiro mudou seu padrão alimentar. http://portalweb02.saude.gov.br/portal/saude. Acesso em 08 de janeiro de 2006.

285. Panagiotakos DB, Pitsavos C, Polychronopoulos E, Chrysohoou C, Zampelas A, Trichopoulou A. Can a Mediterranean diet moderate the development and clinical progression of coronary heart disease? A systematic review. Med Sci Monit 2004;10:RA193-8.

286. Alonso A, de la Fuente C, Martin-Arnau AM, de Irala J, Martinez JA, MartinezGonzalez MA. Fruit and vegetable consumption is inversely associated with blood pressure in a Mediterranean population with a high vegetable-fat intake: the Seguimiento Universidad de Navarra (SUN) Study. Br J Nutr 2004;92:311-9.

287. Hayman LL, Williams CL, Daniels SR, Steinberger J, Paridon S, Dennison BA McCrindle BW. Cardiovascular health promotion in the schools: a statement for health and education professionals and child health advocates from the Committee on Atherosclerosis, Hypertension, and Obesity in Youth (AHOY) of the Council on Cardiovascular Disease in the Young, American Heart Association. Circulation 2004;110:2266-75.

288. Kokkinos P, Panagiotakos DB, Polychronopoulos E. Dietary influences on blood pressure: the effect of the Mediterranean diet on the prevalence of hypertension. J Clin Hypertens (Greenwich) 2005;7:165-70; quiz 171-2.

289. Viegas CAA, Araújo AJ, Menezes AMB, Dórea AJP, Torres BS. Diretrizes para cessação do tabagismo. J Bras Pneumol 2004;30(Supl2):S1-S76

290. Loures DL, Sant Anna I, Baldotto CS, Sousa EB, Nobrega AC. Mental stress and cardiovascular system. Arq Bras Cardiol 2002;78:525-30.

291. Bedi M, Varshney VP, Babbar R. Role of cardiovascular reactivity to mental stress in predicting future hypertension. Clin Exp Hypertens 2000;22:1-22.

292. Unger T, Parati G. Acute stress and long-lasting blood pressure elevation: a possible cause of established hypertension? J Hypertens 2005;23:261-3. 


\section{Diretriz}

293. Garcia-Vera MP, Sanz J, Labrador FJ. Blood pressure variability and stress management training for essential hypertension. Behav Med 2004;30:53-62.

294. Pan American Organization. CARMEN. An Iniciative for integrated prevention of noncommunicable diseases in the Americas. World Health
Organization. Pan American Health Organization 2003.

295. Matsudo SM, Matsudo VR, Araujo TL, Andrade DR, Andrade EL, de Oliveira LC, Braggion GF. The Agita Sao Paulo Program as a model for using physical activity to promote health. Rev Panam Salud Publica 2003;14:265-72. 